\author{
UNIVERSIDADE DE SÃO PAULO \\ INSTITUTO DE FÍSICA \\ INSTITUTO DE QUÍMICA \\ INSTITUTO DE BIOCIÊNCIAS \\ FACULDADE DE EDUCAÇÃO
}

MARCELO CLAYTON DE JESUS E SOUSA

O USO DA REALIDADE AUMENTADA NO ENSINO DE FÍSICA 
MARCELO CLAYTON DE JESUS E SOUSA

\section{O USO DA REALIDADE AUMENTADA NO ENSINO DE FÍSICA}

Dissertação de Mestrado apresentada ao Programa de Pós-Graduação Interunidades em Ensino de Ciências para obtenção do título de Mestre em Ensino de Ciências.

Área de concentração: Ensino de Física

Orientador: Prof. Dr. Ewout ter Haar

\section{São Paulo}


Autorizo a reprodução e divulgação total ou parcial deste trabalho, por qualquer meio convencional ou eletrônico, para fins de estudo e pesquisa, desde que citada a fonte.

\section{FICHA CATALOGRÁFICA \\ Preparada pelo Serviço de Biblioteca e Informação do Instituto de Física da Universidade de São Paulo}

Sousa, Marcelo Clayton de Jesus e

O uso da realidade aumentada no ensino de física

São Paulo, 2015.

Dissertação (Mestrado) - Universidade de São Paulo.

Faculdade de Educação, Instituto de Física, Instituto de Química e Instituto de Biociências.

Orientador: Prof. Dr. Ewout ter Haar

Área de Concentração: Ensino de Física.

Unitermos: 1. Física (Estudo e ensino); 2. Realidade virtual; 3. Tecnologia educacional; 4. Formação de professores; 5. Educação digital; 6. Conhecimento tecnológico. 
À minha linda esposa, Thais Pranzetti Barreira, pelo carinho, pela paciência, pelo apoio incondicional neste trabalho e por acalmar minha alma, mostrando que o farol está mais próximo do que realmente parece.

À minha querida mãe, Isabel Cristina de Sousa, minha eterna gratidão por ser meu exemplo de vida e acreditar nos meus sonhos. 


\section{AGRADECIMENTOS}

Ao meu orientador e amigo, Prof. Dr. Ewout ter Haar, que me inspirou a refletir sobre as novas tecnologias no ensino e acreditando em mim, compartilhou seu tempo e conhecimento para que se fizesse concretizar este trabalho.

Aos meus irmãos, Michel, Marcos, Francisco, Rodrigo e Rafael (que eu tive a sorte de que também fossem meus amigos), por me acompanharem nessa jornada do conhecimento.

À Prof. ${ }^{a}$ Dr. ${ }^{a}$ Luciana Pranzetti Barreira, minha amiga (cunhada e irmã), por estar sempre a disposição e me auxiliar imensamente na revisão deste trabalho.

Aos meus sogros, Domingos Barreira Neto e Lúcia Maria de Freitas Pranzetti, pelo carinho, pela solicitude e por estarem com um notebook sempre a mão.

A toda equipe do Centro de Ensino e Pesquisa Aplicada (CEPA) do IFUSP, pela construção do objeto virtual de Realidade Aumentada que foi utilizado nesse trabalho.

Ao Prof. Dr. Claudio Kirner pelas conversas, referências bibliográficas e indicação de softwares.

À Prof. ${ }^{a}$ Dr. ${ }^{a}$ Anne Louise Scarinci Peres, ao Prof. Dr. Ivan Ramos Pagnossin e ao Prof. Claudio Hiroyuki Furukawa pelo valioso auxílio na elaboração do material didático deste trabalho.

Ao Prof. Dr. Alberto Villani, à Prof. ${ }^{a}$ Dr. ${ }^{a}$ Jesuína L. de A. Pacca, ao Prof. Dr. Luís de C. Menezes e ao Prof. Dr. Osvaldo F. Pessoa Junior, pelas aulas maravilhosas deste curso que me inspiraram a inúmeras reflexões.

Aos meus amigos José Otávio Baldinato, Luís Gomes de Lima, Marcos Matsukuma, companheiros de troca de saberes, inquietações e descontração nessa senda acadêmica. 
À minha filha Isadora e meu sobrinho Pedro Henrique, que pela graça da infância e seus questionamentos nos fazem repensar a vida e o mundo.

À Universidade de São Paulo e à Universidade Virtual do Estado de São Paulo pelo amparo na obtenção de dados dessa pesquisa.

À Banca, por promover criticas valiosas que me permitiram lapidar este trabalho.

A Comissão de Pós-Graduação Interunidades em Ensino de Ciências pela oportunidade de realização do curso de mestrado. 


\section{RESUMO}

SOUSA, M. C. J., O uso da realidade aumentada no ensino de física. 2015. $134 \mathrm{f}$. Dissertação (Mestrado). Faculdade de Educação, Instituto de Física, Instituto de Química e Instituto de Biociências, Universidade de São Paulo, 2015.

A Física utiliza modelos científicos para representar de maneira mais simplificada os fenômenos físicos. Um professor atuando no Ensino de Física precisa mediar o acesso a esse conhecimento. A complexidade e o nível de abstração dos modelos são obstáculos para os alunos, que o professor precisa ajudar a superar. A Realidade Aumentada (RA) é uma Tecnologia de Informação e Comunicação - TIC que permite a sobreposição e o alinhamento de objetos reais e virtuais, em um ambiente real e em tempo real. Já algum tempo o uso de atividades de aprendizagem usando RA como auxilio na compreensão de modelos científicos é investigado. Considerando o exposto, o presente trabalho buscou investigar se as escolas públicas, bem como se alunos licenciandos de Ciências possuem infraestrutura tecnológica mínima para viabilizar o uso da RA para fins didáticos. Buscamos também analisar o processo de criação ou adaptação dos objetos virtuais em 3D, empregados em RA e que simulam modelos científicos, seja por um professor típico, sem conhecimento em linguagens de programação, seja por uma equipe de especialistas, composta por professores e programadores. Analisamos ainda, por meio de uma intervenção com uso de RA, junto a alunos de um curso de licenciatura em Ciências, se essa ferramenta permite interpretar melhor os conceitos que regem um modelo científico (nessa pesquisa escolhemos utilizar o modelo de Drude para condução elétrica). Nossos resultados mostram que o uso da RA no ensino terá maior amparo tecnológico através dos dispositivos móveis (notebooks, smartphones e tablets). Em contrapartida encontramos algumas barreiras para seu uso, principalmente no que concerne a dificuldade de desenvolvimento de objetos virtuais, que coloca o professor numa condição de usuário dessa tecnologia e não como agente ativo na sua produção ou contextualização para sua sala de aula.

Palavras-chave: Realidade Virtual. Tecnologia Educacional. Formação de professores. Educação digital. Conhecimento tecnológico. 


\begin{abstract}
SOUSA, M. C. J., The use of Augmented Reality in Physics Education. 2015. $134 \mathrm{f}$. Dissertation (Master's degree). Faculdade de Educação, Instituto de Física, Instituto de Química e Instituto de Biociências, Universidade de São Paulo, 2015.
\end{abstract}

Physics makes use of scientific models to represent natural phenomena in a simplified way. The role of teachers in physics education is to mediate access to this kind of knowledge. The complexity and level of abstraction of the models are obstacles that students must overcome, helped by their teachers. Augmented Reality (AR) is a technology that permits the superposition of virtual objects in real space, overlaying and aligning these virtual objects in space, in real time. For some time already learning activities using AR technology are being investigated as a way to help students overcome their dificulties with scientific models. This dissertation investigates wether public schools and pre-service science teachers in Brazil have access to the technical infrastructure necessary to make use of learning activities using AR. We also analised the process of creating or customizing of the $3 \mathrm{D}$ virtual objects used in these learning activities, either by an individual teacher without special programing training or by a team of teachers and specialists. Finally, we used a learning activity using AR with a class of pre-service science teachers to evaluate wether its use helped students to interpret one particular scientific model (the Drude model of electrical conduction). Our results show that the use of AR for teaching is best suported through mobile platforms (notebooks, smartphones or tablets). We found some barriers to the use of AR technology, mostly with respect to the creation or adaptation of the virtual objects by individual teachers, which puts them in a role of user of the technology instead of active agents in the production, adaptation or contextualization of the technology for their classrooms.

Keywords: Virtual reality. Educational Technology. Pre-service teacher education. Digital education. Technology Integration. 


\section{LISTA DE FIGURAS}

Figura 1- Magic Leap - Aplicação de RA desenvolvida pelo Google ................................. 17

Figura 2- Aplicação de RA no estudo de lançamentos ................................................... 18

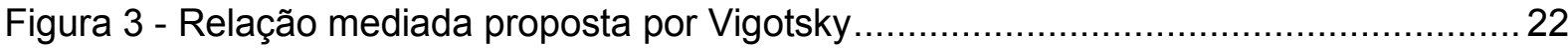

Figura 4 - Continuum de Milgram (MILGRAM, 1994 apud TORI, 2010) ............................. 50

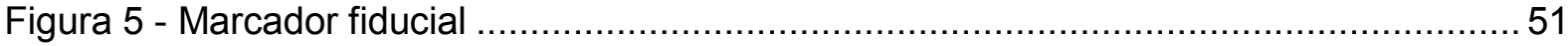

Figura 6 - Diagrama representando a captura de um marcador e a projeção de um objeto

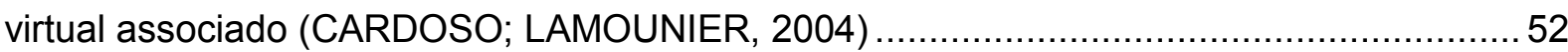

Figura 7 - Optical see-throug (AZUMA, 1997 apud KIRNER; ZORZAL, 2005) .....................53

Figura 8 - Vídeo see-through (AZUMA, 1997; PRINCE, 2002 apud KIRNER; ZORZAL, 2002)

Figura 9 - Sistema de visão por vídeo baseada em monitor (AZUMA, 1997 apud KIRNER, ZORZAL, 2005)

Figura 10 - Exemplo de objetos virtuais associados a marcadores (KIRNER; SANTIM, 2010)

Figura 11 - Layar -aplicativo de RA 57

Figura 12 - Livro em RA sobre o Sistema Solar (OKAWA; KIRNER; KIRNER, 2013) .........57

Figura 13 - Realidade Aumentada no estudo do Eletromagnetismo (DONZELLI;

TOMAZELLO, 2006) 58

Figura 14 - Livros texto com marcadores de RA no estudo de mecânica (CAMARGO;

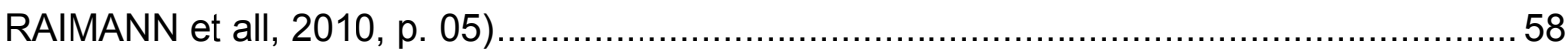

Figura 15 - Exemplo de aplicação de RA no ensino de Física ..........................................59

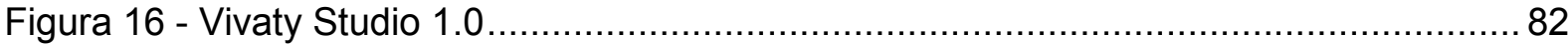

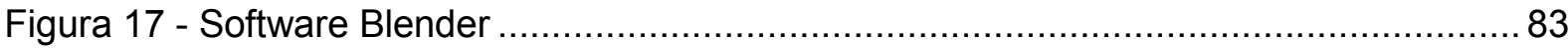

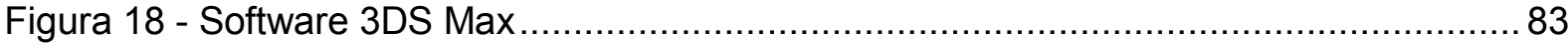

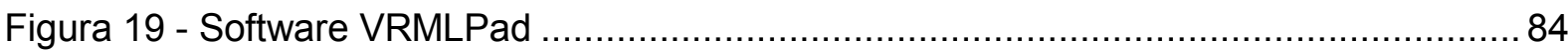

Figura 20 - Objeto virtual representando o Modelo de Drude ............................................ 87 
Figura 21 - Aplicativo de RA desenvolvido pelo CEPA ................................................. 88

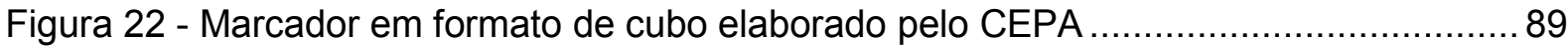

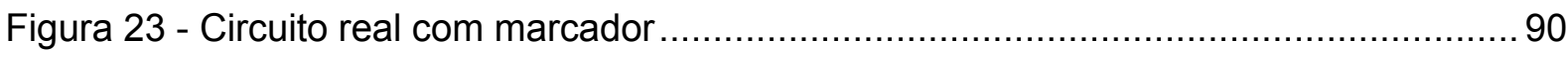

Figura 24 - Intervenção de RA apresentando o circuito fechado.....................................91

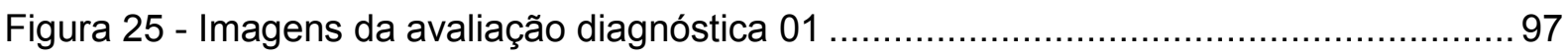

Figura 26 - Representações do modelo clássico de corrente elétrica ................................ 100 


\section{LISTA DE GRAFICOS}

Gráfico 1 - Número de computadores nas escolas (FUNDAÇÃO VICTOR CIVITA, 2010, P. 304) 30

Gráfico 2 - Localização dos computadores nas escolas pesquisadas (FUNDAÇÃO VICTOR CIVITA, 2009, P. 43) 30

Gráfico 3 - Distribuição de alunos por computador em laboratórios de informática (FUNDAÇÃO VICTOR CIVITA, 2010, P. 311).

Gráfico 4 - Usuários de computadores e Internet nas escolas (FUNDAÇÃO VICTOR CIVITA, 2010, p. 310)

Gráfico 5 - Preparação para uso das Tics na graduação (FUNDAÇÃO VICTOR CIVITA, p. 302) 32

Gráfico 6 - Programas de computador mais utilizados (FUNDAÇÃO VICTOR CIVITA, 2010, p. 313) 33

Gráfico 7 - Problemas no uso pedagógico dos computadores nas escolas (FUNDAÇÃO VICTOR CIVITA, 2010, p. 314)

Gráfico 8 - Vantagens da tecnologia na educação (FUNDAÇÃO VICTOR CIVITA, 2010, p. 317) 34

Gráfico 9 - Distribuição dos estudantes de 10 anos ou mais, por rede de ensino e condição de utilização da Internet - Brasil 2005-2011 (PNAD, 2013, p. 38) 36

Gráfico 10 - Proporção de escolas, por tipo de computador (CGI, 2014, p. 138) 38

Gráfico 11 - Proporção de escolas por local de instalação de computadores 2010-2013 (CGI, 2014, p. 139)

Gráfico 12 - Proporção de escolas com conexão à Internet, sem fio, por região (CGI, 2014, p. 141) 40

Gráfico 13 - Proporção de escolas, por velocidade de conexão à Internet (CGI, 2014, p. 141) 
Gráfico 14 - Proporção de professores, por motivos para levar o computador portátil para escola (CGI, 2014, p. 146)

Gráfico 15 - Proporção de professores, por forma de aprendizado do uso de computador e Internet (2010-2013) (CGI, 2014, p. 150)

Gráfico 16 - Proporção de professores, por tipo de recurso obtido na Internet para a preparação de aulas ou atividades com alunos (CGI, 2014, p. 155)

Gráfico 17 - Proporção de alunos, por tipo de computador existente no domicílio (2010-2013)

(CGI, 2014, p. 158)

Gráfico 18 - Número de ingressantes por idade do CLC

Gráfico 19 - Dispositivos que os ingressantes do CLC possuem, em fração. 73

Gráfico 20 - Velocidade de conexão à Internet que os alunos do CLC possuem 75

Gráfico 21 - Frequência de uso da Internet pelos ingressantes do CLC. 75

Gráfico 22 - Sistema operacional executado nos smartphones dos ingressantes do CLC ...76 


\section{LISTA DE TABELAS}

Tabela 1 - Porcentagem de alunos afetados segundo recursos educacionais disponíveis (BRASIL, 2012, p. 59)

Tabela 2 - Learning Object Metadata - LOM (TAROUCO et all, 2007) 62

Tabela 3 - Frequência de uso de dispositivos tecnológicos em atividades acadêmicas 74

Tabela 4 - Percentuais de alunos ingressantes do CLC por nível de conhecimento tecnológico 78

Tabela 5 - Características dos desenhos dos 09 grupos sobre o que acontece no interior do fio condutor.... 93

Tabela 6 - Duplas de imagens escolhidas pelos alunos na Avaliação Diagnóstica 01 98

Tabela 7 - Questão 01 da avaliação diagnóstica 02 - Atribuição de conceito as figuras - Pólo São Paulo 101

Tabela 8 - Questão 01 da avaliação diagnóstica 02 - Atribuição de conceitos - demais Pólos 102

Tabela 9 - 2a Questão da avaliação diagnóstica 02 - Pólo São Paulo. 104

Tabela 10 - 2ª Questão da avaliação diagnóstica 02 - Demais Pólos 104 


\section{SUMÁRIO}

1. INTRODUÇÃO

2. OBJETIVOS

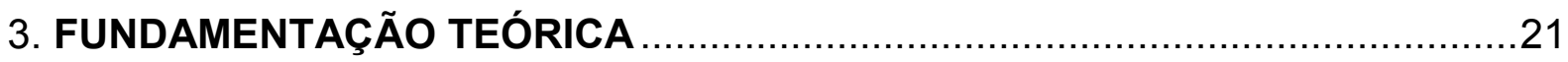

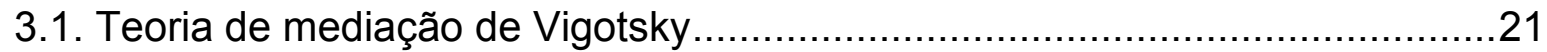

4. AS TECNOLOGIAS DE INFORMAÇÃO E COMUNICAÇÃO APLICADAS AO

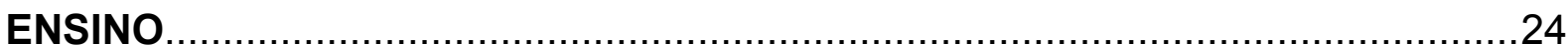

4.1. Um resumo das políticas de inclusão das Tics no ensino brasileiro ...............24

4.2. Panorama atual da aplicação das Tics no ensino brasileiro ...........................29

4.2.1. Discussão sobre os dados apresentados nas pesquisas ..........................45

5. O USO DAS SIMULAÇÕES COMPUTACIONAIS NO ENSINO DE FÍSICA........46

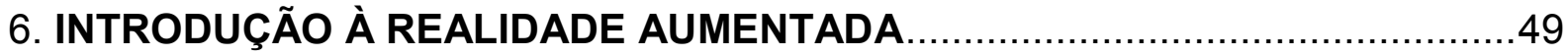

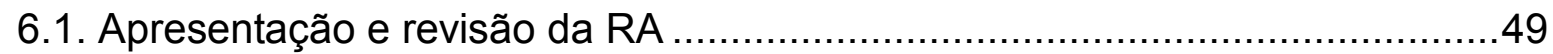

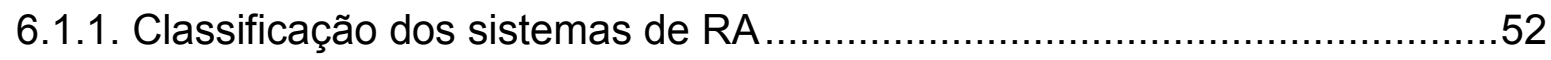

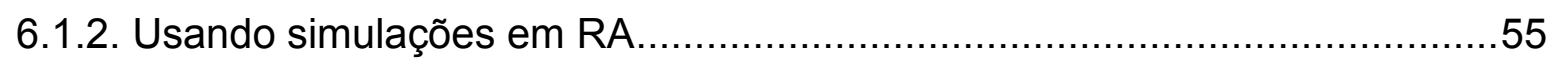

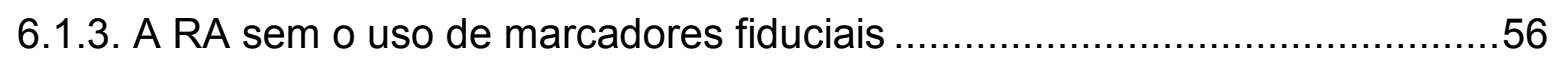

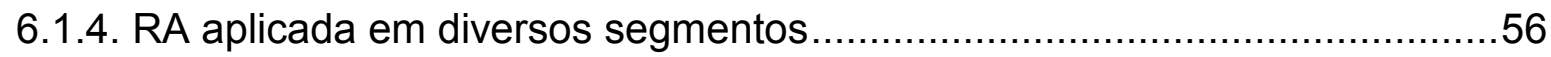

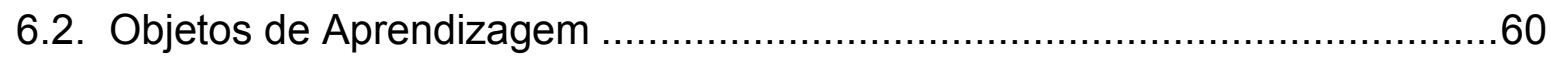

6.2.1 Características dos Objetos de Aprendizagem ......................................61

6.2.2. Repositórios de Objetos de Aprendizagem................................................63

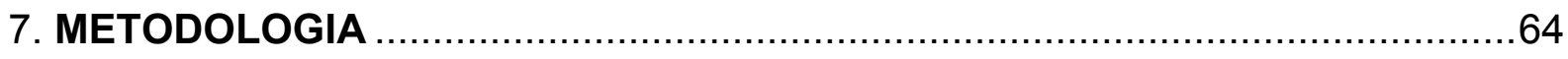

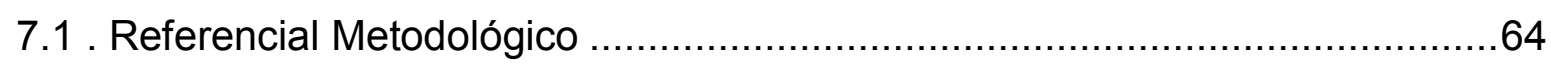

7.2. Análise da criação de um objeto virtual simulado para RA .............................64

7.2.1 O objeto virtual simulado desenvolvido: Características do Modelo Clássico

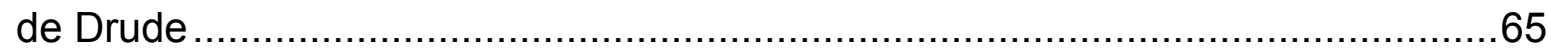

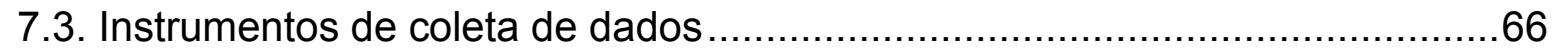

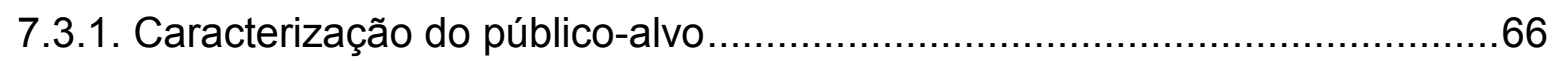

7.3.2. Averiguação sobre infraestrutura tecnológica existente.............................67

7.3.3. Aplicação prática da RA: uma intervenção com alunos do CLC da

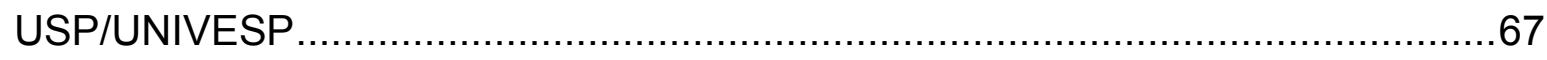

7.3.3.1. Instrumento de coleta de dados da intervenção de RA ...........................68 
8.1. Análise da infraestrutura tecnológica dos alunos do CLC da USP/UNIVESP.70

8.1.1. Discussão dos dados obtidos sobre a infraestrutura tecnológica dos alunos do CLC da USP/UNIVESP

8.2. O Desenvolvimento De Uma Aplicação De Realidade Aumentada: Uma Experiência Prática. .80

8.2.1. Discussão sobre a experiência prática.

8.3. O desenvolvimento de uma aplicação de RA: construindo com professores e programadores .86

8.3.1. Discussão sobre a criação de objetos virtuais por uma equipe de professores especialistas e programadores.

8.4. Análise e discussão da intervenção de RA aplicada aos alunos do CLC da USP/UNIVESP 92

8.4.1 Análise e discussão da Avaliação Diagnóstica 01 .97

8.4.2. Análise e discussão das Avaliações Diagnósticas 02 e 03. .99

9. CONSIDERAÇÕES FINAIS 110

10. BIBLIOGRAFIA 


\section{INTRODUÇÃO}

A Física é uma disciplina que apresenta modelos científicos de alto grau de complexidade, o que dificulta uma contextualização efetiva com o universo do aluno, por vezes tornando sua assimilação dificultosa e produzindo como efeito colateral a rejeição e o desinteresse pela matéria.

Esse quadro se agrava quando os alunos se deparam com um formalismo matemático predominante, que na maioria das vezes é distanciado de uma abordagem fenomenológica do modelo estudado. Não raro, constatamos que a somatória desses fatores prejudica a compreensão desses modelos científicos, como também conduz a avaliações com baixo rendimento, diminuindo ainda mais o interesse em se estudar Física.

Desse modo, a Física que deveria levar o aluno a uma atuação mais efetiva e critica na sociedade em que está inserido, acaba por se transformar em uma disciplina comumente rotulada como maçante e difícil, a qual o aluno se vê obrigado a estudar simplesmente porque está presente em exames vestibulares. Perde-se com isso a oportunidade de despertar a curiosidade e a reflexão sobre a natureza dos fenômenos.

Nesse contexto surge o professor a quem compete à árdua tarefa de modificar essa situação e, para que isso ocorra, ele poderá buscar auxílio nas novas tecnologias e linguagens presentes no mundo contemporâneo, a fim de ir além daquelas presentes na educação tradicional, pautadas na oralidade e na escrita.

Essa busca de novas formas de linguagens e tecnologias, não é uma preocupação exclusiva dos professores, afinal ela também está expressa nos Parâmetros Curriculares Nacionais (PCN) que visam promover uma alfabetização científica menos limitada, sugerindo que sejam:

Buscadas novas e diferentes formas de expressão do saber da Física, desde a escrita, com a elaboração de textos ou jornais, ao uso de esquemas, fotos, recortes ou vídeos, até a linguagem corporal e artística. Também deve ser estimulado o uso adequado dos meios tecnológicos, como máquinas de calcular, ou das 
diversas ferramentas propiciadas pelos microcomputadores (PCN, 2002, p.112)

O estímulo a utilização de meios tecnológicos adequados acaba por nos conduzir as chamadas Tecnologias de Informação e Comunicação (TICs) que podem ser utilizadas como ferramentas auxiliares no aprendizado de Física, visando contribuir na compreensão de fenômenos físicos, promover seu significado e seu pertencimento no universo do aluno. Contudo é necessário entender que não basta exclusivamente à utilização dessas tecnologias, "tudo depende da pedagogia de base que inspira e orienta estas atividades: a inovação ocorre muito mais nas metodologias e estratégias de ensino do que no uso puro e simples de aparelhos eletrônicos" (BELLONI, 1999, p. 73).

A recomendação de uso das TICs nos processos de ensino e aprendizagem não esta expressa única e exclusivamente nos PCN, a importância dessas tecnologias como ferramentas auxiliares na educação vem ganhando espaço no cenário nacional, a ponto de ser tratada como imprescindível na formação de professores. É isso o que a Conferência Nacional de Educação (CONAE, 2010), ocorrida em 2010, prevê em seu plano de Educação para 2011-2020:

Garantia do desenvolvimento de competências e habilidades para o uso das tecnologias de informação e comunicação (TIC) na formação inicial e continuada dos/das profissionais da educação, na perspectiva de transformação da prática pedagógica e da ampliação do capital cultural dos/das professores/as e estudantes (CONAE, 2010, p.81).

Prever que as TICs estejam presentes na formação inicial dos professores pode favorecer que elas sejam utilizadas por esses profissionais para criar materiais didáticos mais diversificados e auxiliar sua relação dialógica com os alunos e o conhecimento científico. Assim, de acordo com os documentos apresentados (PCN, 2002; CONAE, 2010), verifica-se que existe uma tendência em promover o uso dessas tecnologias no ensino; logo, não se trata de apologia as TICs, mas um reconhecimento de seu potencial no auxilio à ação do professor.

No mundo contemporâneo a presença das TICs é tão disseminada que alunos e professores tem acesso a diversos aparatos do universo digital como computadores, 
notebooks, tablets, Internet, smartphones, videogames, smart TVs, aplicativos de celular, redes sociais, entre outros. Tamanha é a presença dessas tecnologias no cotidiano que sua presença nas escolas não só já é comum, como provavelmente não irá causar estranhamento.

Diversas TICs ou recursos tecnológicos já são normalmente utilizados no ensino, sejam editores de texto ou apresentações, simulações, programas de busca, entre outros, o que se propõe nesse trabalho é a utilização de uma nova TIC, que embora pouco explorada no ensino, acredita-se ter potencial para auxiliar os alunos a compreenderem melhor os modelos científicos da Física.

Essa tecnologia é chamada de Realidade Aumentada (RA). A RA permite ao usuário ver o mundo real, com objetos virtuais sobrepostos ou compostos a ele, complementando a realidade ao invés de substituí-la completamente (AZUMA, 1997). Azuma (1997) define ainda que os sistemas de RA devem possuir as propriedades de combinar o real e o virtual, permitir interação em tempo real e alinhar os objetos virtuais no mundo real. A figura $01^{1}$ apresenta um exemplo de aplicação de RA desenvolvida pelo Google.

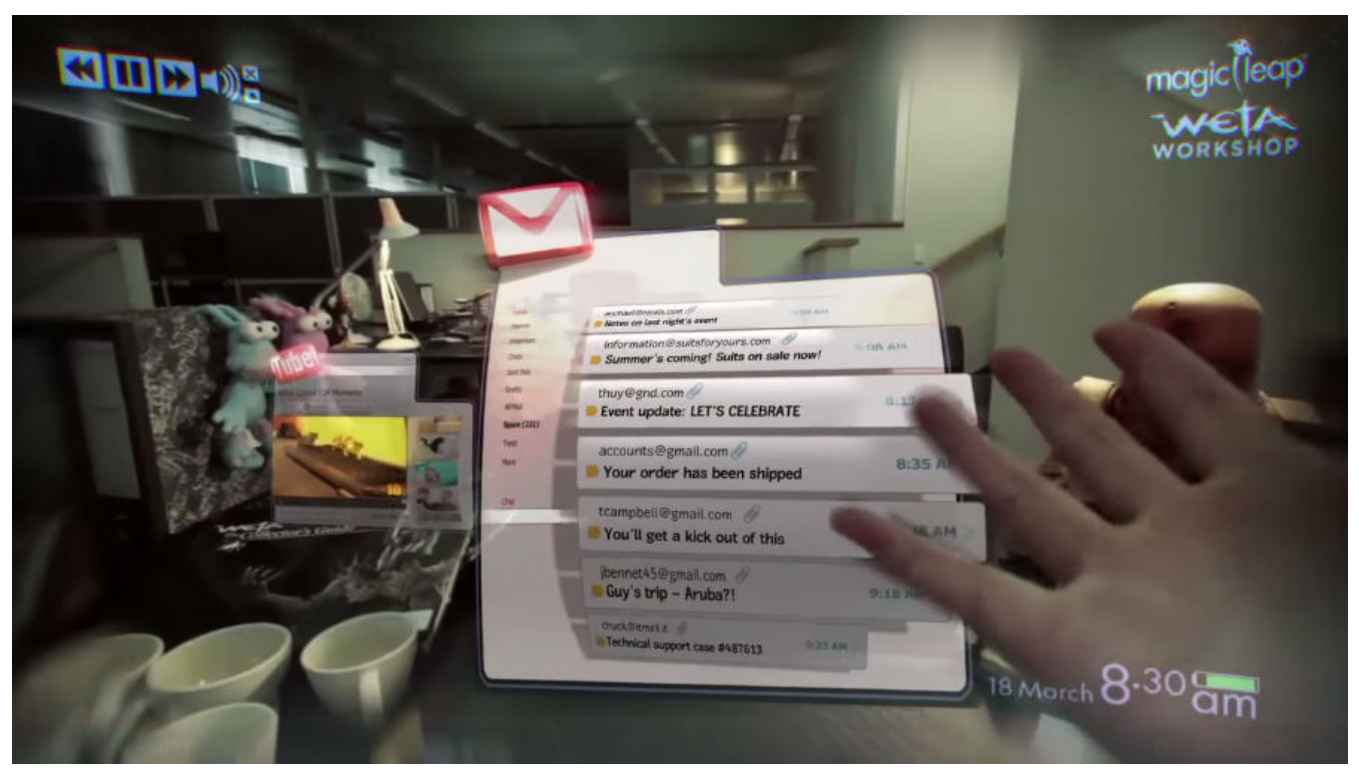

Figura 1- Magic Leap - Aplicação de RA desenvolvida pelo Google

Por proporcionar uma imersão interativa, a RA tem sido utilizada em manuais instrutivos de produtos, na visualização de modelos de veículos e seus interiores, em jogos, em tratamento e cirurgias médicas (SIELHORST; TRAUB, 2004), bem

\footnotetext{
${ }^{1}$ Fonte: http://www.tecmundo.com.br/realidade-aumentada/76861-magic-leap-mostra-realidadeaumentada-melhorar-nossa-vida.htm. Acesso em 15 de fev 2015.
} 
como no ensino de Física, uma vez que permite ao usuário interagir com o objeto virtual, rotacionando-o e transladando-o de maneira que se possa observá-lo de maneira apropriada (Figura $02^{2}$ ).

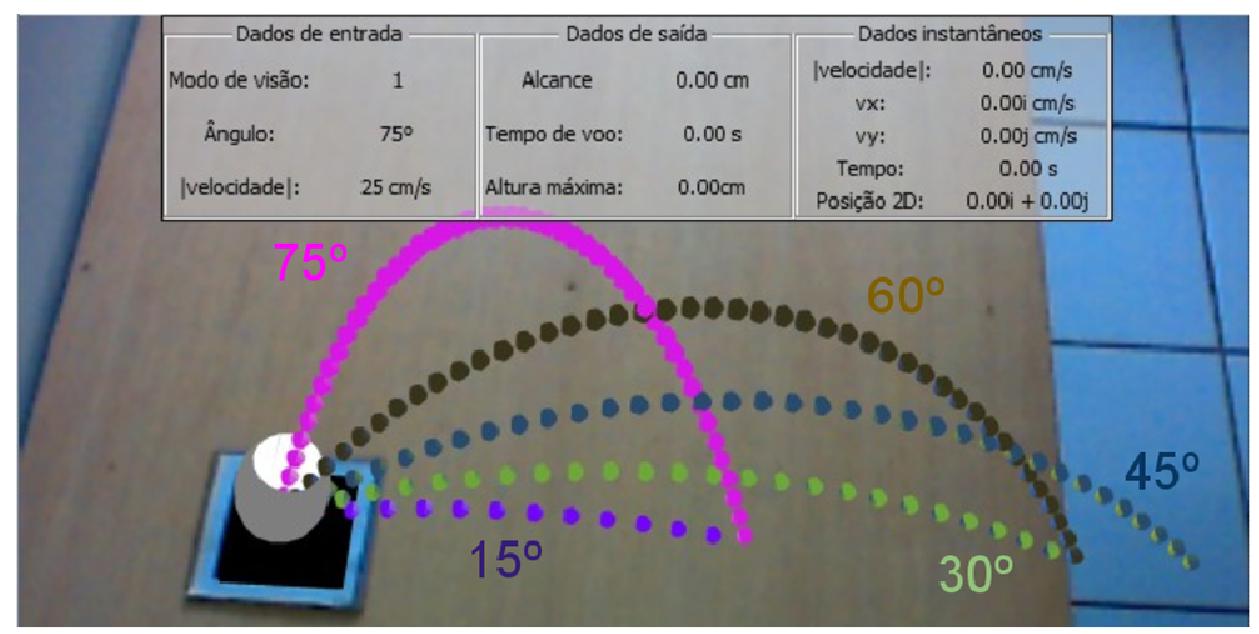

Figura 2- Aplicação de RA no estudo de lançamentos

Os recursos da RA permitem que ela seja associada a uma espécie de simulação, que como tal não substitui "os raciocínios humanos, mas prolongam e transformam a capacidade de imaginação e pensamento" (LÉVY, 1999, p. 167). Entretanto caberá ao professor, quando do uso dessa tecnologia, mediar e criar situações que proporcionem relações dialógicas e investigativas junto aos alunos, pois conforme Levy (1999, p. 171):

O professor torna-se um animador da inteligência coletiva dos grupos que estão ao seu encargo. Sua atividade será centrada no acompanhamento e na gestão das aprendizagens: o incitamento à troca de saberes, a mediação relacional e simbólica, a pilotagem personalizada dos percursos de aprendizagem, etc.

Já para o aluno será a oportunidade de observar um objeto virtual que simula um fenômeno apresentado conceitualmente nos livros didáticos, de tal maneira que interagindo com essa simulação sua atenção seja focada e convidada a refletir sobre o fenômeno, como propõe Giordan (2003, p. 06):

Nas circunstâncias em que a atenção do aluno esteja mobilizada por uma aplicação simuladora do fenômeno, o controle sobre suas variáveis pode ser exercido com o intuito de observar regularidades, fazer previsões, ou ainda a própria representação do fenômeno

\footnotetext{
${ }^{2}$ Fonte: <http://ckirner.com/apoio/lancaobliquo/> Acesso em janeiro 2015
} 
simulado pode servir de suporte para o aluno elaborar narrativas ou explicações acerca do fenômeno no meio natural.

Considera-se neste trabalho que a RA pode promover não somente a visualização de objetos virtuais que representam modelos científicos, mas também, por conta de sua interativatividade, podem promover o lúdico, o interesse investigativo e a compreensão de fenômenos, pois se trata de uma experimentação e como tal cumpre com as orientações Parâmetros Curriculares Nacionais:

É indispensável que a experimentação esteja sempre presente ao longo de todo o processo de desenvolvimento das competências em Física, privilegiando-se o fazer, manusear, operar, agir, em diferentes formas e níveis (PCN, 2002, p. 84, grifo nosso).

Além dessas potencialidades considera-se que um diferencial da RA para outros tipos de simulação é sua propriedade de registro, que permite alinhar com precisão os objetos virtuais no ambiente real. Isso possibilita que se utilize essa tecnologia acoplada a um local ou ambiente específico, permitindo explorar características ou eventos que não são observáveis a olho nú ou ainda que estejam ocultos.

Apesar de evidências do potencial da RA esse trabalho teve como foco utilizar essa tecnologia como um elemento mediador entre o aluno e um modelo científico, buscando verificar se o seu uso pode auxiliar a compreensão dos conceitos que regem esse modelo. O modelo científico adotado para esta investigação é o Modelo de Drude para corrente elétrica, que permite estudar a natureza dos movimentos dos elétrons livres no interior de um fio condutor, na ausência ou presença de um campo elétrico, movimentos estes que não são observáveis sem auxílio de instrumentos, nem são facilmente representáveis em figuras estáticas de livros didáticos, o que pode interferir na compreensão do fenômeno em questão. Investigou-se também neste trabalho se escolas e professores dispõem de infraestrutura tecnológica mínima para utilização dessa tecnologia, bem como as possibilidades de criação e customização dos objetos virtuais de RA por professores e equipes especializadas, compostas por professores e programadores. 


\section{OBJETIVOS}

O objetivo geral desse trabalho é investigar se a ferramenta tecnológica denominada RA pode auxiliar a compreensão de conceitos de física, por meio da aplicação do Modelo de Drude para corrente elétrica.

Para tanto, o presente trabalho apresenta como objetivos específicos:

- Analisar o resultado de pesquisas realizadas junto às escolas públicas, quanto à infraestrutura necessária para uso da RA nestes estabelecimentos.

- Investigar por meio de enquete quais as condições de infraestrutura e conhecimentos que alunos licenciandos possuem para uso da RA em sala de aula.

- Averiguar se é possível para um professor de física sem conhecimento em programação construir e customizar objetos virtuais utilizados no software de RA.

- Participar do processo de criação de um objeto virtual conjuntamente a professores e especialistas em programação.

- Investigar se o uso da Realidade Aumentada pode auxiliar os alunos de Física a interpretar melhor os conceitos que regem modelos científicos complexos.

\section{Hipótese:}

O ensino de Física baseia-se muitas vezes em conceitos abstratos, não observáveis cotidianamente, prejudicando sua compreensão. Para este trabalho considera-se a hipótese que o uso da RA possibilitará aos professores e alunos uma compreensão mais significativa de um modelo científico do que uma explanação baseada exclusivamente na oralidade e escrita. 


\section{FUNDAMENTAÇÃO TEÓRICA}

Tendo em vista que um dos objetivos dessa pesquisa é avaliar se o uso da Realidade Aumentada pode promover uma melhor compreensão de modelos científicos, faz-se necessário entender como se dá esse processo. Aqui reside nossa primeira preocupação: investigar como a RA pode atuar na mediação entre o aluno e o conhecimento científico, representado por meio de modelos científicos.

Com base nisso, apresenta-se no próximo capítulo o referencial teórico adotado nesse trabalho, a saber, a teoria da mediação, proposta por Lev Semenovitch Vigotsky.

\subsection{Teoria de mediação de Vigotsky}

Nas situações de ensino e aprendizagem provenientes do ensino de física, o aluno se depara com uma enorme quantidade de fórmulas matemáticas, conceitos e representações de modelos físicos que nada mais são que símbolos sociais elaborados pela cultura humana e que servem para mediar à relação dele com o conhecimento.

A mediação e a compreensão desses conceitos científicos, na ótica de Lev Semenovitch Vigotsky (1896-1934), ocorre no desenvolvimento das chamadas funções psicológicas superiores, que tem em comum "o fato de serem processos mediados, melhor dizendo, de incorporarem à sua estrutura, como parte central de todo o processo, o emprego de signos como meio fundamental de orientação e domínio dos processos psíquicos" (VIGOTSKY, 2001, p. 161)

Essas funções superiores são frutos das interações sociais, históricas e culturais que o indivíduo tem com o mundo que o cerca e são caracterizadas por serem intencionais, conscientemente controladas pelo indivíduo, distinguindo-o dos demais animais que só apresentam funções psicológicas elementares, também presente 
nos homens, mas que são de origem biológica, caracterizadas por serem determinadas por estimulação do meio.

Para Vigotsky (1998) as relações que homem desenvolve com o meio não se dão de maneira direta, pelo contrário, ocorre de forma indireta, por meio elementos mediadores: os instrumentos e os signos. Os instrumentos são elementos externos ao homem e são criados com o objetivo de auxiliar o homem na prática de tarefas especificas, como por exemplo, um machado que é criado para cortar madeira, ou seja, permite ao homem promover mudanças nos objetos. Os instrumentos são impregnados de significados culturais oriundos da atividade humana para qual foi desenvolvido, segundo Leontiev (1978, p. 163):

O instrumento não é para o homem um simples objeto de forma exterior determinada e possuindo propriedades mecânicas definidas; ele manifesta-se-lhe como um objeto no qual gravam modos de ação, operações de trabalho socialmente elaboradas.

O signo por sua vez age diretamente sobre o indivíduo, ou seja, é orientado internamente. São tidos como instrumentos psicológicos, pois tem a função de auxiliar o homem em suas atividades psíquicas. Segundo Vigotsky (1999, p. 70) "a invenção e o uso de signos como meios auxiliares para solucionar um dado problema psicológico (lembrar, comparar coisas, relatar, escolher, etc.) é análoga à invenção e uso de instrumentos, só que agora no campo psicológico"

Para Oliveira (1997, p. 30) os "signos podem ser definidos como elementos que representam ou expressam outros objetos, eventos, situações”.

A maneira como um signo age como elemento mediador se dá por meio da estrutura de operações com signos que requer um elo intermediário na relação direta Estímulo Resposta (SR) de uma ação, de tal maneira que ela não seja mais direta. Assim, nessa situação o signo atua como um estímulo de segunda ordem no interior dessa operação, criando uma nova relação entre S e R (VIGOSTKY, 2001), como mostra a figura 01.

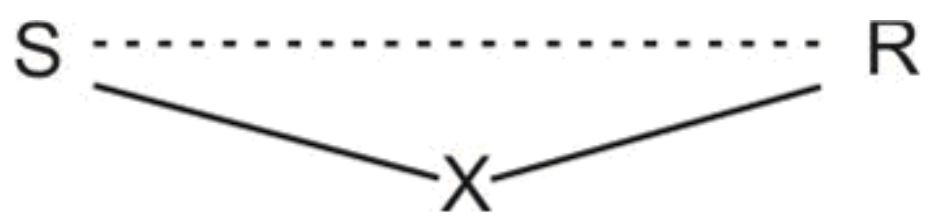

Figura 3 - Relação mediada proposta por Vigotsky 
Para Vigotsky (1999, p. 54) essa relação configura um novo processo onde:

O elo intermediário nessa fórmula não é simplesmente um método para aumentar a eficiência da operação preexistente, tampouco representa meramente um elo adicional na cadeia S-R. Na medida em que esse estímulo auxiliar possui função especifica de ação reversa, ele confere à operação psicológica formas qualitativamente novas e superiores, permitindo aos seres humanos, com o auxílio de estímulos extrínsecos, controlar seu próprio comportamento. O uso de signos conduz os seres humanos a uma estrutura específica de comportamento que se destaca do desenvolvimento biológico e cria novas formas de processos psicológicos enraizados na cultura.

A linguagem é um dos signos utilizados pelo homem que permite: a comunicação entre seus pares; dar significado a objetos e ações; a realização de processos de abstração e generalização.

Outra característica dos signos é que eles podem ser compartilhados por pessoas pertencentes a um determinado grupo social, permitindo uma comunicação eficiente entre os indivíduos que compõem esse grupo. Uma comunidade cientifica é um grupo social que compartilha signos, como por exemplo, os modelos científicos elaborados para representar um determinado fenômeno físico. Mas pelo fato de alguns modelos científicos serem muito difíceis de compreender, essa comunicação fica comprometida. Considera-se que o uso das TICs nessas situações pode auxiliar a compreensão desses modelos difíceis, demasiadamente abstratos, pois de acordo com Vigotsky (1981, p. 137):

A introdução de uma nova ferramenta cultural num processo ativo, inevitavelmente o transforma. Nessa visão, recursos mediadores como a linguagem e as ferramentas técnicas não facilitam simplesmente as formas de ação que irão ocorrer, mas alteram completamente a estrutura dos processos mentais.

A RA com seus objetos virtuais que representam modelos científicos, ao permitirem que o aluno compreenda melhor os conceitos que regem esse modelo, estará funcionando como uma nova linguagem, um signo que permitirá o diálogo com o universo científico. 


\section{AS TECNOLOGIAS DE INFORMAÇÃO E COMUNICAÇÃO APLICADAS AO ENSINO}

É comum a afirmação que as TICs devem ser aplicadas ao ensino, desde que estejam pedagogicamente amparadas, contudo essas tecnologias estão realmente disponíveis para uso no ensino? Existem políticas públicas que amparam o seu uso? Como surgiram as políticas públicas de fomentação ao uso das TICs no Brasil e quais são seus objetivos? É assim também para Internet? Essas questões são importantes para aqueles professores que irão fazer uso das TICs e serão brevemente apresentadas na primeira seção desse capítulo.

A segunda seção desse capítulo apresenta um panorama atual da infraestrutura tecnológica no cenário escolar, sendo baseada em pesquisas que analisaram a disponibilidade e o uso computador, assim como da Internet nas escolas; os locais mais frequentes de uso; a velocidade de conexão da Internet; os softwares utilizados pelos professores, entre outros.

Este capitulo servirá de respaldo para analisar se existe infraestrutura adequada nas escolas para permitir o uso da RA.

\subsection{Um resumo das políticas de inclusão das Tics no ensino brasileiro}

Eric J. Hobsbawm (1977, p. 16) em seu livro A Era das Revoluções ao se referir as palavras que surgiram na revolução que eclodiu entre 1789 e 1848, tais como "industria", "proletariado", "ferrovia", entre outras, diz que imaginar o mundo moderno sem elas é uma maneira de medir a profundidade dessa revolução. Raciocínio similar a esse pode ser aplicado em relação à Revolução Digital, pois palavras como "download", "internet", "deletar", "email" ou expressões como "copiar e colar", "exclusão digital" estão tão impregnadas em nosso cotidiano que sua ausência é difícil de ser imaginada.

Uma análise dos computadores, protagonistas dessa Revolução Digital, permitirá observar que quando tiveram seu poder de processamento, memória e capacidade 
gráfica aumentados, eles evoluíram da condição de grandes máquinas de calcular para se tornarem precursores da fase da automação da industria e dos bancos, fundindo-se depois com as telecomunicações, a editoração, o cinema, a televisão e, concomitantemente com o surgimento da Internet, tornaram-se também um "novo espaço de comunicação, de sociabilidade, de organização e de transação, mas também novo mercado da informação e do conhecimento" (LEVY, 1999, p. 32).

O surgimento dos "personal computers" ajudou na disseminação dos computadores junto à sociedade, que somado as demais Tecnologias de Informação e Comunicação - TICs entendidas como "o conjunto convergente de tecnologias em microeletrônica, computação (software e hardware), telecomunicações-radiodifusão, e optoeletrônica" (CASTELLS, 2000, p. 49) praticamente fundiram sua presença junto a todos os segmentos sociais, econômicos e culturais.

A educação não se absteve de participar da Revolução Digital e fez uso das TICs para criar novas formas de aperfeiçoar os processos de ensino e aprendizagem. Segundo Levy (1999, p. 172):

Não se trata aqui de usar as tecnologias a qualquer custo, mas sim de acompanhar consciente e deliberadamente uma mudança de civilização que questiona profundamente as formas institucionais, as mentalidades e a cultura dos sistemas educacionais tradicionais e sobretudo os papéis de professores e de aluno

No Brasil a preocupação com a inserção das TIC'S no ensino levou a criação de inúmeros projetos para implementar seu uso e estudar suas vantagens e/ou desvantagens.

Em 1981 ocorreu o $1^{\circ}$ Seminário Nacional de Informática na Educação, realizado na Universidade de Brasília, onde uma equipe intersetorial formada por membros da Secretaria Especial de Informática (SEI), do Ministério da Educação e Cultura (MEC), do Conselho Nacional de Desenvolvimento Científico e Tecnológico (CNPq) e da Financiadora de Estudos e Projetos (FINEP) sugeriu que os computadores fossem utilizados como ferramentas que ampliassem a ação do professor, sem substituí-lo. Segundo Nascimento entre as recomendações que se originaram nesse seminário destacam-se:

Aquelas relacionadas à importância de que as atividades de informática na educação fossem balizadas por valores culturais, sociopolíticos e pedagógicos da realidade brasileira, bem como a necessidade do prevalecimento da questão pedagógica sobre as 
questões tecnológicas no planejamento de ações (NASCIMENTO, 2007, p. 14-15)

Já em 1983, a SEI elaborou o Projeto EDUCOM - Educação com Computadores que segundo Tavares (2002, p. 02) consistia na "implantação de centros-piloto em universidades públicas, voltados à pesquisa no uso de informática educacional, à capacitação de recursos humanos e à criação de subsídios para a elaboração de políticas no setor".

Em 1986 a Secretaria de Informática do MEC assume a coordenação e a supervisão técnica do Projeto EDUCOM, nesse período o MEC iniciou atividades de pesquisa nas universidades por meio de capacitação de professores de sistemas estaduais de ensino público, com isso temos a fusão do Projeto FORMAR com o Projeto EDUCOM (TAVARES, 2002).

O Projeto Formar visava à capacitação de professores para atuarem em centros de informática educativa dos sistemas estaduais e municipais de educação e os professores formados assumiam o compromisso de estruturar e implantar os Centros de Informática Educativa (Cied) com apoio técnico e financeiro do MEC, junto as Secretárias de Ensino que os indicaram ao Projeto FORMAR (TAVARES, 2002).

Em outubro de 1989 o MEC cria o Programa Nacional de Informática na Educação PRONINFE, que posteriormente seria integrado à Secretaria Nacional de Educação Tecnológica - SENETE. O programa tinha por finalidade

\footnotetext{
Desenvolver a informática educativa no Brasil, através de projetos e atividades articulados e convergentes, apoiados em fundamentação pedagógica sólida e atualizada, de modo a assegurar a unidade política e técnico-científica imprescindível ao êxito dos esforços e investimentos envolvidos (BRASIL, 1991, p.11)
}

O PRONINFE visava à criação de: núcleos de informática educativa, chamados Centros de Informática na Educação, geograficamente espalhados pelo país com o objetivo de atender as necessidades dos diferentes sistemas de ensino e incentivar o uso e a produção de programas educativos computacionais (BRASIL, 1994). A experiência obtida com o PRONINFE permitiu ao MEC utilizá-lo como na elaboração de novos programas, como o Programa Nacional de Tecnologia Educacional PROINFO. 
O PROINFO foi criado pela Portaria $n^{\circ}$ 522/MEC, de 9 de abril de 1997, com a finalidade de disseminar o uso pedagógico das TIC's no ensino fundamental e médio pertencentes às redes estaduais e municipais, tendo como suas principais características a instalação de recursos informatizados condicionados à capacidade das escolas; promover infraestrutura de suporte técnico de informáticas para as redes de ensino público; estimular a interligação de computadores nas escolas visando a formação de uma ampla rede de comunicação; preparar alunos capazes de interagir com uma sociedade cada vez mais tecnologicamente desenvolvida; entre outros (BRASIL, 1997, p. 9)

O PROINFO previa também a criação de Núcleos de Tecnologia Educacional - NTE, estruturas descentralizadas de apoio ao processo de informatização, compostos por uma equipe de educadores e especialistas em informática, com infra-estrutura adequada, tendo por objetivos: sensibilizar e motivar as escolas para uso das TICs; capacitar e reciclar os professores e as equipes administrativas das escolas; realizar cursos especializados para as equipes de suporte técnico; assessorar as escolas para o uso pedagógico das TICs; entre outros (BRASIL, 1997, p. 12).

No que se refere à capacitação dos professores, o Programa visava estruturar a formação continuada dos professores no uso das TIC's; privilegiar a aprendizagem cooperativa e autônoma com vistas à intercomunicação e interação dos professores com especialistas; e a preparação dos professores para se tornarem independentes no uso e na incorporação das TIC's em sua ação, buscando a transformação de sua prática pedagógica (BRASIL, 1997).

Em dezembro de 2007, por meio do Decreto n. 6300 (BRASIL, 2007) o PROINFO no âmbito do Plano Nacional de Desenvolvimento da Educação - PDE passou por algumas modificações, entre elas a alteração da nomenclatura passando-se a chamar Programa Nacional de Tecnologia Educacional - PROINFO INTEGRADO. Entre os objetivos desse novo Programa estão: promover o uso pedagógico das TICs nas escolas de educação básica, urbanas e rurais; fomentar a melhoria dos processos de ensino e aprendizagem por meio do uso das TICs; promover a capacitação dos agentes educacionais envolvidos nas ações do Programa; contribuir para inclusão digital por meio da ampliação de acesso a computadores e à Internet; fomentar a produção de conteúdos educacionais digitais; entre outros (BRASIL, 2007). 
O PROINFO Integrado apresenta ainda um projeto vinculado a ele chamado Projeto UCA ou PROUCA que é uma iniciativa do Governo Federal, que se assemelha ao Programa One Laptop per Child - OLPC desenvolvido por pesquisadores do Instituto de Tecnologia de Massachusetts - MIT. O PROUCA tem por objetivo:

Promover a inclusão digital nas escolas das redes públicas de ensino federal, estadual, distrital, municipal ou nas escolas sem fins lucrativos de atendimento a pessoas com deficiência, mediante a aquisição e a utilização de soluções de informática, constituídas de equipamentos de informática, de programas de computador (software) neles instalados e de suporte e assistência técnica necessários ao seu funcionamento (BRASIL, 2010)

Entre os pontos inovadores do PROUCA, segundo o MEC, estão:

1. Uso do notebook por todos os estudantes e educadores da escola pública em um ambiente que permita a imersão em uma cultura digital;

2. Mobilidade de uso do equipamento em outros ambientes dentro e fora da escola;

3. Conectividade, pela qual o processo de utilização do notebook e a interação entre estudantes e professores ocorrerão por meio de redes sem fio conectadas à Internet;

4. Incentivo ao uso de softwares livres e inserção em comunidades para a disseminação do conhecimento;

5. Uso pedagógico das diferentes mídias colocadas à disposição no notebook educacional. (BRASIL, 2010, p. 03)

Por fim, para atender as necessidades de conexão à Internet provenientes das ações do PROUCA e PROINFO Integrado foi criado, por meio do Decreto n. ${ }^{\circ} 6.424$ de 04 de abril de 2008, o Programa Banda Larga nas Escolas - PBLE com o objetivo de conectar as escolas públicas urbanas a internet através de tecnologias que propiciem qualidade, velocidade e serviços para incrementar o ensino público do País (BRASIL, 2013).

Nesse capítulo foi apresentado um resumo de programas e projetos do governo brasileiro que estimulam o uso dos computadores e da Internet nos processos de ensino aprendizagem. O uso dessas tecnologias já não é mais visto como um simples acessório na ação de educar, pois segundo o MEC (BRASIL, 1997, p. 67) "é indiscutível a necessidade crescente do uso de computadores pelos alunos como instrumento de aprendizagem escolar, para que possam estar atualizados em 
relação às novas tecnologias da informação e se instrumentalizarem para as demandas sociais presentes e futuras."

Assim, apresentadas as políticas de incentivo de uso das TICs no ensino público brasileiro, resta verificar qual o panorama atual da utilização desses recursos nas escolas brasileiras.

\subsection{Panorama atual da aplicação das Tics no ensino brasileiro}

Embora as políticas públicas de incentivo e capacitação para o uso das TIC's nas escolas públicas tenham sido implementadas no Brasil desde o início dos anos 80, é conveniente analisar como esse quadro se apresenta atualmente, haja vista o avanço dessas tecnologias, as condições de acessibilidade, a formação de professores e a estruturação das escolas para utilizarem e comportarem as TICs. Com base em pesquisas realizadas por órgãos nacionais e internacionais, que avaliam as políticas educacionais, pode-se tecer um panorama atualizado do uso das TICs no ensino público.

No âmbito nacional, foi realizada uma pesquisa pela Fundação Victor Civita que investigou o uso do computador e da Internet em escolas públicas brasileiras no período de 2007 a 2009. Tal pesquisa se deu por intermédio do Laboratório de Sistemas Integráveis - LSI, do Departamento de Engenharia de Sistemas Eletrônicos da Escola Politécnica da Universidade de São Paulo, com a participação do Ibope Inteligência, onde se analisaram 400 escolas de Ensino Fundamental e Médio das capitais brasileiras.

Foram realizadas entrevistas via telefone com diretores de escola, ou alguém indicado por ele, tendo por intuito de pesquisa "agrupar e mapear os tipos de uso feitos nas escolas públicas e, depois do mapeamento, procurar entender quais fatores mais contribuem para o uso dos computadores e da Internet de forma pedagógica" (FUNDAÇÃO VICTOR CIVITA, 2010, p. 294).

Os dados obtidos na pesquisa referentes à infraestrutura escolar revelam que $99 \%$ das escolas pesquisadas possuem computadores funcionando. O número de computadores presentes nas escolas pode ser observado no gráfico 01: 


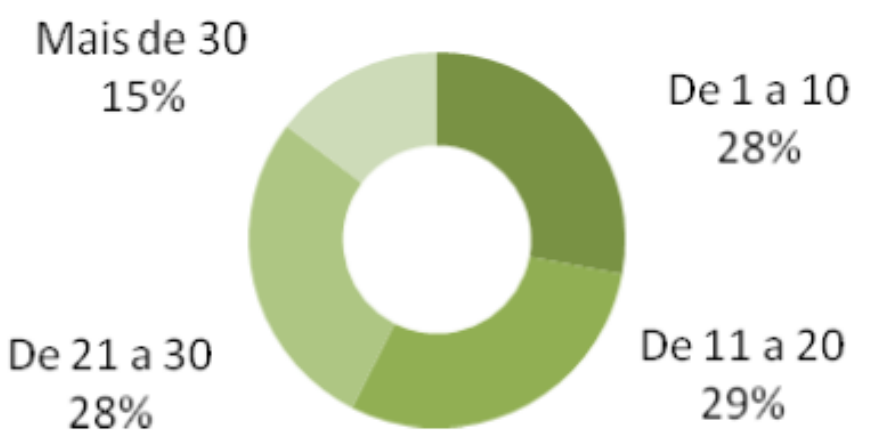

Gráfico 1 - Número de computadores nas escolas (FUNDAÇÃO VICTOR CIVITA, 2010, P. 304)

Todavia, convêm ressaltar que entre as escolas pesquisadas, as pertencentes às regiões Sul e Sudeste possuem maior número de computadores do que as regiões Centro Oeste, Norte e Nordeste.

Segundo a pesquisa, no que concerne a localização dos computadores, observa-se pelo gráfico 02 que estes dispositivos são predominantemente encontrados nas secretarias $(91 \%)$ e somente em $4 \%$ dos casos está nas salas de aula.

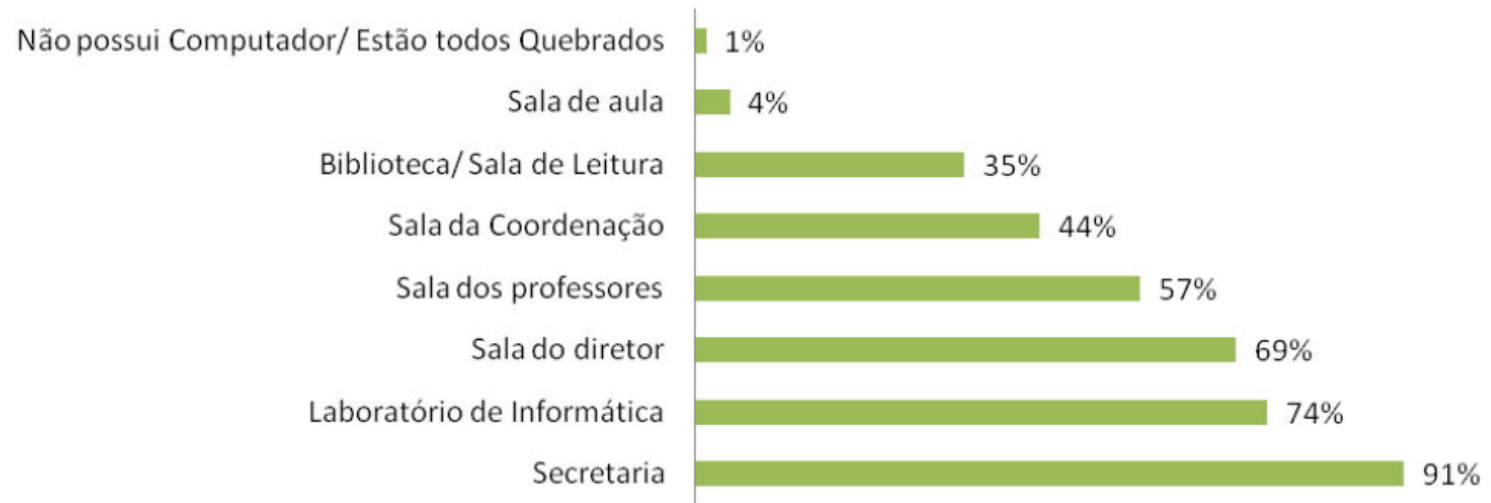

Gráfico 2 - Localização dos computadores nas escolas pesquisadas (FUNDAÇÃO VICTOR CIVITA, 2009 , P. 43)

Verifica-se na pesquisa que a distribuição de alunos nos laboratórios de informática apresenta a seguinte configuração: em $54 \%$ dos casos utilizam os computadores em duplas e em apenas $11 \%$ dos casos um aluno utiliza o computador individualmente (Gráfico 03), cabe ressaltar que à época da pesquisa $27 \%$ das escolas das capitais não possuíam laboratório de Informática. 


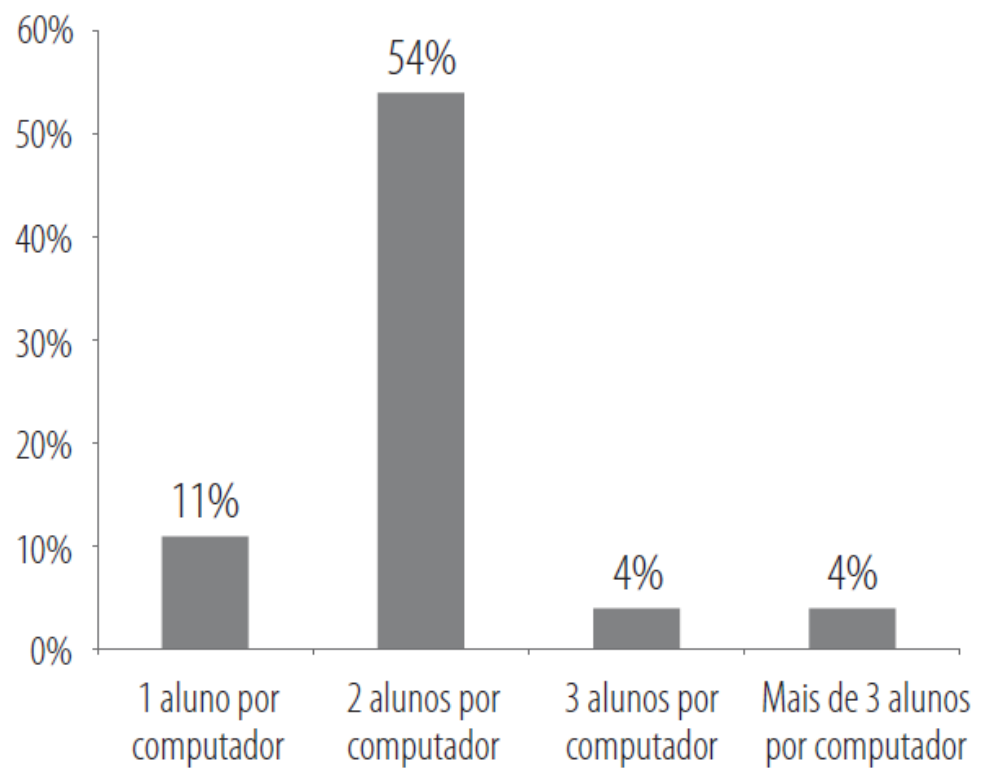

Gráfico 3 - Distribuição de alunos por computador em laboratórios de informática (FUNDAÇÃO VICTOR CIVITA, 2010, P. 311)

A pesquisa analisou também quem são os usuários de computador e internet nas escolas e verificou que funcionários administrativos e diretores são os que mais utilizam esses recursos (99\%), enquanto que professores com alunos e alunos sem professor, representam respectivamente $67 \%$ e $21 \%$ dos casos analisados, conforme gráfico 04.

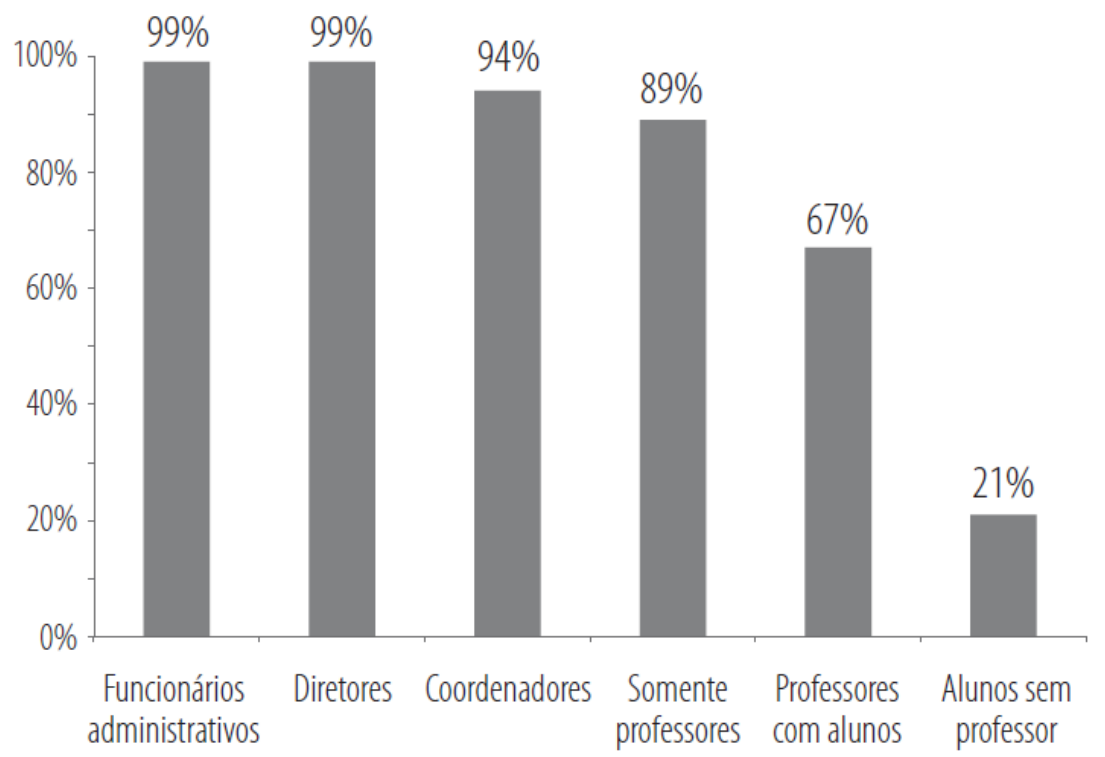

Gráfico 4 - Usuários de computadores e Internet nas escolas (FUNDAÇÃO VICTOR CIVITA, 2010, p. 310) 
Um dado pertinente apresentado na pesquisa mostra que $70 \%$ dos professores informam ter tido pouca ou nenhuma preparação para uso das TICs durante sua graduação e apenas 3\% dizem estar bem preparados para o uso dessas tecnologias, conforme gráfico 05 :

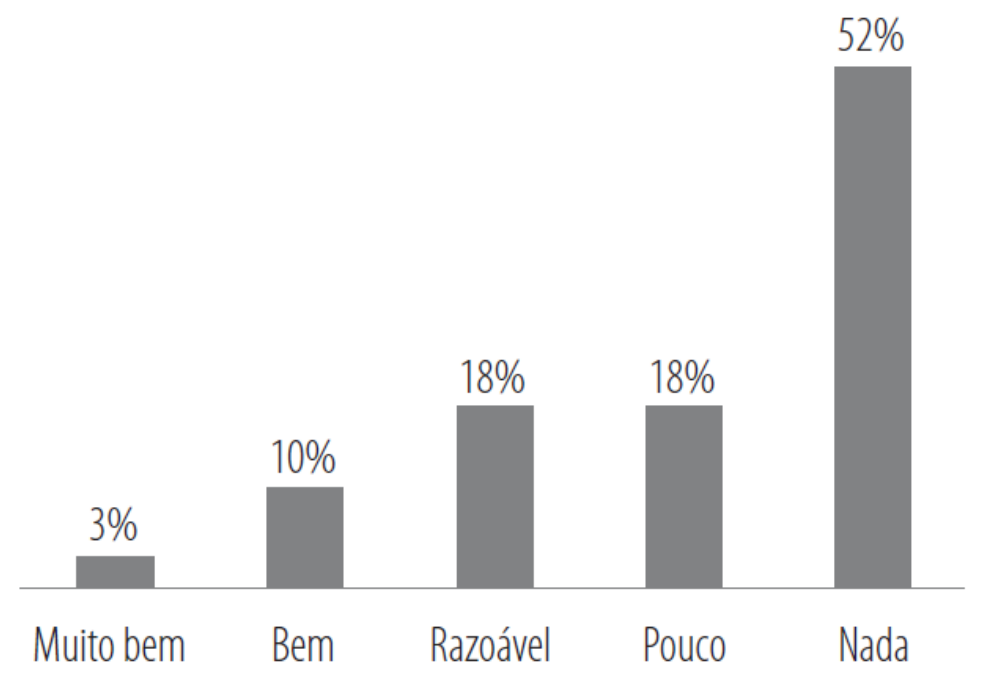

Gráfico 5 - Preparação para uso das Tics na graduação (FUNDAÇÃO VICTOR CIVITA, p. 302)

Quanto ao uso dos computadores, a pesquisa aponta haver uma grande variação nos programas de computador utilizados, seja apenas pelos professores, seja pelos professores com os alunos, mostrando predominância no uso de editores de texto em ambos os casos, e baixa incidência no uso de softwares de programação e modelagem 3D e simulações, conforme se observa no gráfico 06 : 


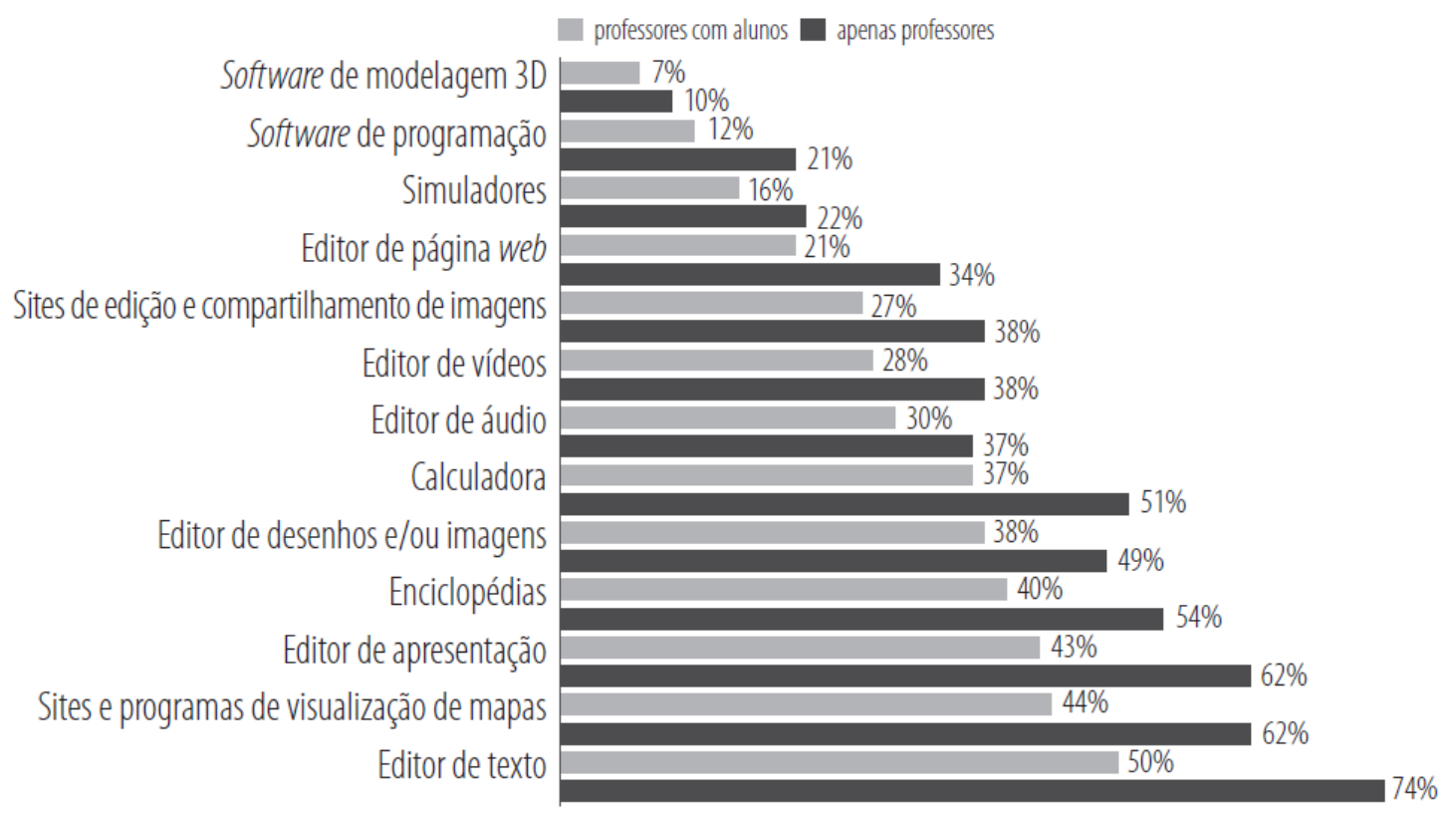

Gráfico 6 - Programas de computador mais utilizados (FUNDAÇÃO VICTOR CIVITA, 2010, p. 313)

No que se refere aos principais problemas para o uso pedagógico dos computadores nas escolas, a pesquisa aponta que em $44 \%$ dos casos os problemas decorrem da falta de professores especializados em informática educativa e $39 \%$ dos problemas está associado ao número insuficiente de computadores ou computadores defeituosos, outros problemas apontados podem ser observados no gráfico 07 :

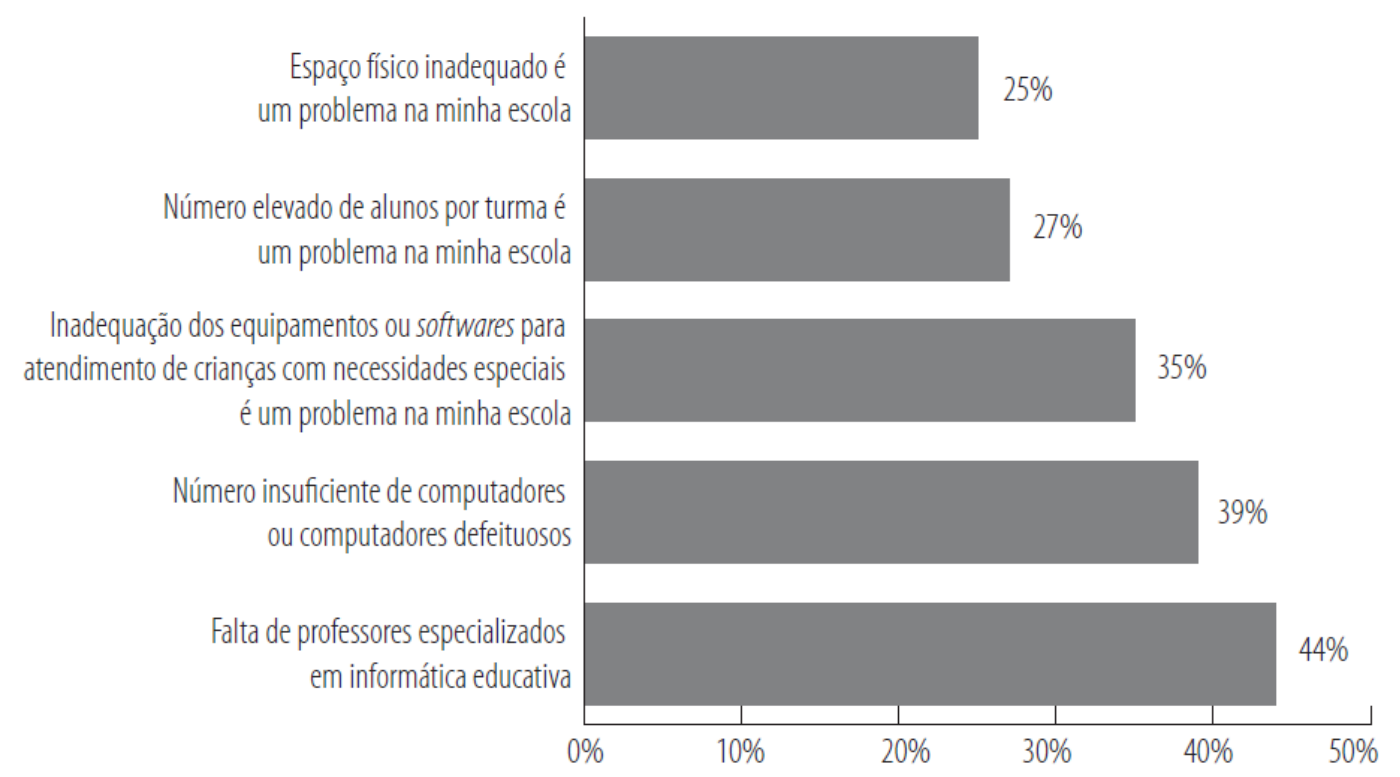

Gráfico 7 - Problemas no uso pedagógico dos computadores nas escolas (FUNDAÇÃO VICTOR CIVITA, 2010, p. 314) 
Além de analisar os problemas relacionados ao uso dos computadores nas escolas, a pesquisa avaliou também quais seriam as vantagens do uso da TIC's no ensino. Segundo os entrevistados entre as vantagens, está à ampliação de exploração dos temas e conteúdos (78\%), o aumento da motivação dos professores (46\%), conforme gráfico 08 :

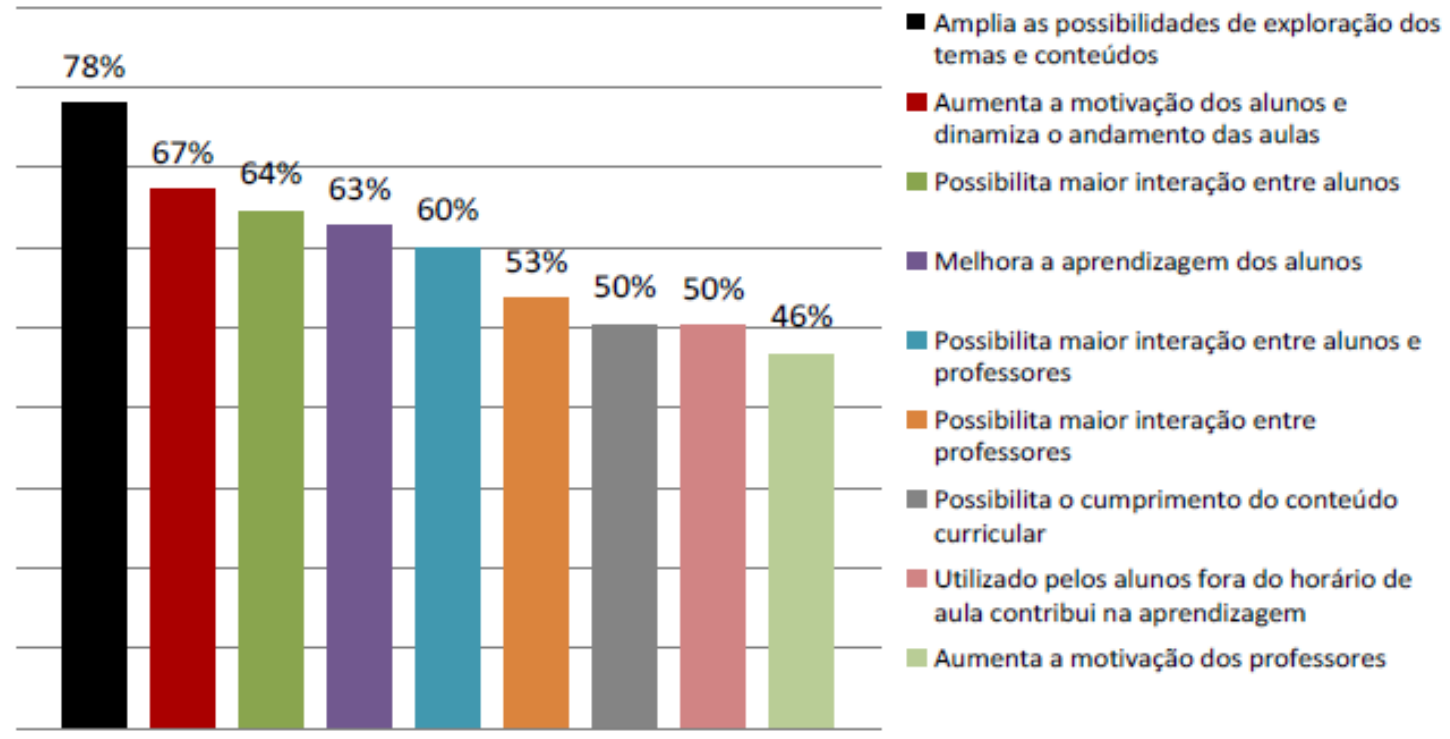

Gráfico 8 - Vantagens da tecnologia na educação (FUNDAÇÃO VICTOR CIVITA, 2010, p. 317)

Diversos outros fatores relacionados com o uso das TICs no ensino foram investigados na pesquisa da Fundação Victor Civita e a análise dos dados obtidos permitiu aos pesquisadores chegarem a diversas conclusões, entre elas "que apesar dos dados levantados sobre recursos e infraestrutura serem favoráveis, infraestrutura, formação de professores e problemas com acesso à internet são apontados como os principais problemas para o uso pedagógico do computador" (FUNDAÇÃO VICTOR CIVITA, 2010, p. 327-328), outra conclusão obtida na pesquisa é que "na maioria das escolas, as atividades que utilizam tecnologia e são realizadas com os alunos têm pouca complexidade ou usam recursos simples" (FUNDAÇÃO VICTOR CIVITA, 2010, p. 328).

Além de pesquisas de âmbito nacional, pode-se utilizar também como referência pesquisas de âmbito internacional, que analisam direta ou indiretamente o uso das TICs no ensino, entre elas esta o Programa Internacional de Avaliação de Estudantes - PISA que é um programa internacional de avaliação comparada desenvolvido pela Organização para a Cooperação e Desenvolvimento Econômico - 
OCDE que é aplicado a alunos na faixa dos 15 anos, e que tem por objetivos fornecer indicadores de alta qualidade para o ensino, que viabilizem a elaboração de políticas de melhoria do ensino básico.

As avaliações do PISA são trienais e abrangem três áreas do conhecimento, Leitura, Matemática e Ciências, havendo maior destaque para uma destas áreas a cada vez que o Programa é aplicado. Os resultados obtidos pelo PISA são interpretados dentro do contexto de cada país, sendo que no Brasil compete ao Instituto Nacional de Estudos e Pesquisas Educacionais Anísio Teixeira - Inep sua coordenação. O PISA, por meio da aplicação de questionários visa também avaliar as instituições de ensino, analisando os diversos fatores presentes no cenário escolar que influenciam nos resultados educacionais obtidos nas edições do Programa.

Segundo dados oriundos do Relatório Nacional PISA 2012 (BRASIL, 2012, p. 13), foram avaliadas 767 escolas e 18.589 estudantes, pertencentes das 27 Unidades Federativas do Brasil. Nesta edição do Programa, o Questionário da Escola, que é preenchido por diretores de escola ou um responsável por ele indicado, apontou que os recursos da escola que mais afetam o ensino, segundo o percentual de alunos afetados, são (Tabela 01):

Tabela 1 - Porcentagem de alunos afetados segundo recursos educacionais disponíveis (BRASIL, 2012, p. 59)

\begin{tabular}{|c|c|c|c|c|c|c|c|c|c|c|c|c|}
\hline & \multicolumn{2}{|c|}{$\begin{array}{c}\text { Escassez ou } \\
\text { inadequação } \\
\text { dos } \\
\text { equipamentos } \\
\text { do laboratório } \\
\text { de ciências }\end{array}$} & \multicolumn{2}{|c|}{$\begin{array}{c}\text { Escassez ou } \\
\text { inadequação } \\
\text { do material } \\
\text { pedagógico } \\
\text { (por exemplo, } \\
\text { livros didáticos) }\end{array}$} & \multicolumn{2}{|c|}{$\begin{array}{c}\text { Escassez ou } \\
\text { inadequação } \\
\text { de } \\
\text { computadores } \\
\text { para o ensino }\end{array}$} & \multicolumn{2}{|c|}{$\begin{array}{c}\text { Escassez ou } \\
\text { inadequação } \\
\text { de conexão } \\
\text { com a internet }\end{array}$} & \multicolumn{2}{|c|}{$\begin{array}{c}\text { Escassez ou } \\
\text { inadequação } \\
\text { de software } \\
\text { para o ensino }\end{array}$} & \multicolumn{2}{|c|}{$\begin{array}{c}\text { Escassez ou } \\
\text { inadequação } \\
\text { dos recursos da } \\
\text { biblioteca }\end{array}$} \\
\hline & 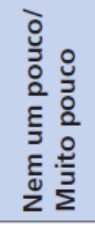 & 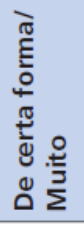 & 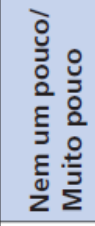 & 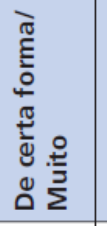 & 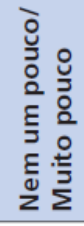 & 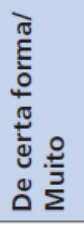 & 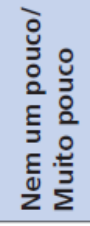 & 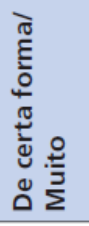 & 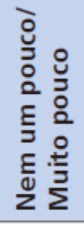 & 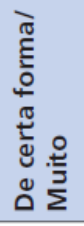 & 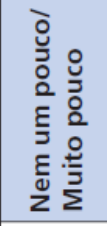 & 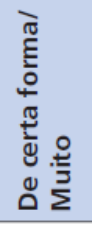 \\
\hline Colômbia & 26 & 73 & 33 & 66 & 31 & 69 & 30 & 70 & 25 & 74 & 30 & 69 \\
\hline Peru & 27 & 71 & 41 & 57 & 39 & 60 & 43 & 57 & 33 & 66 & 29 & 70 \\
\hline México & 38 & 61 & 60 & 39 & 39 & 60 & 46 & 54 & 42 & 57 & 45 & 54 \\
\hline Brasil & 34 & 65 & 85 & 14 & 44 & 54 & 49 & 50 & 37 & 60 & 56 & 42 \\
\hline Argentina & 44 & 55 & 61 & 38 & 48 & 50 & 46 & 53 & 48 & 51 & 68 & 31 \\
\hline Chile & 47 & 53 & 72 & 28 & 71 & 28 & 71 & 27 & 42 & 56 & 67 & 31 \\
\hline Finlândia & 74 & 26 & 81 & 19 & 57 & 43 & 72 & 22 & 48 & 46 & 62 & 32 \\
\hline Espanha & 68 & 29 & 90 & 9 & 60 & 38 & 68 & 31 & 57 & 42 & 73 & 25 \\
\hline Coreia do Sul & 68 & 32 & 84 & 16 & 82 & 18 & 88 & 7 & 71 & 23 & 63 & 32 \\
\hline Uruguai & 82 & 18 & 76 & 24 & 71 & 29 & 71 & 29 & 56 & 43 & 72 & 28 \\
\hline Portugal & 71 & 27 & 90 & 9 & 75 & 24 & 79 & 18 & 64 & 34 & 82 & 15 \\
\hline EUA & 78 & 20 & 84 & 14 & 66 & 32 & 84 & 15 & 76 & 23 & 81 & 18 \\
\hline
\end{tabular}


Pela tabela 01 pode-se observar que nas escolas brasileiras avaliadas, as condições de informatização (computadores (54\%), Internet (50\%) e softwares (60\%)) são apontadas como aquelas cuja escassez ou inadequação afetam "De certa forma/Muito" o ensino, perdendo apenas para os laboratórios de ciências. É necessário ressaltar que tais recursos de informatização são de grande importância na análise do PISA, sendo inclusive convertidos em índices que permitirão uma correlação com o desempenho do estudante em matemática (PISA, 2012). Na edição 2012 do Programa o Brasil apresentou ligeira melhora no desempenho de matemática, 391 pontos, em comparação a edição de 2009, quando obteve 386 pontos, contudo, apesar da melhora não houve avanço no ranking, de forma que o país caiu para $58^{a}$ posição em matemática, quando em 2009 ocupava a $53^{a}$ posição. Outra pesquisa, que visava mais especificamente analisar o uso da Internet em escolas públicas e privadas foi realizada pelo Instituto Brasileiro de Geografia e Estatística - IBGE, por meio da Pesquisa Nacional por Amostra de Domicílio PNAD e os dados obtidos apresentam informações comparativas entre os anos de 2005 e 2011, mostrando que "dos 38,8 milhões de estudantes com 10 anos ou mais de idade em 2005, 31,1 milhões eram de rede pública dos quais 24,1\% utilizaram a Internet", já em 2011 esses números evoluem para 37,5 milhões de estudantes, dos quais 29,2 milhões pertencem à rede pública de ensino e desses 65,8 \% utilizaram a Internet. Complementar a esse quadro, em 2005, dos 7,7 milhões de estudantes pertencentes à rede privada, 82,4\% fizeram uso da Internet, e em 2011 dos 8,4 milhões dessa rede de ensino o percentual apresentado de acesso a Internet foi de 96,2\% (PNAD, 2013, p.38).

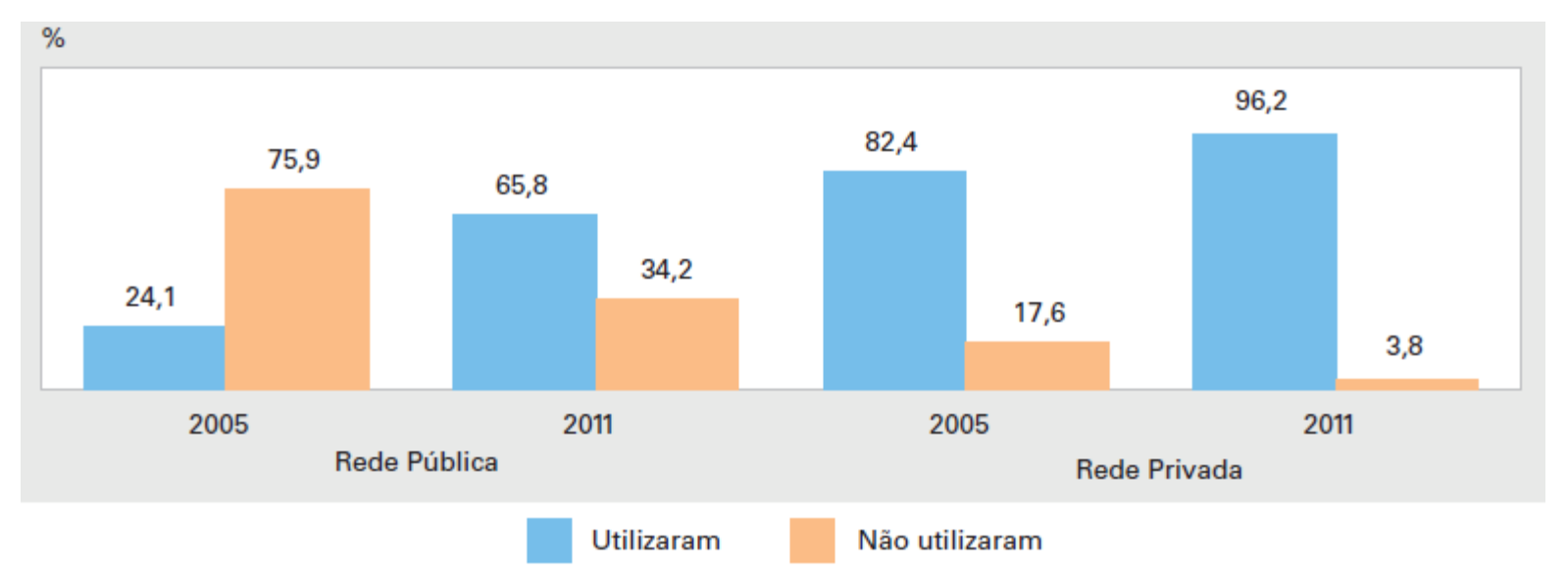

Gráfico 9 - Distribuição dos estudantes de 10 anos ou mais, por rede de ensino e condição de utilização da Internet - Brasil 2005-2011 (PNAD, 2013, p. 38) 
Pode-se observar pelo gráfico 09 que embora o percentual de estudantes que acessam a Internet da rede privada seja superior ao da rede pública, é conveniente perceber que no período de 2005 a 2011 o percentual de estudantes da rede pública quase triplicou (PNAD, 2013), contudo, não é possível por essa pesquisa analisar as condições de uso da internet junto aos alunos entrevistados, assim nada podemos afirmar quanto ao tipo de conexão ou em relação à velocidade e estabilidade de conexão.

Pesquisa mais recente visando medir os impactos das TIC's na educação foi elaborada pelo Comitê Gestor da Internet no Brasil - CGI.br, por meio do Núcleo de Informação e Coordenação do Ponto BR - NIC.br e do Centro de Estudos sobre as Tecnologias da Informação e da Comunicação - Cetic.br, com intuito criar indicadores e estatísticas que ajudem no desenvolvimento de políticas públicas que subsidiem o uso das TIC's.

A Pesquisa Sobre o Uso das Tecnologias de Informação e Comunicação nas Escolas Brasileiras - TIC Educação 2013 (CGI.br, 2014, p. 112-113), teve por objetivo identificar os usos e apropriações das TIC's nas escolas brasileiras por meio da prática pedagógica e da gestão escolar. A pesquisa analisou 994 escolas, 939 diretores, 869 coordenadores, 1.987 professores e 9.657 alunos, de escolas públicas (estaduais e municipais) e particulares de áreas urbanas do Brasil, que oferecem pelo menos um dos níveis de ensino e séries: da $4^{a}$ série $/ 5^{\circ}$ ano do Ensino Fundamental I, $8^{\mathrm{a}}$ série $/ 9^{\circ}$ ano do Ensino Fundamental II e $2^{\circ}$ ano do Ensino Médio. A pesquisa compara dados obtidos no período de 2010 a 2013 e aponta que $100 \%$ das escolas urbanas do Brasil possuem computadores, sendo que dessas todas possuem ao menos um computador de mesa (desktop) e $73 \%$ possuem pelo menos um computador portátil (notebook, laptop ou netbook). Além disso, pode-se observar pelo gráfico 10 , que houve um aumento do uso de tablets nas escolas públicas, passando de $2 \%$ em 2012 para $11 \%$ em 2013: 


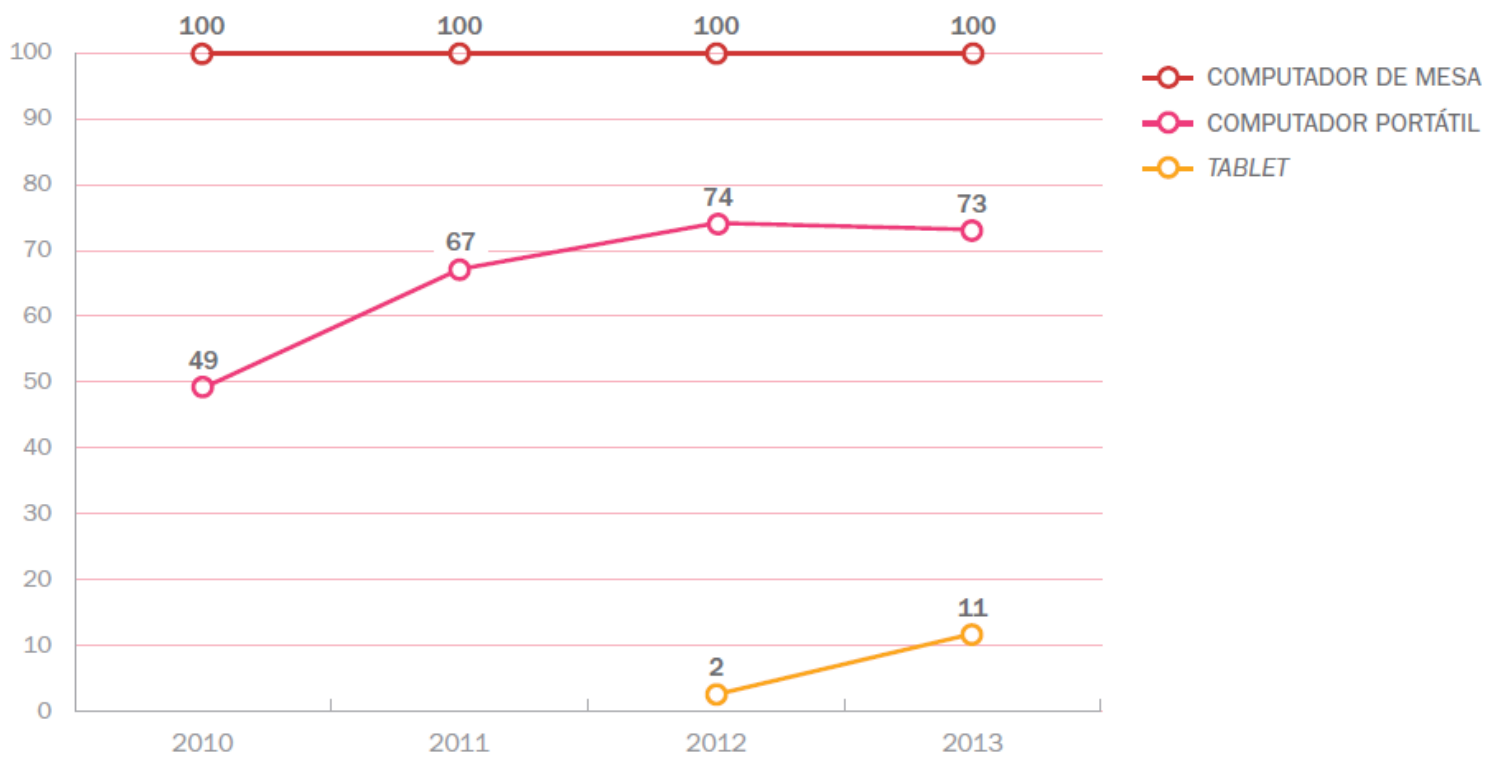

Gráfico 10 - Proporção de escolas, por tipo de computador (CGI, 2014, p. 138)

Ainda em relação à presença de computadores nas escolas, a pesquisa (CGI, 2014) informa que em 2013, as escolas públicas possuíam em média 19,1 computadores de mesa (desktop) para uma média de 653 alunos, evidenciando a limitação de uso individualizado no cotidiano escolar.

No que se refere ao local de instalação dos computadores nas escolas públicas, a Pesquisa TIC Educação 2013 aponta que os dois locais de maior incidência de instalação desses equipamentos são a sala coordenador pedagógico ou do diretor e o laboratório de informática, conforme podemos observar no gráfico 11 : 


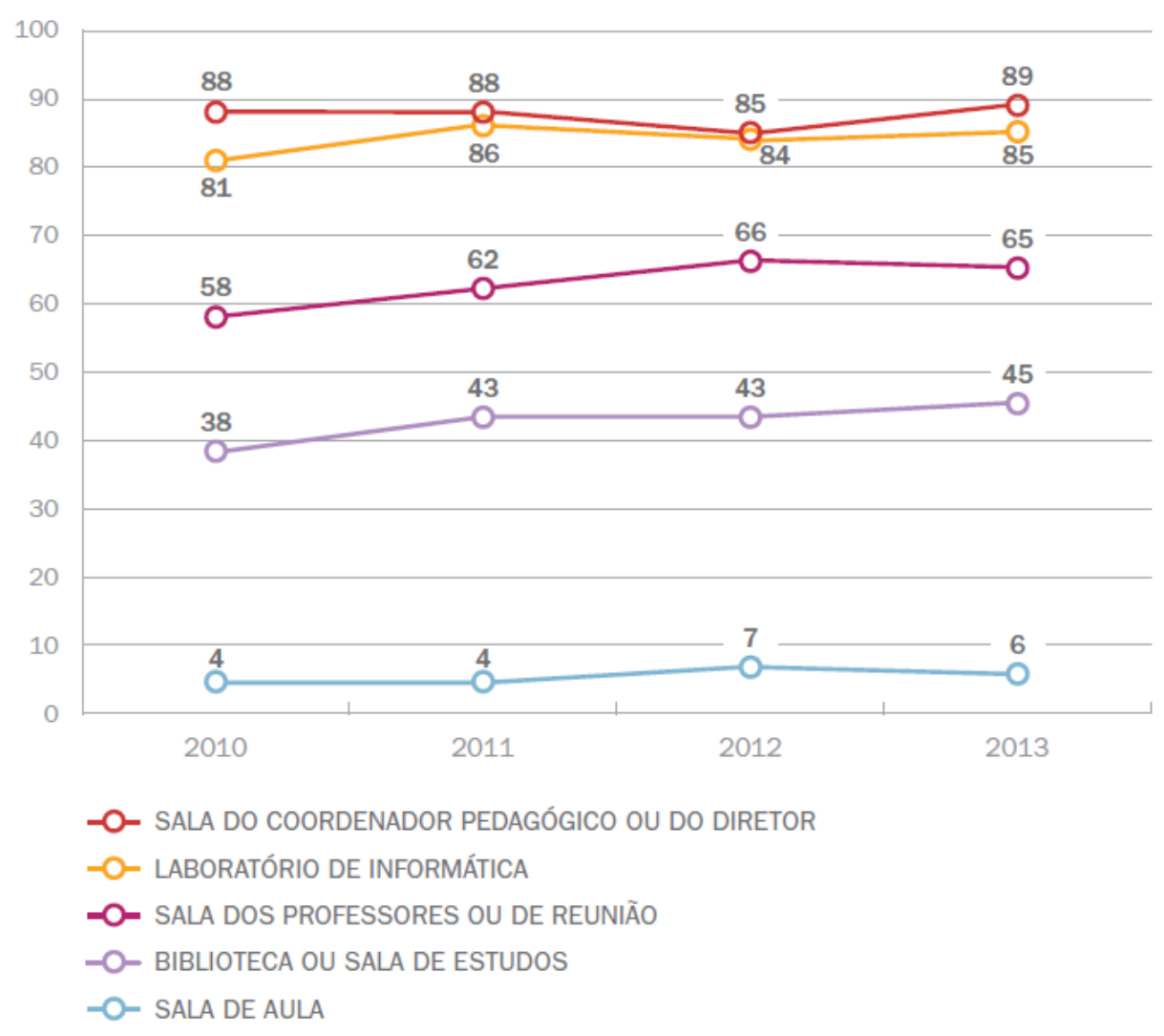

Gráfico 11 - Proporção de escolas por local de instalação de computadores 2010-2013 (CGI, 2014, p. 139)

Em relação à presença de Internet nas escolas, a Pesquisa TIC Educação 2013 (CGI, 2014) informa que em 2013, 95\% das escolas públicas em áreas urbanas possuíam computador com acesso a Internet, contudo esse acesso não é universalizado devido à existência de desigualdades regionais, fazendo com que esteja presente em $86 \%$ das escolas da região Norte e Nordeste, e em $100 \%$ das escolas da região Sudeste. No que concerne a Internet com conexão sem fio, a pesquisa aponta as escolas públicas da região Centro-Oeste (87\%) são as que mais possuem este tipo de conexão, seguidas das escolas da região Sul (83\%), Sudeste (74\%), Norte (66\%) e Nordeste (54\%), conforme mostra o gráfico 12 : 


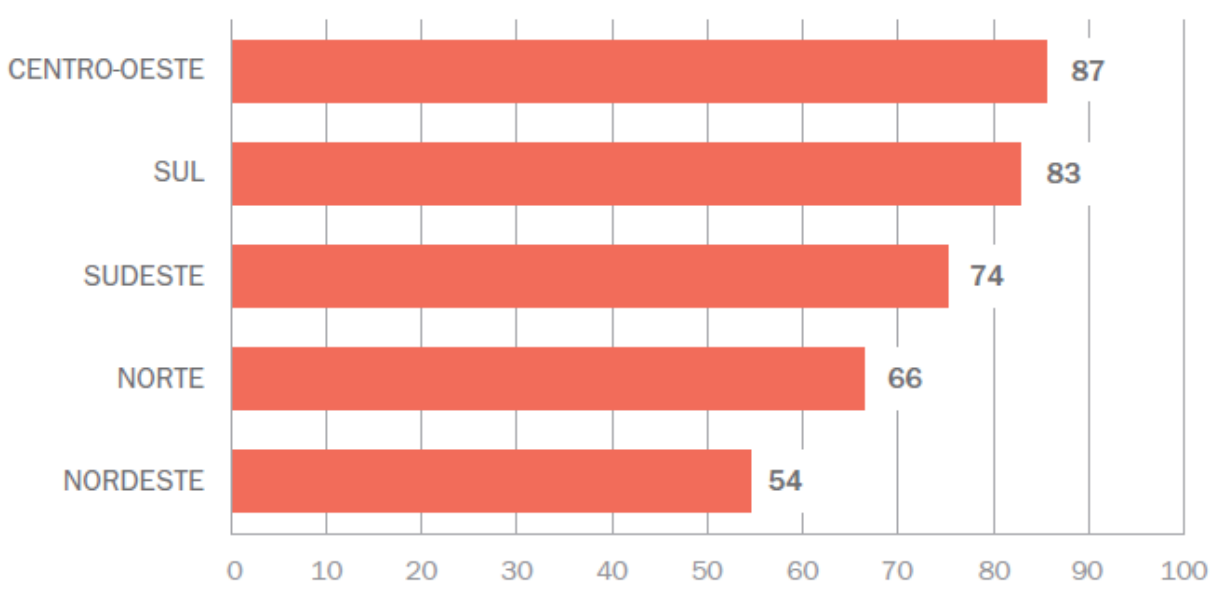

Gráfico 12 - Proporção de escolas com conexão à Internet, sem fio, por região (CGI, 2014, p. 141)

Todavia, embora haja nas escolas públicas brasileiras conexão à Internet, sem fio, ainda predomina como fator limitante a velocidade de conexão, conforme gráfico 13 , onde $55 \%$ das escolas contam com conexões com até $2 \mathrm{Mbps}$ e apenas $19 \%$ contam com velocidades superiores a essa:

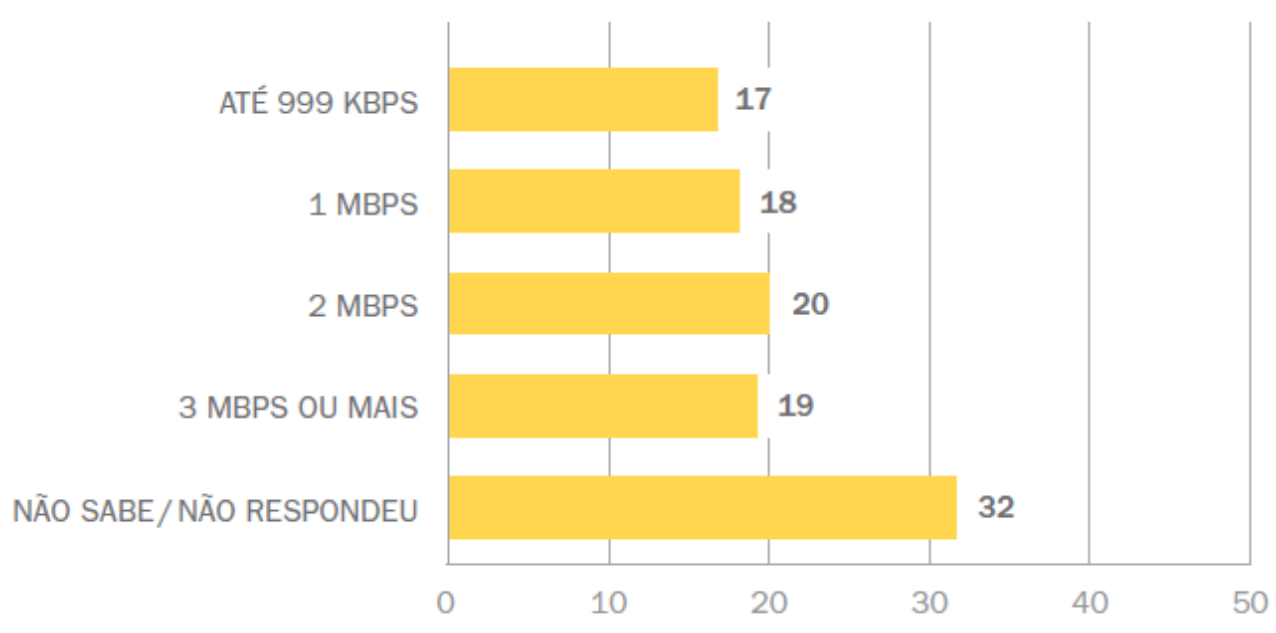

Gráfico 13 - Proporção de escolas, por velocidade de conexão à Internet (CGI, 2014, p. 141)

Segundo a Pesquisa TIC Educação 2013 (CGI, 2014) a velocidade de conexão pode ser considerada como um dos principais fatores de limitações de infraestrutura das escolas públicas, pois implica diretamente na capacidade de compartilhamento da rede por diversos dispositivos de forma simultânea.

A pesquisa apontou também que os professores tem levado seus próprios computadores portáteis para escola, sendo que o motivo mais apontado para essa ação é o apoio as atividades pedagógicas, em $77 \%$ dos casos, enquanto que em $29 \%$ dos casos era para uso em atividades pessoais, conforme gráfico 14 : 


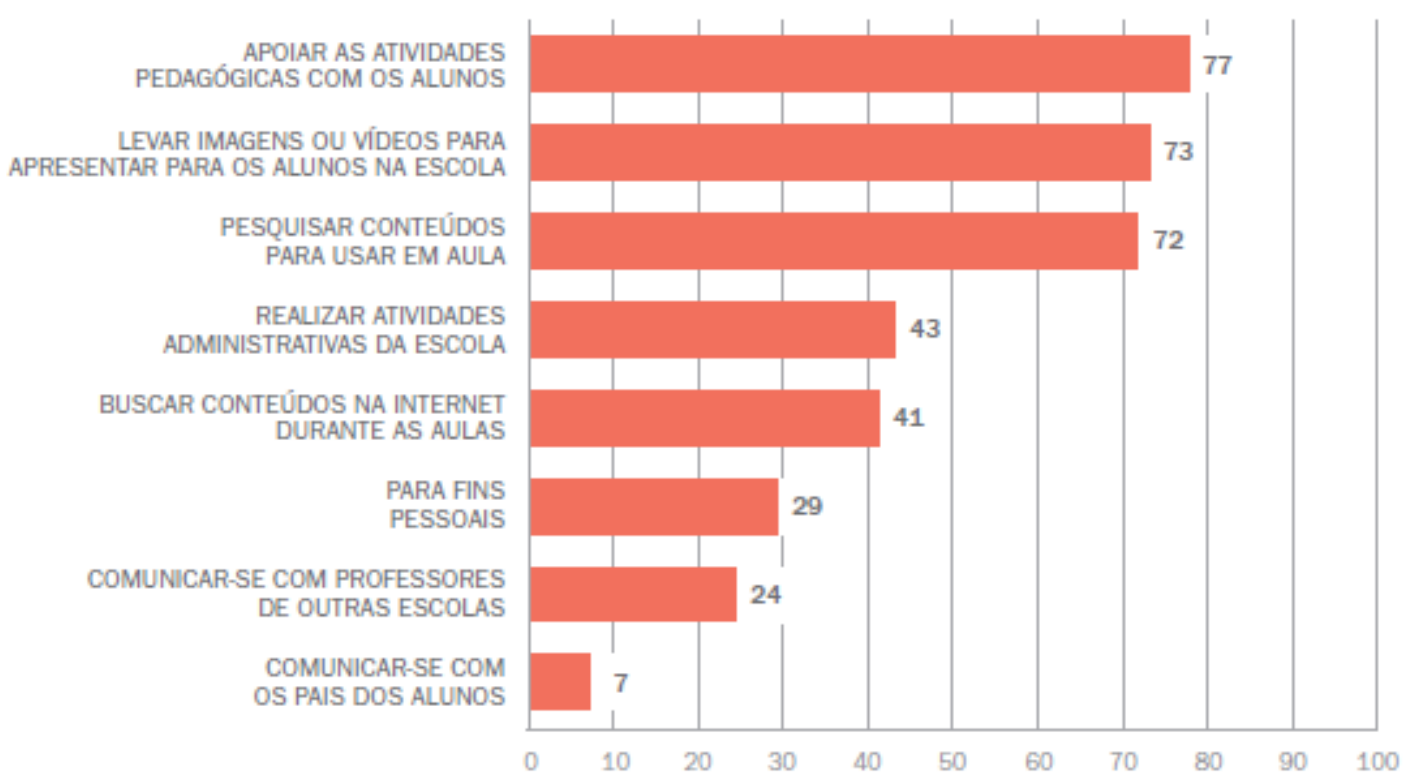

Gráfico 14 - Proporção de professores, por motivos para levar o computador portátil para escola (CGI, 2014, p. 146)

Esse comportamento dos professores encontra ressonância em iniciativas como a do tipo Traga o Seu Próprio Dispositivo, do inglês Bring Your Own Device - BYOD. Esse conceito é apontado como uma tendência, segundo o Relatório Horizon 2015 (NMC, 2015), onde empresas privadas adotam a política de permitir que seus funcionários tragam seus dispositivos móveis (notebooks, smartphones, tablets) para uso no trabalho; estudantes utilizam seus próprios dispositivos móveis em ambientes educacionais.

A Pesquisa TIC Educação 2013 mostrou que os professores, em relação à forma de aprendizagem do uso do computador e da Internet, optam por realizar cursos específicos, ou acabam aprendendo por si mesmos a utilizar essas tecnologias, como podemos observar no gráfico 15 : 


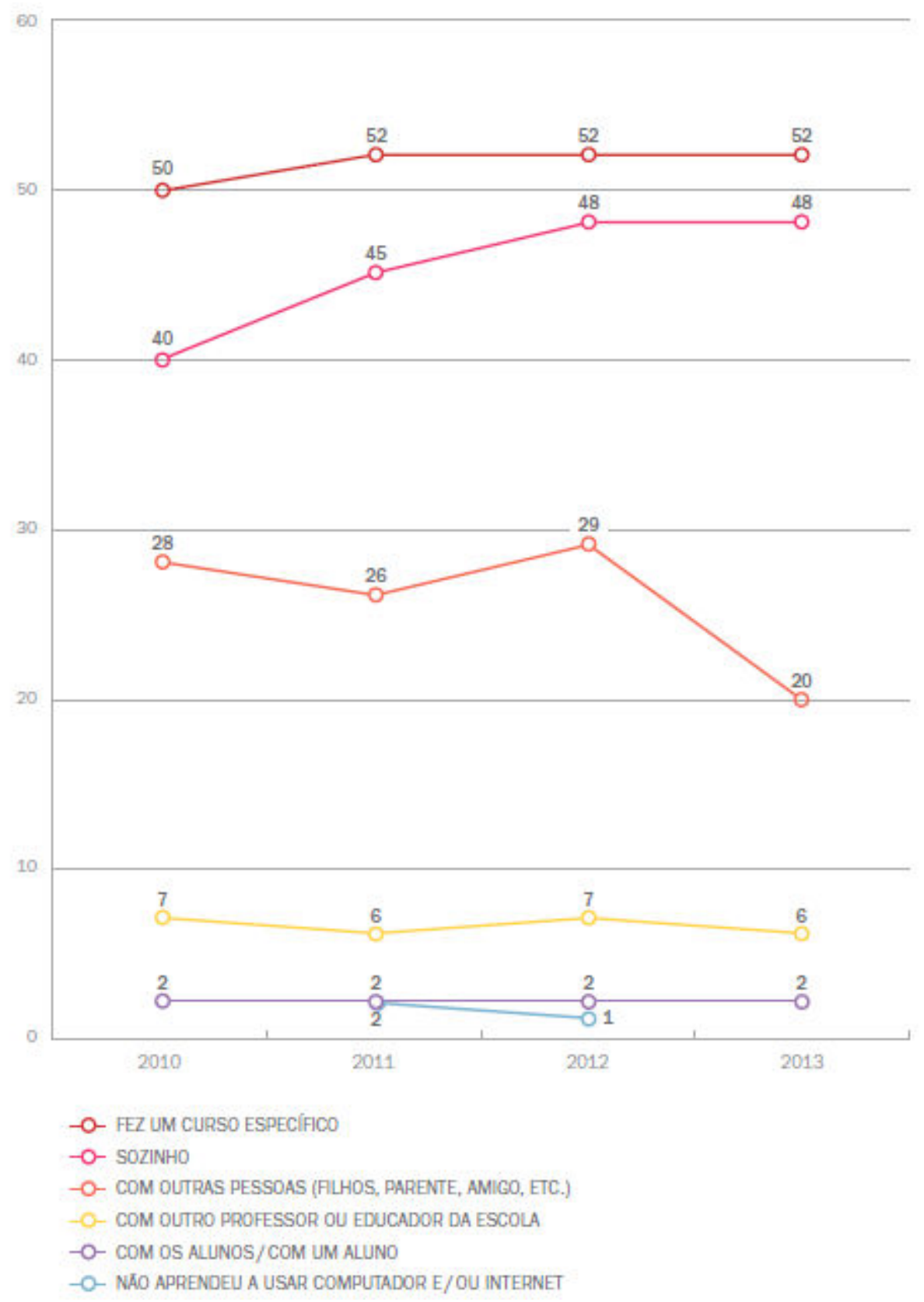

Gráfico 15 - Proporção de professores, por forma de aprendizado do uso de computador e Internet (2010-2013) (CGI, 2014, p. 150)

Ainda em relação aos professores, a pesquisa mostra (gráfico 16) que os tipos de recursos da Internet mais utilizados por esses profissionais para preparo de aulas ou atividades com alunos são: imagens, figuras, ilustrações e fotos $(84 \%)$, textos variados $(83 \%)$ e questões de provas e avaliações $(79 \%)$, enquanto que softwares educacionais e podcasts são os menos utilizados, com $39 \%$ e $13 \%$, respectivamente. 


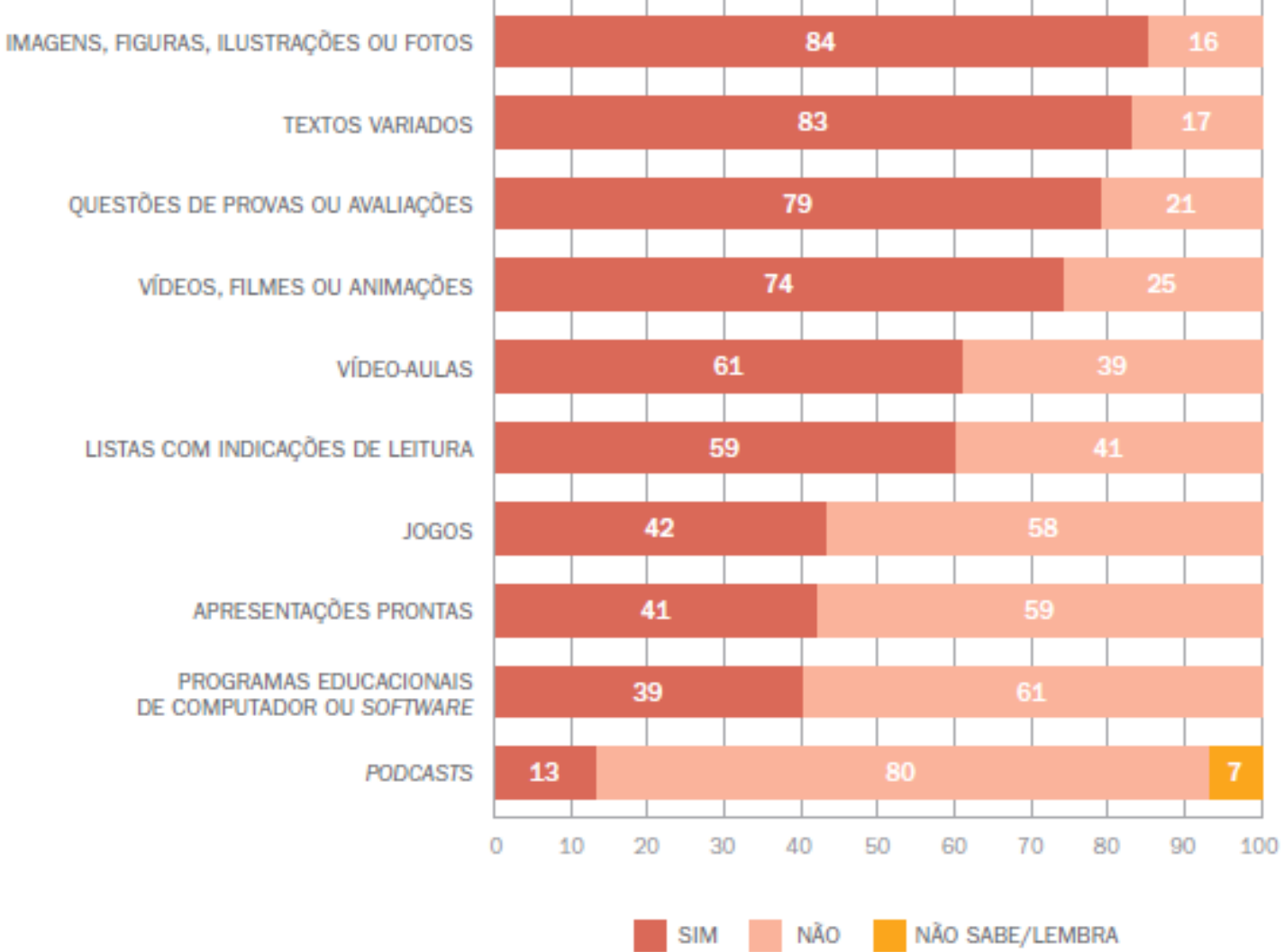

Gráfico 16 - Proporção de professores, por tipo de recurso obtido na Internet para a preparação de aulas ou atividades com alunos (CGI, 2014, p. 155)

A Pesquisa TIC Educação 2013 (CGI, 2014) também informa que 88\% dos professores de escolas públicas afirmam ter realizado alguma alteração no material original que obtiveram na Internet para preparação de aula, o que indica postura de autoria por parte desses profissionais, contudo, apenas $21 \%$ dos docentes entrevistados informam ter publicado ou postado na Internet os conteúdos que produziram.

Com relação ao uso das TICs por alunos de escolas públicas localizadas em áreas urbanas, a Pesquisa TIC Educação 2013 aponta que 69\% dos alunos possuem computadores de mesa / desktop em casa, havendo também crescimento significativo na presença de computadores portáteis / laptops ao longo dos anos, indo de $18 \%$ em 2010 para 51\% em 2013, conforme gráfico 17. A Pesquisa ressalta que devem ser observadas as desigualdades regionais na presença de computadores nas residências dos alunos, sendo maior o percentual nas regiões Sul e Sudeste, $80 \%$ e 79\%, respectivamente, e menor nas regiões Norte e Nordeste, onde é pouco maior que a metade, 53 e $51 \%$, respectivamente. 


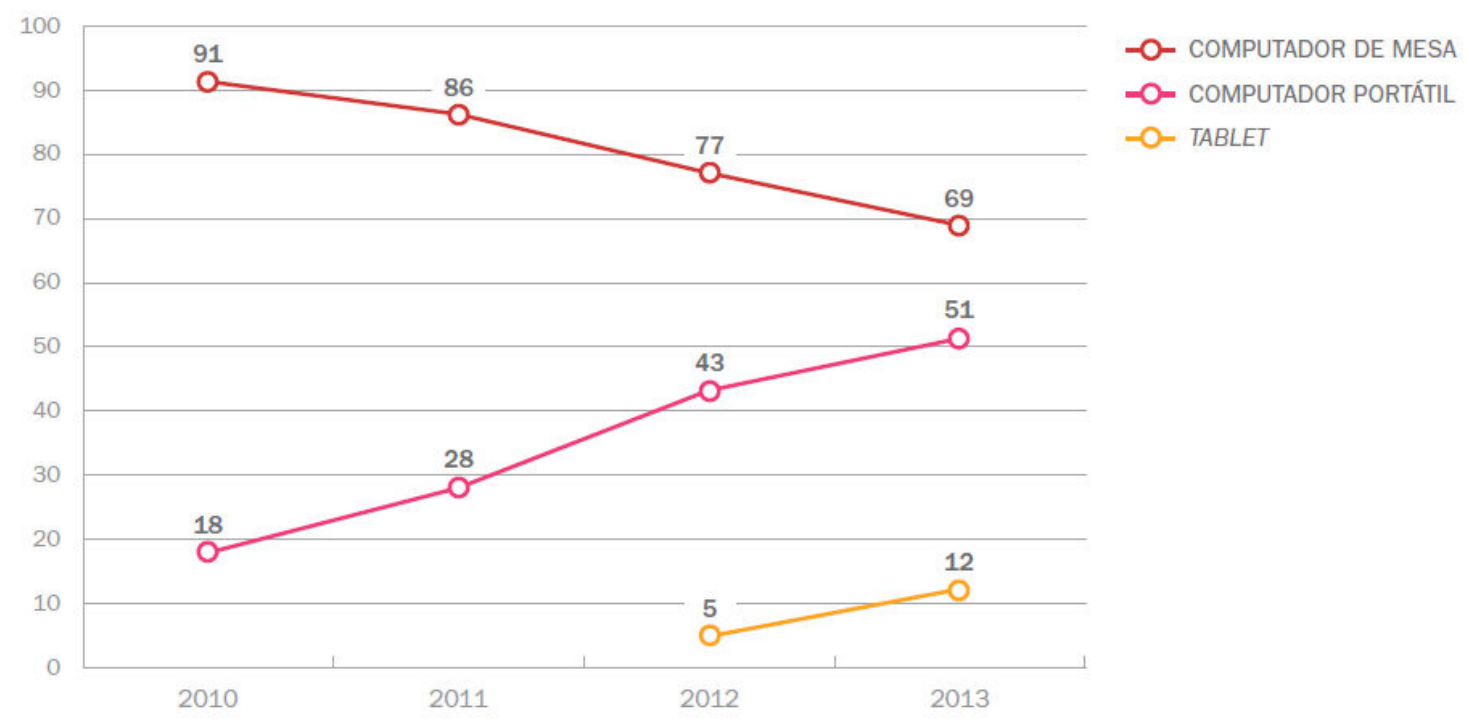

Gráfico 17 - Proporção de alunos, por tipo de computador existente no domicílio (2010-2013) (CGI, 2014, p. 158)

Analisando ainda os alunos de escolas públicas, a Pesquisa TIC Educação 2013 informou ter havido crescimento do acesso à Internet junto às residências, aumentando de $44 \%$ em 2010 , para $65 \%$ em 2013 , porém a pesquisa ressalta que também ocorreram desigualdades regionais com relação ao acesso domiciliar à Internet, sendo que $52 \%$ dos alunos da região Norte e $48 \%$ da região Nordeste possuem acesso à Internet em casa (CGI, 2014, p. 159).

A Pesquisa TIC Educação 2013 com base nos dados obtidos conclui que: quantidade de computadores ainda é fator limitante para um uso personalizado dos estudantes; a disponibilidade de redes sem fio, incluindo redes $\mathrm{Wi}-\mathrm{Fi}$, deve receber atenção das políticas de provimento de acesso à Internet, principalmente no que se refere à velocidade e estabilidade de conexão. Com relação à formação de professores para uso das TICs, a pesquisa considera haver postura proativa dos docentes em relação ao desenvolvimento de habilidades associadas às TICs, seja em busca de formação especifica, seja no uso de recursos digitais na prática docente, contudo, ressalta haver reduzida parcela de professores que publicam ou disponibilizam material na Internet, reforçando a necessidade de haver desenvolvimento de plataformas e mecanismos de incentivo para compartilhamento de materiais pedagógicos desenvolvido por professores de escolas públicas (CGI, 2014, p. 167-168). 


\subsubsection{Discussão sobre os dados apresentados nas pesquisas}

Pelas pesquisas apresentadas pode-se observar a evolução quanto à disponibilidade de computadores e o uso da Internet no universo escolar, contudo, diversos fatores ainda precisam ser revistos para permitir suporte adequado, tais como: uma formação inicial e continuada de professores de forma a contemplar efetivamente o uso das TICs nos processos de ensino e aprendizagem, número adequado de computadores que atenda a demanda de alunos por escola, Internet com velocidade adequada para o uso dos recursos digitais, uso de softwares mais sofisticados que não somente editores de texto ou de apresentação, entre outros. Os dados obtidos nesse capítulo mostram, a princípio, que as escolas públicas possuem recursos tecnológicos mínimos para uso da RA. Mesmo algumas limitações como a dificuldade do uso individualizado de computadores não impedem o uso efetivo dessa tecnologia alunos, pois é possível utilizá-la com vários alunos ao mesmo tempo e em um mesmo computador.

Ressalte-se que o uso da RA no ensino servirá também como contrapartida para ampliar a ação dos professores, que em sua grande maioria ainda não faz uso de simulações ou recursos digitais mais complexos. 


\section{O USO DAS SIMULAÇÕES COMPUTACIONAIS NO ENSINO DE FÍSICA}

As simulações computacionais segundo Hollocks (1992, apud Ripoll, 1998) envolvem a criação de um programa de computador que representa alguma parte do mundo real, de tal forma que os experimentos no modelo são como a antevisão do que acontecerá na realidade. Para Medeiros e Medeiros:

Qualquer simulação está baseada em um modelo de uma situação real, modelo este, matematizado e processado pelo computador, a fim de fornecer animações de uma realidade virtual. A construção, portanto, de uma simulação computacional pressupõe, necessariamente, a existência de um modelo que lhe dá suporte e que the confere significado. As simulações podem ser vistas como representações ou modelagens de objetos específicos reais ou imaginários, de sistemas ou fenômenos. (MEDEIROS e MEDEIROS, 2002, p. 79)

A previsão de eventos na Física comumente ocorre por meio de formalismos matemáticos que expressam um dado fenômeno físico, contudo os resultados decorrentes dessas expressões matemáticas nem sempre permitem a elaboração mental da evolução de um sistema físico, algo que as simulações podem fornecer ao modelizar esse fenômeno. Nesse sentido, as simulações computacionais encontram aplicação constante na Ciência, seja ao lidar com modelos macroscópicos ou microscópicos que escapam da percepção humana, segundo Levy (1993, p. 122):

Cientistas de todas as disciplinas recorrem cada vez mais a
simulações digitais para estudar fenômenos insensíveis à
experiência (nascimento do universo, evolução biológica ou
demográfica) ou simplesmente para avaliar de maneira menos
custosa o interesse de novos modelos, mesmo quando a
experimentação é possível.

Isso também ocorre nos processos de ensino e aprendizagem devido a dificuldade em se reproduzir diversos fenômenos seja pela natureza materiais envolvidos, seja pela periculosidade dos experimentos ou pelas limitações dos laboratórios de ciências. As simulações surgem como ferramentas eficientes na tentativa de propiciar uma melhor compreensão de modelos científicos, apresentando as 
seguintes vantagens, segundo levantamento realizado por Gaddis (2000, apud MEDEIROS; MEDEIROS, 2002, p. 80):

- fornecer um feedback para aperfeiçoar a compreensão dos conceitos;

- permitir aos estudantes coletarem uma grande quantidade de dados rapidamente;

- permitir aos estudantes gerarem e testarem hipóteses

- apresentar uma versão simplificada da realidade pela destilação de conceitos abstratos em seus mais importantes elementos;

- tornar conceitos abstratos mais concretos;

- reduzir a ambiguidade e ajudar a identificar relacionamentos de causas e efeitos em sistemas complexos;

- servir como uma preparação inicial para ajudar na compreensão do papel de um laboratório;

- desenvolver habilidades de resolução de problemas;

- promover habilidades do raciocínio crítico;

- fomentar uma compreensão mais profunda dos fenômenos físicos;

- auxiliar os estudantes a aprenderem sobre o mundo natural, vendo e interagindo com os modelos científicos subjacentes que não poderiam ser inferidos através da observação direta;

- acentuar a formação dos conceitos e promover a mudança conceitual.

Tais vantagens podem propiciar uma ação mais ativa do aluno na exploração e compreensão de modelos científicos, permitindo que ele possa analisá-los de maneira mais dinâmica que a proporcionada pelos livros didáticos, que é predominantemente estática, baseada em desenhos ou formulas matemáticas. As simulações que permitem a alteração de valores das variáveis que descrevem o modelo analisado possibilitam que os alunos possam compreender melhor como elas estão relacionadas e de que maneiras elas modificam o sistema. De acordo com Tavares e Santos (TAVARES; SANTOS, 2003, p. 134):

As animações interativas, construídas a partir da modelagem de situações físicas de interesse pedagógico, tem se mostrado adequadas para introduzir o estudante em conteúdos nos quais ele não está familiarizado. Pode-se criar uma representação real ou ideacional de um fenômeno físico, apresentar aos estudantes as características do fenômeno para a observação, além de serem sensíveis aos critérios individuais, onde o aprendiz pode agir na modificação das condições iniciais e observar as respostas, relacionar grandezas e outros atributos pertinentes ao fenômeno físico. 
As simulações podem servir como linguagem adicional na relação dos professores com os alunos permitindo uma abordagem diferenciada e interativa entre as partes envolvidas. Elas também possibilitam que o professor forneça aos alunos outras formas de analisar um fenômeno físico que não exclusivamente por meio de resolução de exercícios. Permitem também agilidade na realização de experiências, uma vez que a presença delas torna desnecessária a montagem de equipamentos.

Ao escapar do quadro tradicional de ensino, as simulações podem despertar a curiosidade e o estimulo necessário para os alunos compreenderem melhor a natureza e a importância do estudo da Física. Segundo Levy (1999, p. 167):

As técnicas de simulação, em particular aquelas que utilizam imagens interativas, não substituem os raciocínios humanos mas prolongam e transformam a capacidade de imaginação e de pensamento. De fato, nossa memória de longo prazo pode armazenar uma enorme quantidade de informações e de conhecimentos.

Contudo, mesmo havendo inúmeros fatores positivos no uso de simulações é necessário ter o cuidado na forma como elas são apresentadas aos alunos, pois conforme Giordan (2005, p. 292):

Referir-se aos entes representados como os próprios entes, figura de linguagem conhecida como metonímia, pode se configurar em um obstáculo verbal mais prejudicial à construção do conhecimento do que a metáfora do objeto[...] na medida em que pela metonímia não se evidencia o caráter de modelização.

Respeitada essa ressalva e considerando todas características positivas decorrentes do uso das simulações no ensino, entende-se que essa ferramenta tecnológica fornece uma "nova forma de expressar a Física" como propõe os PCN (2002). Nesse trabalho será feito uso da RA, que possui objetos virtuais simulados, os quais possuem todos os potenciais oriundos das simulações, além de outras possibilidades de uso e interação. No próximo capítulo apresenta-se uma breve introdução sobre a Realidade Aumentada para explicar seu funcionamento, suas aplicações e como pode ser utilizada no ensino de Física. 


\section{INTRODUÇÃO À REALIDADE AUMENTADA}

Neste capítulo pretende-se apresentar resumidamente o conceito de RA, suas principais propriedades e características, sua relação com simulações, suas aplicações e perspectivas futuras.

\subsection{Apresentação e revisão da RA}

A Realidade Aumentada é comumente definida como um ambiente ou sistema que sobrepõe objetos virtuais, gerados por computador e concebidos em três dimensões, em um ambiente real e em tempo real, permitindo uma melhor visualização bem como um aumento da visão do usuário (AZUMA, 1997; KIRNER; TORI, 2004). Para Tori (2010, p. 06) o desafio da Realidade Aumentada está em fazer "com que os elementos virtuais pareçam fazer parte do ambiente real e a este se integrar". Azuma (1997, p. 02, tradução nossa), define ainda que os sistemas de RA partilham das seguintes propriedades:

\footnotetext{
Mistura o real e o virtual, em um ambiente real; Interação em tempo real;

Registro em 3D.
}

O registro é entendido como o alinhamento preciso dos objetos virtuais no ambiente real. Na ausência de um registro preciso a ilusão de que os objetos virtuais podem existir no ambiente real estará severamente comprometida (AZUMA et all, 2001).

A Realidade Aumentada é um caso particular do amálgama entre os ambientes reais e virtuais, que se associam num conceito denominado Realidade Misturada, proposto por Milgram (1994) em seu "Continuum Real - Virtual" (figura 04). Para Tori (2006, p. 23) a Realidade Misturada "incorpora elementos virtuais ao ambiente real ou leva elementos reais ao ambiente virtual, complementando ambientes". 


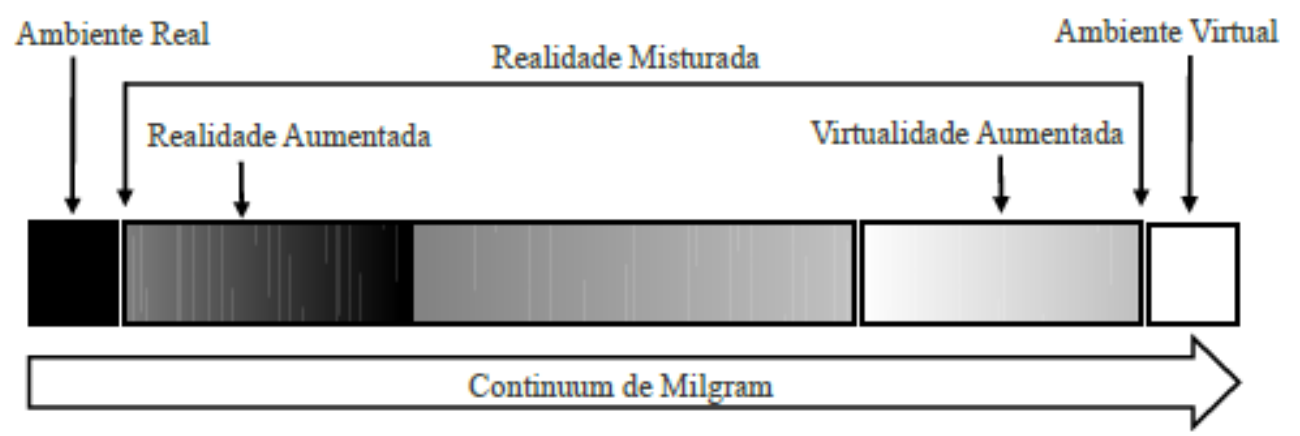

Figura 4 - Continuum de Milgram (MILGRAM, 1994 apud TORI, 2010)

Dessa maneira, em um dos extremos do "continuum" da Realidade Misturada tem-se a ocorrência da Realidade Aumentada quando houver a inserção de objetos virtuais no mundo real, enquanto que no outro extremo teremos a Virtualidade Aumentada quando elementos reais forem inseridos no mundo virtual.

A manipulação dos objetos virtuais presentes nesses extremos pode se dar tanto pela Realidade Aumentada quanto pela Realidade Virtual, sendo que essas, comparativamente, apresentam as seguintes características, conforme Tori e Kirner (2006, p. 24):

- Realidade Virtual trabalha unicamente com o mundo virtual; transfere o usuário para o ambiente virtual; e prioriza as características de interação do usuário.

- Realidade Aumentada possui um mecanismo para combinar o mundo real com o mundo virtual; mantém o senso de presença do usuário no mundo real; e enfatiza a qualidade das vantagens e a interação do usuário.

Outra característica da RV, em contraste com a RA, é a participação plena do usuário com o ambiente em que está inserido, o que segundo Tori $(2010$, p. 06) é chamado de imersão.

Para Tori (2010) a diferença da RA para RV está no fato de não ter a imersão como característica principal, mas sim fazer com que os elementos virtuais pareçam estar integrados no ambiente real. Para se obter isso é necessário um computador com webcam, executando um software de RA, que por meio de técnicas de visão computacional e processamento de imagens é capaz de misturar a cena do ambiente real, capturada pela webcam, com objetos virtuais gerados por computador (KIRNER; ZORZAL, 2005). Segundo Kirner e Tori (2006, p. 29), um software de RA deve: 
Promover o rastreamento de objetos reais estáticos e móveis e ajustar os objetos virtuais no cenário, tanto para pontos de vista fixos quanto para pontos de vista em movimento. Além disso, o software de realidade aumentada deve permitir a interação do usuário com os objetos virtuais e a interação entre objetos reais e virtuais em tempo real [...] O suporte em tempo real também deve: atuar no controle da simulação/animação dos objetos virtuais colocados na cena; cuidar da visualização da cena misturada; e implementar a comunicação em rede para aplicações colaborativas.

Um exemplo de software de RA é o ARToolkit (ARTOOLKIT). Ele possui uma biblioteca baseada em linguagem $\mathrm{C}$ e $\mathrm{C}++$ que permite a sobreposição dos objetos virtuais em um cenário real, por meio de técnicas de visão computacional, utilizadas para calcular a posição de uma câmera real e sua orientação em relação a marcadores fiduciais permitindo que o sistema sobreponha os objetos virtuais sobre os marcadores. A figura 05 apresenta um modelo de marcador fiducial, que consiste numa placa quadrada com um símbolo característico em seu interior. De acordo com Tori, esses marcadores são utilizados para rastrear e registrar os objetos virtuais da seguinte forma:

O símbolo do marcador é identificado, indicando qual objeto deve ser inserido na cena, e sua deformação analisada, de forma a se obter a matriz de transformação geométrica que define o posicionamento relativo entre marcador e câmera de vídeo. De posse dessas informações o software pode inserir na cena real objetos tridimensionais interativos, registrando-os perfeitamente com os elementos ao seu redor (2010, p. 07)

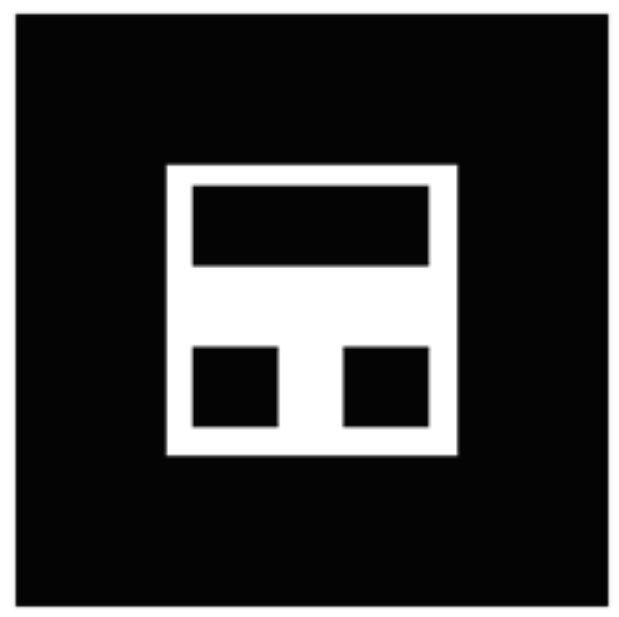

Figura 5 - Marcador fiducial

Em suma, o funcionamento do ARToolkit pode ser representado esquematicamente de acordo com a figura 06 : 


\section{ARToolkit}

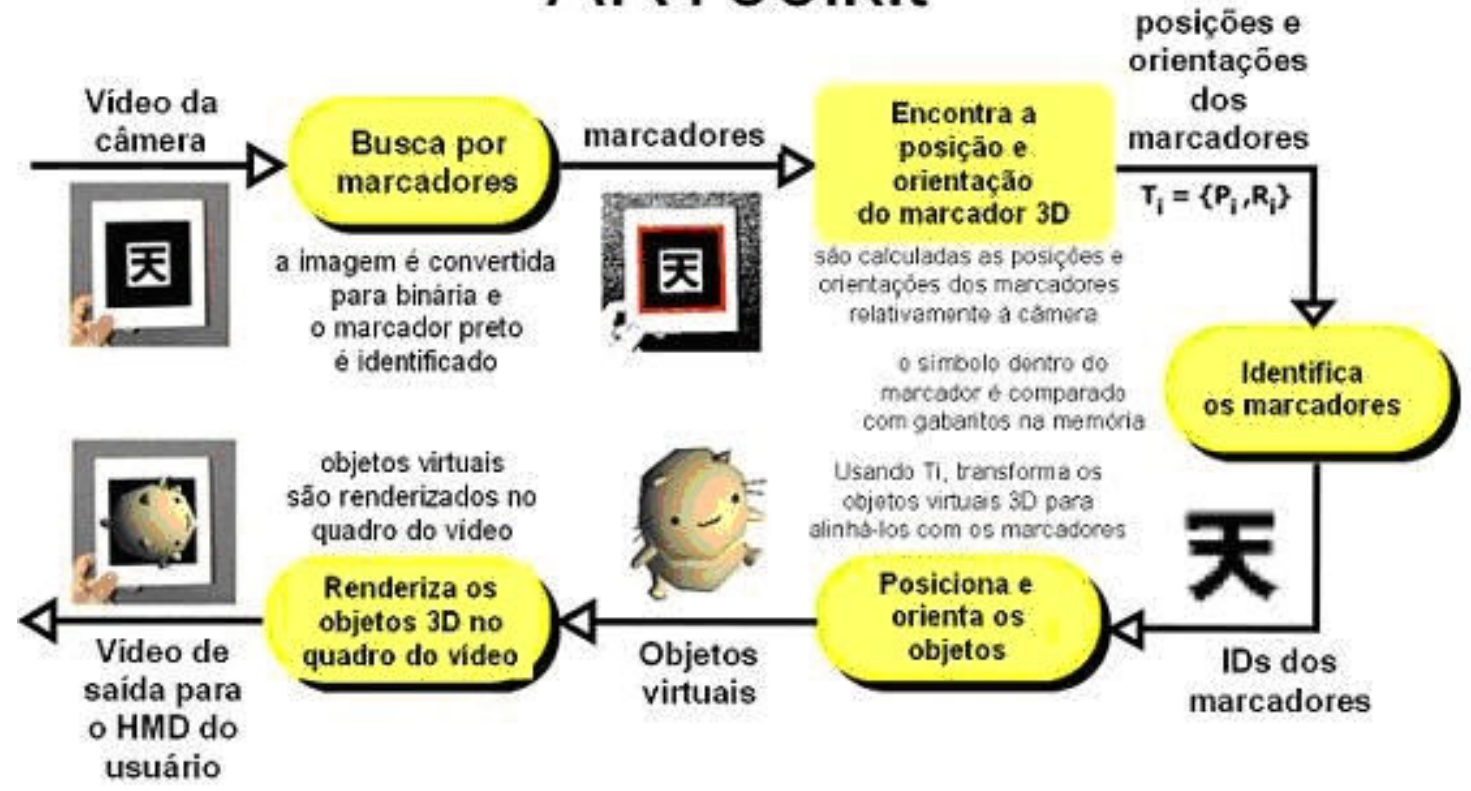

Figura 6 - Diagrama representando a captura de um marcador e a projeção de um objeto virtual associado (CARDOSO; LAMOUNIER, 2004)

Os objetos virtuais utilizados pelo ARToolkit podem ser desenvolvidos em linguagem VRML - Virtual Reality Modeling Language, também conhecida como Linguagem para Modelagem em Realidade Virtual, que permite criar objetos em 3 dimensões, estáticos ou animados, com propriedades de textura, níveis de detalhe, iluminação, entre outros. O desenvolvimento de objetos virtuais em VRML pode se dar por meio de editores de texto ou ainda por programas específicos de modelagem tridimensional como Blender, Flux Stúdio, 3DS Studio Max, entre outros.

O ARToolkit possui também versões que utilizam outras bibliotecas, como o JARToolkit (GEIGER, 2002) baseado em Java e o Flartoolkit (SAQOOSHA, 2013) baseado em Actionscript 3 - AES3. O Flartoolkit faz uso do plugin Papervision 3D na exibição dos objetos virtuais que possibilita o desenvolvimento de aplicações de RA voltada para web.

\subsubsection{Classificação dos sistemas de RA}

Segundo Tori (2010, p. 7) a RA pode ser exibida por meio de quatro técnicas, baseadas em visão ótica ou visão por vídeo, são elas: 
Optical see-through: óculos com visores semitransparentes nos quais são exibidas imagens que se misturam à cena real visualizada pelo usuário.

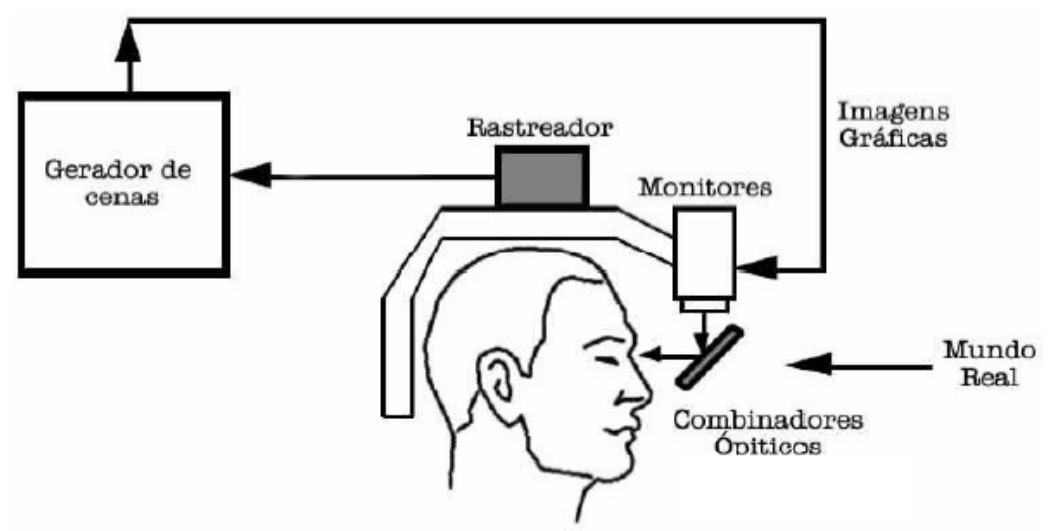

Figura 7 - Optical see-throug (AZUMA, 1997 apud KIRNER; ZORZAL, 2005)

Video see-through: uso de capacetes de realidade virtual para exibição do mundo real, captado por câmeras de vídeo em tempo-real, misturado a elementos virtuais inseridos e registrados computacionalmente.

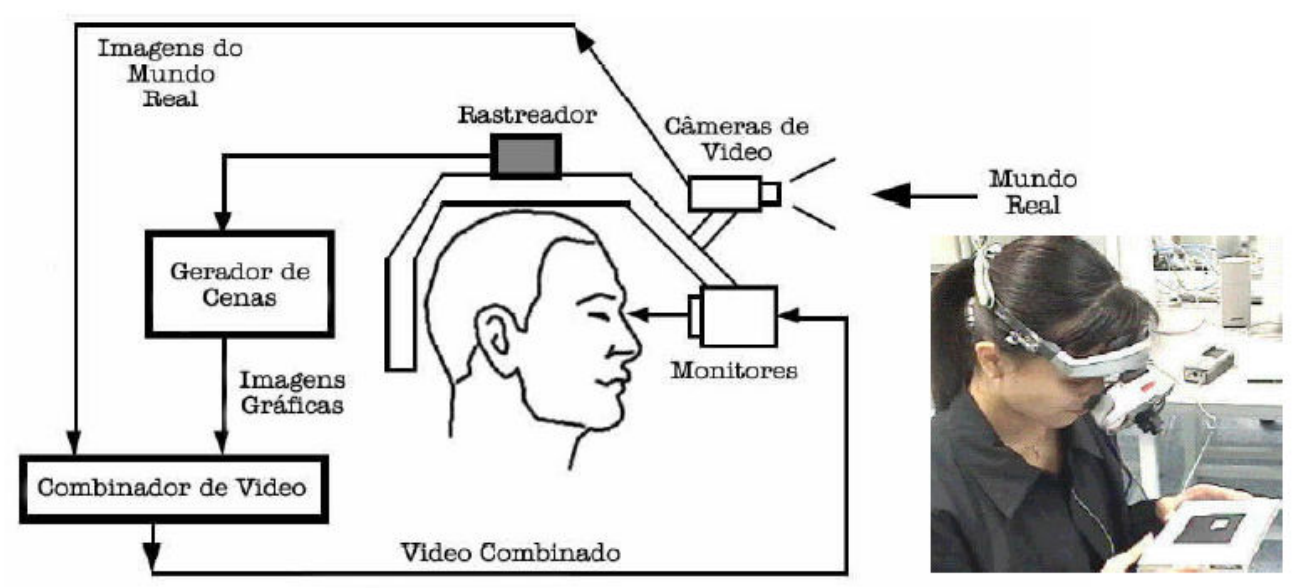

Figura 8 - Vídeo see-through (AZUMA, 1997; PRINCE, 2002 apud KIRNER; ZORZAL, 2002)

Monitor: uso de um monitor de vídeo para exibição do mundo real, captado por câmeras de vídeo em tempo-real, misturado a elementos virtuais inseridos e registrados computacionalmente. 


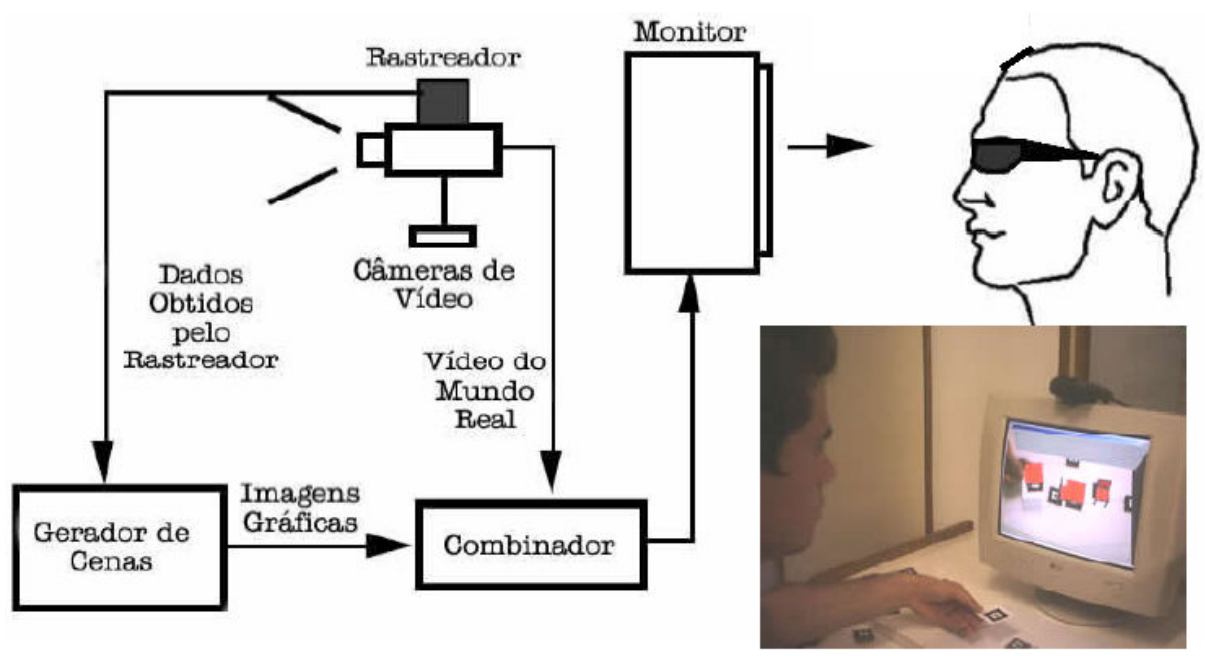

Figura 9 - Sistema de visão por vídeo baseada em monitor (AZUMA, 1997 apud KIRNER; ZORZAL, 2005)

Projeção: uso de projetores para cobrir superfícies de objetos reais com texturas virtuais, o que possibilita a visualização da cena real enriquecida com elementos virtuais; essa técnica é limitada em relação às demais, mas nas situações em que pode ser empregada possui a vantagem de liberar $\mathrm{o}$ usuário da necessidade de acoplar equipamentos ao corpo ou de precisar observar o mundo pro meio de um monitor.

Outra categorização da RA está relacionada com a maneira que o usuário observa a sobreposição do real com o virtual. Ela é chamada de visão direta (imersiva) quando o usuário olha diretamente para as posições reais do mundo misturado, utilizando para isso um capacete ótico ou um capacete com microcâmeras acopladas, ou então é chamada de visão indireta (não imersiva), obtida quando o usuário vê objetos reais e virtuais, não alinhados com as posições reais, em um vídeo por meio de monitores ou projetores (KIRNER; TORI; SISCOUTO, 2006). Para Tori (2009) o uso da RA por meio de visualização indireta apresenta as vantagens de ter baixo custo, podendo fazer uso apenas do computador, da webcam e um monitor comum, além de dispensar o uso de dispositivos acoplados ao corpo, por outro lado suas desvantagens seriam a impossibilidade de visão direta do ambiente e o campo de visão limitado.

A visualização indireta, além de permitir maior liberdade ao usuário para transitar com o marcador pelo campo de visão da webcam, possibilita também uso de vários 
marcadores ao mesmo tempo, proporcionando um enriquecimento do cenário gerado na tela do monitor (KIRNER; TORI; SISCOUTTO, 2006).
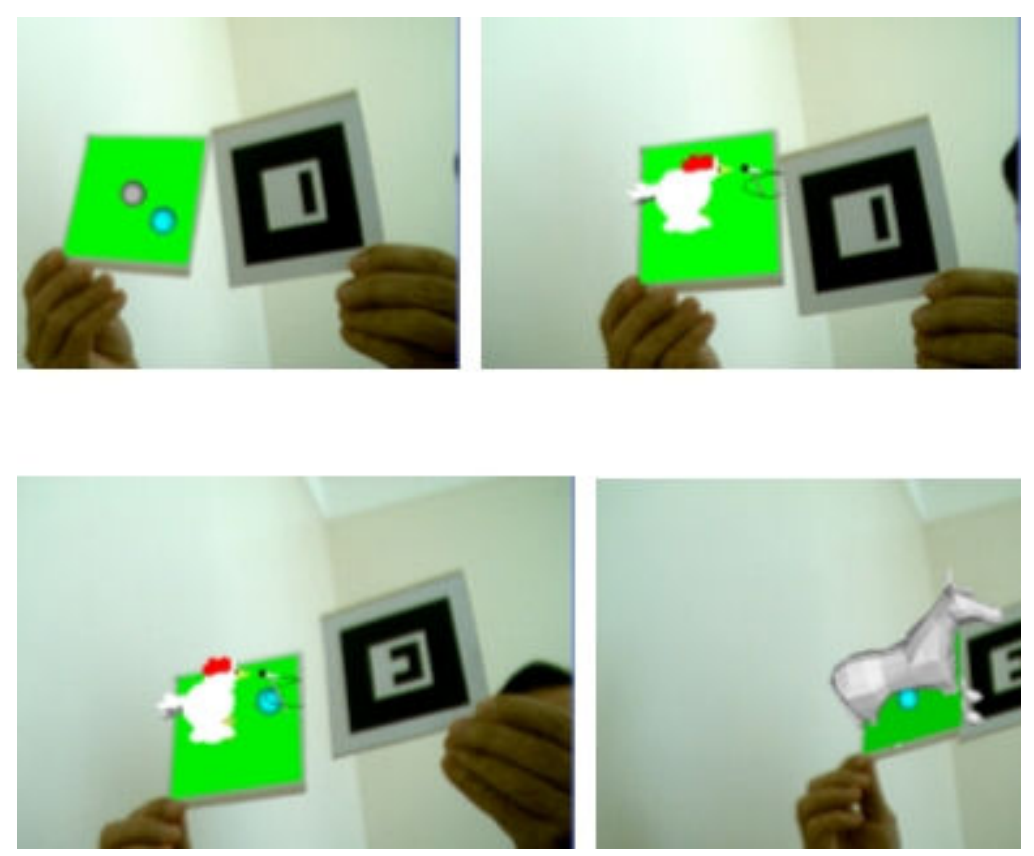

Figura 10 - Exemplo de objetos virtuais associados a marcadores (KIRNER; SANTIM, 2010)

\subsubsection{Usando simulações em RA}

A RA pode fazer uso de simulações que produzam algum comportamento apropriado nos objetos virtuais sobrepostos ao ambiente real. Tais simulações podem ser criadas com o propósito de obter um objeto virtual que possua as características de um modelo científico, como o Sistema Solar ou Modelo de Drude para corrente elétrica. Estes "objetos virtuais simulados" podem ser autônomos (inteligentes) ou controlados pelo usuário, nesse caso é conveniente que haja uma interface gráfica que permita ao usuário alterar os parâmetros de comportamento da simulação. Todavia, deve-se considerar que o uso de simulações pode consumir muito da capacidade de processamento do computador o que pode acarretar prejuízos na atualização em tempo real do objeto virtual (KIRNER; TORI; SISCOUTTO, 2006). 


\subsubsection{A RA sem o uso de marcadores fiduciais}

A RA não necessita obrigatoriamente do uso de marcadores fiduciais para inserir objetos virtuais na cena real, é possível também utilizar informações que caracterizam o ambiente como linhas, pontos, arestas e texturas. Essas aplicações de RA são chamadas de Markless Augmented Reality (MAR) e podem ser classificadas em dois tipos fundamentais: técnicas baseadas em modelos e técnicas baseadas em estruturas do movimento (TEICHRIEB et al, 2007).

As técnicas baseadas em modelos necessitam que o mundo real seja previamente conhecido e armazenado em um modelo 3D, que será usado para estimar o posicionamento da câmera, enquanto que nas técnicas baseadas em estrutura do movimento, o movimento da câmera é estimado ao longo de uma sequência de quadros, sem que se possua conhecimento prévio da cena, que é adquirido durante o rastreamento (SIMÕES et al, 2008).

\subsubsection{RA aplicada em diversos segmentos}

A RA vem ganhando popularidade e possui uso nos mais diversos segmentos. Entre suas aplicações estão procedimentos de manutenção e reparo de equipamentos (HENDERSON; FEINER, 2007), publicidade (KIRNER, 2010), procedimentos cirúrgicos (SIELHORST; TRAUB, 2004), mediação museológica (SILVEIRA; BIAZUS, 2013), sistemas de rastreamento e orientação espacial (WAGNER \& SCHMALSTIEG, 2003), reconstrução virtual de templos em sítios arqueológicos (VLAHAKIS; IOANNIDIS; KARIGIANNIS, 2002), jogos eletrônicos (PIEKARSKY \& THOMAS, 2002), projetos arquitetônicos (MEIGUINS et all, 2005), aplicativos para dispositivos móveis (LAYAR, 2009) ( AURASMA, 2015), entre outras. 


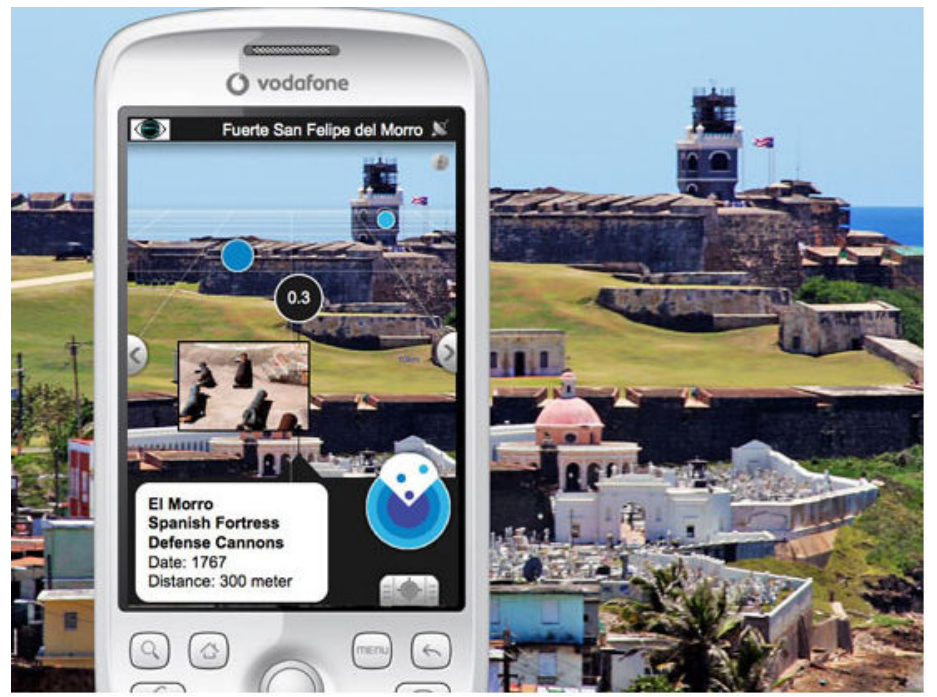

Figura 11 - Layar -aplicativo de RA

A RA pode também apresentar seus marcadores fiduciais impressos em páginas de livros didáticos. Assim será possível sobrepor objetos virtuais simulados às figuras estáticas do livro, permitindo uma inspeção em três dimensões da figura. Exemplos desses livros são o projeto LIRA - Livro Interativo com Realidade Aumentada (OLIVEIRA; RECCHIA, 2005) o projeto "MagicBook" (BILLINGHURST; KATO; POUPYREV, 2001) e o Livro sobre o Sistema Solar potencializado com Realidade Aumentada (OKAWA; KIRNER; KIRNER, 2013).

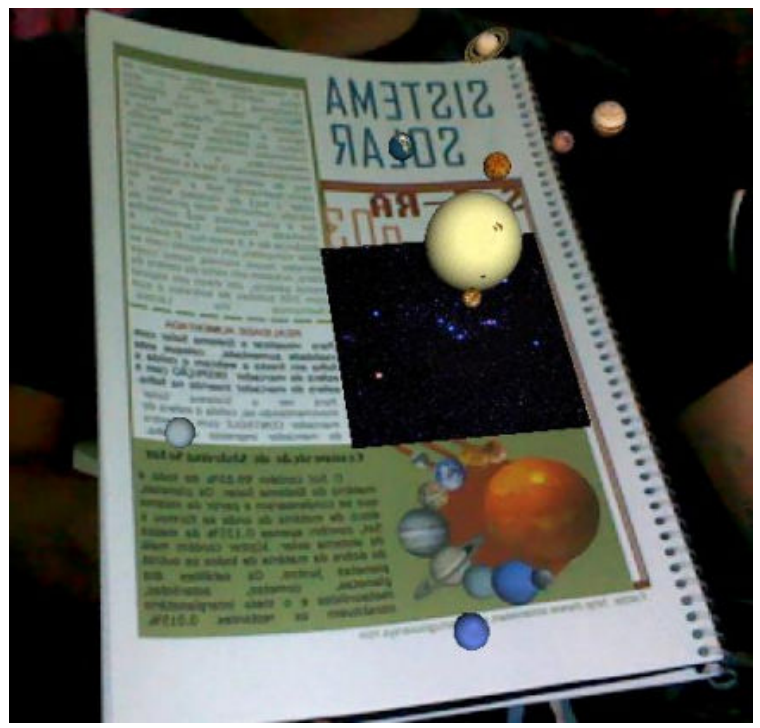

Figura 12 - Livro em RA sobre o Sistema Solar (OKAWA; KIRNER; KIRNER, 2013)

Outras aplicações voltadas para o ensino incluem o uso de RA em Biologia e Química no estudo do processo de fotossíntese e transporte de solutos em plantas 
(SILVA et all, 2008), no ensino de Química no estudo da estrutura atômica (SILVA; ROGADO, 2008). No ensino de Física encontram-se aplicações de RA no estudo da força de atrito e sua atuação sobre um corpo (DUARTE; CARDOSO; JUNIOR, 2005), na análise de conceitos de queda livre e lançamento de projeteis (SILVA, 2012), na simulação de conceitos de eletromagnetismo, como campos virtuais e magnéticos (DONZELLI; TOMAZELLO, 2006), no estudo de Mecânica, Termodinâmica e Eletricidade por meio do Livro de Marcadores para o Ensino de Física (CAMARGO; RAIMANN et all, 2010), entre outras.

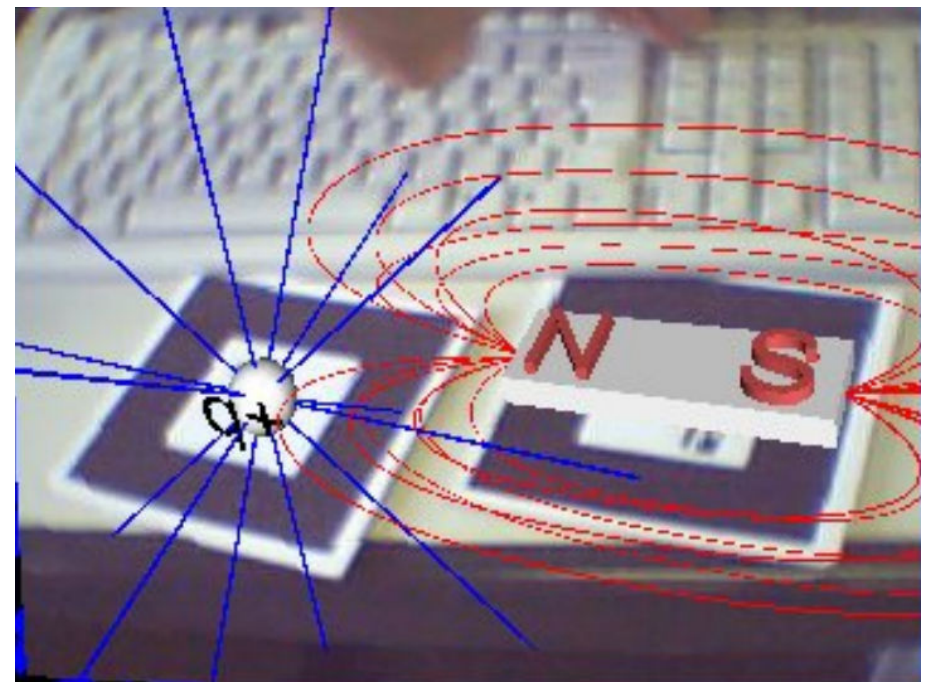

Figura 13 - Realidade Aumentada no estudo do Eletromagnetismo (DONZELLI; TOMAZELLO, 2006)

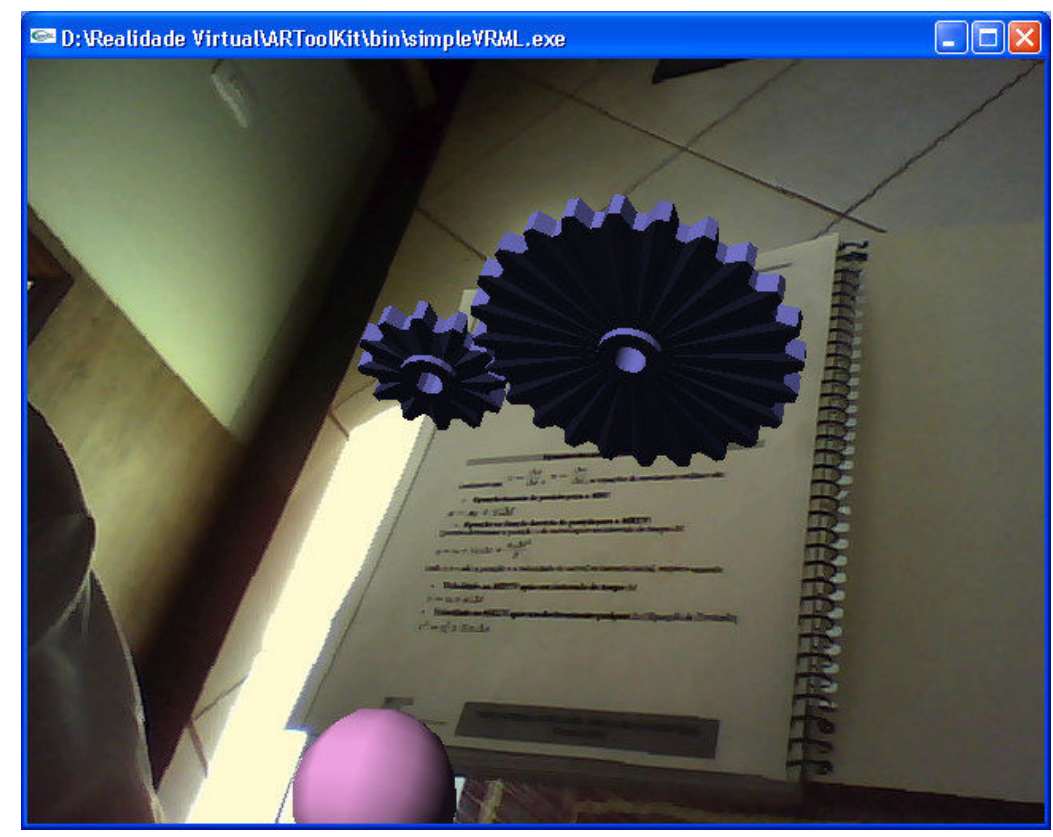

Figura 14 - Livros texto com marcadores de RA no estudo de mecânica (CAMARGO; RAIMANN et all, 2010, p. 05) 
Considera-se que o grande diferencial da RA para os demais tipos de TIC's, em especial aquelas relacionadas a animações ou simulações, é sua propriedade de registro que permite alinhar os objetos virtuais no ambiente real. Isso propicia o uso dessa tecnologia diretamente em equipamentos, ambientes, cirurgias, entre outros, e permite explorar características ou eventos que não são visíveis a olho nú ou que estejam ocultos.

No ensino de Física pode-se fazer uso dessa propriedade de registro, por exemplo, associando-se a um circuito real, um objeto virtual simulado que além de representar uma seção transversal desse circuito, apresenta também todas as entidades (elétrons livres em movimento, ions fixos, estrutura cristalina, etc.) que caracterizam o modelo científico de corrente elétrica, como se observa na figura 15.

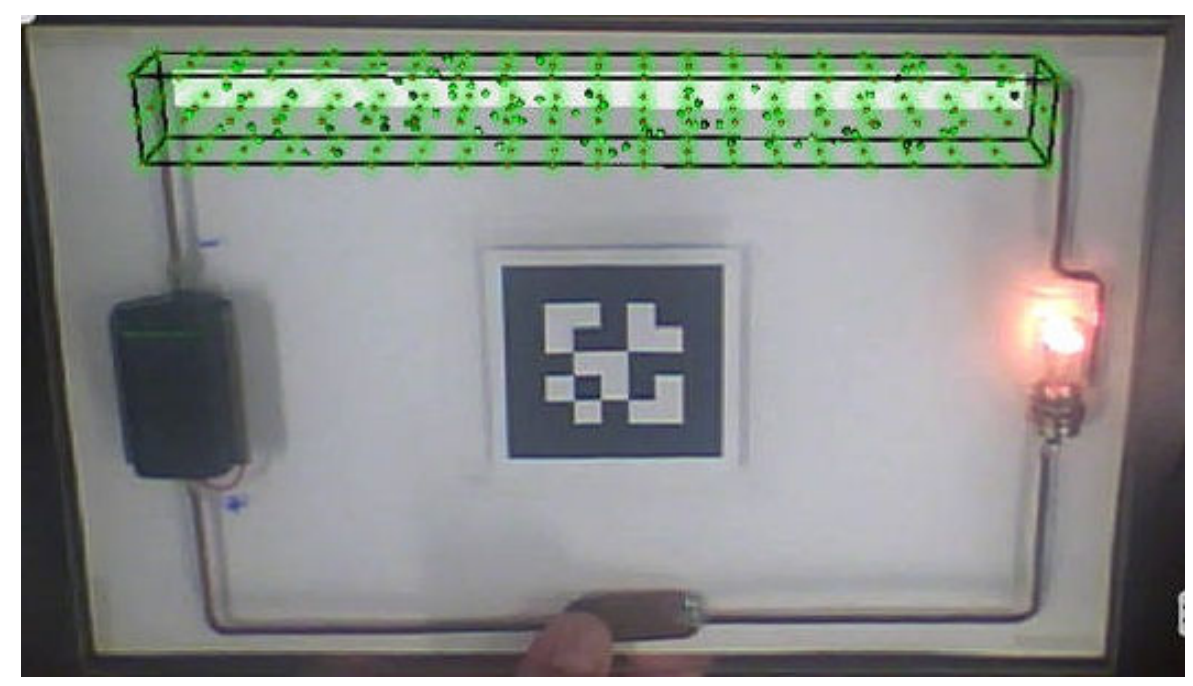

Figura 15 - Exemplo de aplicação de RA no ensino de Física

Ao permitir isso a RA não apenas enriquece o mundo real, como também a imaginação do aluno, favorecendo a investigação do modelo científico e auxiliando na compreensão do fenômeno físico. Ressalte-se também que as aplicações de RA que permitem controlar os parâmetros dos objetos virtuais simulados, que possuam as características de um modelo científico, tornam o processo exploratório mais rico, pois possibilita aos professores e alunos analisar a evolução desse modelo e a relação entre as variáveis que o compõem.

A RA e seus objetos virtuais, simulados ou não, assim como as demais Tecnologias da Informação e Comunicação (TICs), podem ser valiosos aliados no ensino de Física, por essa importância são classificados como Objetos de Aprendizagem (OA) e podem ser obtidos e disponibilizados em repositórios virtuais na Internet. 


\subsection{Objetos de Aprendizagem}

Elaborar material didático inovador é uma tarefa bastante complexa, podendo por vezes requerer conhecimento especializado como linguagens de programação, edição de som e vídeo, entre outros. Essa dificuldade de criação faz com que a reutilização desses materiais por outros professores e alunos seja considerada quase que obrigatória, ainda mais quando impera no universo digital a ação de compartilhar.

Compartilhar material didático digital é uma ação que está associada aos chamados Objetos de Aprendizagem (OA) ou Learning Objects. O Comitê Learning Technology Standards Committee (LTSC) do Institute Of Eletrical and Eletronics Engineers (IEEE) define os OA como "qualquer entidade, digital ou não digital, que pode ser utilizada para a aprendizagem, a educação ou treinamento" (LTSC, 2003, p. 06, tradução nossa).

Na definição de Wiley (2002, p. 04) os OA são "qualquer recurso digital que pode ser reusado para assistir a aprendizagem". Pimenta e Batista (PIMENTA; BATISTA, 2004, p. 102) se referem aos OA como:

Unidades de aprendizagem de pequena dimensão, desenhada e desenvolvida de forma a fomentar a sua reutilização, eventualmente em mais do que um curso ou em contextos diferenciados, e passível de combinação e/ou articulação com outros objetos de aprendizagem de modo a formar unidades mais complexas e extensas

Macedo (2003, p.20) apresenta uma definição mais ampla quanto a construção e formatos de OA:

Os OA podem ser criados em qualquer mídia ou formato, podendo ser simples como uma animação ou uma apresentação de slides ou complexos como uma simulação. Os Objetos de Aprendizagem utilizam-se de imagens, animações e applets, documentos VRML (realidade virtual), arquivos de texto ou hipertexto, dentre outros. 
Uma propriedade dos OA como entidades digitais é poderem ser veiculados pela Internet, permitindo que possam ser acessados e utilizados simultaneamente por inúmeras pessoas (WILEY, 2002).

\subsubsection{Características dos Objetos de Aprendizagem}

Embora existam OA em uma diversidade de formatos digitais, eles possuem características que são comum a todos eles, segundo Mendes, Souza e Caregnato (2005, p. 4-5) elas são:

Reusabilidade: reutilizável diversas vezes em diversos ambientes de aprendizagem;

Adaptabilidade: adaptável a qualquer ambiente de ensino;

Granularidade: conteúdo em pedaços, para facilitar sua reusabilidade;

Acessibilidade: acessível facilmente via Internet para ser usado em diversos locais;

Durabilidade: possibilidade de continuar a ser usado, independente da mudança de tecnologia;

Interoperabilidade: habilidade de operar através de uma variedade de hardware, sistemas operacionais e browsers, intercâmbio efetivo entre diferentes sistemas.

Os OA apresentam diversas outras características, como os Metadados que descrevem atributos relevantes desses objetos e permitem sua catalogação em repositórios virtuais, além disso, possibilita que eles possam ser localizados por sistemas de busca. Tarouco et all (2007, p.84), apresentam um conjunto de atributos utilizados para categorizar os OA que foi criado pelo IEEE (2002). Ele é chamado padrão 1484.12.1 Standard for Learning Object Metadata - LOM: 
Tabela 2 - Learning Object Metadata - LOM (TAROUCO et all, 2007)

\begin{tabular}{|c|c|}
\hline Categoria & Alguns exemplos de atributos \\
\hline $\begin{array}{l}\text { Geral: agrupa informações gerais } \\
\text { que descrevem o objeto }\end{array}$ & $\begin{array}{l}\text { Identificador, Título do objeto, Descrição, } \\
\text { Palavras-chave, Linguagem, Descrição, Escopo }\end{array}$ \\
\hline $\begin{array}{l}\text { Ciclo de vida: agrupa } \\
\text { informações que descrevem as } \\
\text { características relacionadas ao } \\
\text { histórico e estado atual dos } \\
\text { objetos e todos aqueles que o } \\
\text { têm afetado durante sua evolução }\end{array}$ & $\begin{array}{l}\text { Versão, Status, Tipo de contribuição, } \\
\text { Entidades que contribuíram, Data }\end{array}$ \\
\hline $\begin{array}{l}\text { Metadados: agrupa dados sobre } \\
\text { a instância de metadados em si }\end{array}$ & $\begin{array}{l}\text { Esquema de catalogação, referência de } \\
\text { Catalogação }\end{array}$ \\
\hline $\begin{array}{l}\text { Técnica: agrupa os requisitos e } \\
\text { características técnicas do objeto }\end{array}$ & $\begin{array}{l}\text { Formato, Tamanho, Localização, Tipo de } \\
\text { tecnologia, Nome da tecnologia, Requisitos, } \\
\text { Duração, Comentários sobre a instalação }\end{array}$ \\
\hline $\begin{array}{l}\text { Educacional: agrupa as } \\
\text { características educacionais e } \\
\text { pedagógicas do objeto }\end{array}$ & $\begin{array}{l}\text { Tipo de interatividade, Recurso de } \\
\text { aprendizagem, Nível de interatividade, } \\
\text { Usuário final esperado, Ambiente de } \\
\text { utilização, Faixa etária, Contexto, } \\
\text { Dificuldade, Descrição }\end{array}$ \\
\hline $\begin{array}{l}\text { Direitos: agrupa os direitos de } \\
\text { propriedade intelectual e as } \\
\text { condições de uso do objeto }\end{array}$ & Custo, Direito autoral e Condições de uso \\
\hline $\begin{array}{l}\text { Relacionamento: agrupa } \\
\text { características que definem o } \\
\text { relacionamento entre um objeto } \\
\text { de aprendizagem e outros OA }\end{array}$ & $\begin{array}{l}\text { Tipo (natureza do relacionamento), } \\
\text { Recurso, Identificação, Descrição }\end{array}$ \\
\hline $\begin{array}{l}\text { Anotação: provê comentário } \\
\text { sobre o uso educacional do } \\
\text { Objeto de Aprendizagem }\end{array}$ & Entidade, Data e Conteúdo \\
\hline $\begin{array}{l}\text { Classificação: descreve o objeto } \\
\text { de aprendizagem em relação a } \\
\text { algum sistema de classificação }\end{array}$ & $\begin{array}{l}\text { Sistema de classificação, Identificação, } \\
\text { Descrição, Palavra-chave }\end{array}$ \\
\hline
\end{tabular}


Além do IEEE existem outros órgãos que visam a catalogação dos objetos de aprendizagem como o projeto Ariadne (ARIADNE), o Learning Design do IMS Instructional Management Systems (IMS, 2006) e o SCORM - Sharable Content Object Reference Model (SCORM, 2004), desenvolvido e distribuído pela Advanced Distributed Learning (ADL), que permite facilitar seu reuso e sua busca em repositórios.

\subsubsection{Repositórios de Objetos de Aprendizagem}

Um repositório de Objetos de Aprendizagem, também chamado de LOR - Learning Object Repository, deve permitir segundo Harbas (2007, apud TAROUCO; SCHMITT, 2010, p. 03):

- o armazenamento propriamente dito;

- o controle de versões e de publicação;

- a busca dos objetos a partir de suas características;

- o controle de acesso;

- a avaliação dos objetos.

São exemplos de repositórios internacionais: o MERLOT - Multimedia Educational Resource for Learning and Online Teaching (MERLOT), o National Learning Network (NATIONAL LEARNING NETWORK), Wisconsin On-line Resource Center (WISCONSIN ON-LINE RESOURCE CENTER), a OER - Open Educational Resources (OER), o National Digital Learning Resources Networking (NATIONAL DIGITAL LEARNING RESOURCES NETWORKING) entre outros. Entre os repositórios nacionais temos: o RIVED - Rede Interativa Virtual de Educação (RIVED), a Biblioteca Digital de Ciências da Unicamp (BIBLIOTECA DIGITAL DE CIÊNCIAS), o LabVirt - Laboratório Didático Virtual da Escola do Futuro da Universidade de São Paulo (LABVIRT), o Portal do Professor (PORTAL DO PROFESSOR), entre outros. 


\section{METODOLOGIA}

\subsection{Referencial Metodológico}

Os dados oriundos dessa pesquisa visam: averiguar a infraestrutura tecnológica existente e utilizada pelos alunos do Curso de Licenciatura em Ciências (CLC), oferecido pela Universidade de São Paulo (USP) em parceria com a Universidade Virtual do Estado de São Paulo (UNIVESP), para o uso da Realidade Aumentada (RA); analisar o processo de criação e customização de objetos virtuais simulados de Realidade Aumentada (RA), por seja por um professor típico, sem conhecimento em linguagens de programação, seja por uma equipe formada por professores especialistas e programadores; investigar se o uso da Realidade Aumentada (RA) no ensino de Física auxilia a melhor compreensão dos conceitos que regem modelos científicos complexos.

Para a tomada desses dados, assim como para realizar as análises e discussões optou-se por adotar um viés qualitativo baseado em textos de BOGDAN \& BIKLEN (1994), de ALVES-MAZZOTTI (1991) e LUDKE \& ANDRÉ (1996).

\subsection{Análise da criação de um objeto virtual simulado para RA}

A análise do processo de criação e customização de objetos virtuais simulados de RA traz um viés diferenciado para pesquisa, pois nesse ponto ela assume uma característica empírica de cunho qualitativo, uma vez que esse mestrando, na figura de um professor sem conhecimento em linguagens de programação apresenta: a análise de sua experiência prática na tentativa de elaborar um objeto virtual simulado por meio de softwares de modelagem 3D; e a análise do processo de criação da simulação por meio de uma equipe de professores especialistas do Instituto de Física da USP (IFUSP) e programadores do Centro de Ensino e Pesquisa Aplicada (CEPA) do Instituto de Física da USP. 
A experiência prática do processo de criação ocorreu no período de agosto/2011 a maio/2012 onde foram utilizados os seguintes softwares: Flux Studio da Media Machines, Vivaty Studio da Vivaty, Blender da Blender Foundation, 3ds Max da Autodesk e o VrmIPad da Parallelgraphics.

A equipe de professores do IFUSP e programadores do CEPA desenvolveu o objeto virtual simulado que representa o modelo clássico de Drude para corrente elétrica, no período de setembro a outubro de 2012, utilizando o software $3 \mathrm{ds}$ Max da Autodesk.

Ressalta-se que o foco dessa análise é avaliar se professores leigos em linguagens de programação conseguem desenvolver objetos virtuais simulados de RA para uso no ensino de Física.

\subsubsection{O objeto virtual simulado desenvolvido: Características do Modelo Clássico de Drude}

No modelo de Drude, os elétrons livres de um condutor metálico, quando na ausência de um campo elétrico aplicado, se movem aleatoriamente por conta da agitação térmica, podendo adquirir velocidades bastante grandes, da ordem de $10^{6}$ m/s (TIPLER, 2002). Já na presença de um campo elétrico externo, esses elétrons livres estarão submetidos a uma força - eE adquirindo uma velocidade no sentido oposto ao campo elétrico. Nesse movimento os elétrons livres colidirão aleatoriamente com os íons fixos da estrutura cristalina do sólido, bem como com outros elétrons livres.

No referido modelo, os choques entre os elétrons livres são desconsiderados e os choques com os íons fixos da estrutura cristalina farão com que os elétrons livres movimentem-se em uma direção aleatória, com uma velocidade que não tem qualquer relação com a que eles possuíam antes da colisão. Todavia, como estão submetidos a um campo elétrico eles manterão uma pequena velocidade chamada de velocidade de migração, no sentido contrário ao campo. Essa velocidade de migração dos elétrons é muito pequena comparada à velocidade de origem térmica, sendo da ordem de $10^{-2} \mathrm{~m} / \mathrm{s}$.

Embora a velocidade de migração seja inferior a velocidade de origem térmica ela manterá os elétrons livres deslocando-se no sentido contrário ao campo elétrico e o 
fluxo desses elétrons dará origem a uma corrente elétrica, definida como a taxa de passagem de cargas, nesse caso elétrons livres, através da área da seção reta do condutor, num dado intervalo de tempo (TIPLER, 2002).

Assim, sendo $\Delta Q$ a carga que passa por uma área $A$ da seção reta do condutor, no intervalo de tempo $t$, a corrente elétrica será:

$$
\mathrm{I}=\Delta \mathrm{Q} / \Delta \mathrm{t}
$$

\subsection{Instrumentos de coleta de dados}

Apresenta-se a seguir os instrumentos de coletas de dados e as características do público-alvo que foi investigado para avaliar a infraestrutura tecnológica existente, bem como se o uso da RA no ensino de Física auxilia a melhor compreensão dos conceitos que regem modelos científicos complexos.

\subsubsection{Caracterização do público-alvo}

Nas duas investigações propostas (averiguação da infraestrutura tecnológica existente e aplicação prática de RA em sala de aula) utilizou-se como público-alvo os alunos do Curso de Licenciatura em Ciências (CLC), oferecido pela Universidade de São Paulo (USP) em parceria com a Universidade Virtual do Estado de São Paulo (UNIVESP), que tem natureza semi-presencial e apresenta como objetivo principal a formação de professores, na área de Ciências, para atuação no Ensino Fundamental, buscando entre outras ações "possibilitar aos alunos o domínio do uso das novas tecnologias disponíveis na sociedade e, especialmente, nas escolas"; além de "contribuir para interação entre os diversos níveis e modalidades de ensino, visando o aperfeiçoamento e modernização do Ensino Fundamental e Médio" (LICENCIATURA EM CIÊNCIAS, 2013, grifo nosso). 


\subsubsection{Averiguação sobre infraestrutura tecnológica existente}

A investigação da infraestrutura tecnológica existente e utilizada pelos alunos do CLC foi realizada por meio de enquete (ANEXO 01) que foi veiculada na forma digital e respondida voluntariamente pelos alunos ingressantes do CLC, no período de 10 a 17/02/2014, na semana zero de acesso ao Ambiente Virtual de Aprendizagem - AVA, que é o "local virtual" (LICENCIATURA EM CIÊNCIAS, 2013) onde ocorrem as atividades do CLC. Nesse período, o questionário esteve disponível a uma população de 352 alunos ingressantes, dentre 198 mulheres e 154 homens, da qual 233 responderam a enquete. Os dados obtidos foram comparados com as pesquisas apresentadas no Capitulo 4.2 "PANORAMA ATUAL DA APLICAÇÃO DAS TICs NO ENSINO", a fim de avaliar se há consonância entre os resultados obtidos neste trabalho realizado com os alunos do CLC e a estrutura tecnológica existente e utilizada pelos públicos-alvo das pesquisas apresentadas no capitulo em questão.

Ressalta-se que o foco dessa análise é a infraestrutura necessária para o uso da RA.

\subsubsection{Aplicação prática da RA: uma intervenção com alunos do CLC da USP/UNIVESP}

Após a criação do objeto virtual simulado de RA, descrita no Item 7.2, a investigação sobre o seu uso no ensino de Física ocorreu em uma intervenção didática onde essa tecnologia foi utilizada para discutir o conceito de corrente elétrica com alunos do CLC da USP/UNIVESP.

A intervenção ocorreu em uma aula (matinal) presencial da disciplina de Eletricidade, ocorrida em 03/11/2012 (sábado) e ministrada por uma professora do IFUSP. Participaram dessa aula 40 alunos, numa proporção equilibrada de homens e mulheres. Antes do início da intervenção, os alunos foram cientificados que estariam participando de uma pesquisa, bem como quais seriam os seus objetivos. Durante toda intervenção, o pesquisador atuou como observador participante, 
procurando ter a menor influência possível nos resultados, pois conforme BOGDAN e BIKLEN (1994, p. 167) os pesquisadores qualitativos "sabem que nunca podem atingir um nível de compreensão e reflexão que possa resultar notas puras, isto é, notas que não reflitam a influência do observador".

\subsubsection{Instrumento de coleta de dados da intervenção de RA}

Os instrumentos de coleta de dados nessa etapa da pesquisa foram notas de campo e 03 avaliações diagnósticas. Durante a aula foi aplicada a avaliação diagnóstica 01 a fim de verificar qual compreensão do conceito de corrente elétrica os alunos do CLC possuíam. Após a aula foram aplicadas duas avaliações diagnosticas, sendo que uma delas (avaliação diagnóstica 02) possuía duas questões e a outra (avaliação diagnóstica 03) apenas uma. O objetivo das duas avaliações era o mesmo da avaliação realizada em aula.

As avaliações diagnósticas pós-aula foram veiculadas no AVA no período de 03/11 a 13/11/12. Ressalte-se que a avaliação diagnostica 02 revertia em nota para o aluno, enquanto a avaliação diagnóstica 03 não valia nota alguma, tinha caráter apenas participativo. Dos 91 alunos dos diferentes Pólos (Piracicaba, Ribeirão Preto, São Carlos e São Paulo) do CLC que participaram das avaliações diagnosticas pós-aula: 79 responderam a questão 01 da avaliação diagnóstica 02, dos quais 49 eram do Pólo São Paulo e os outros 30 dos demais Pólos (Piracicaba, Ribeirão Preto e São Carlos); 71 alunos responderam a questão 02 da avaliação diagnóstica 02, dos quais 44 eram do Pólo São Paulo e 27 alunos dos demais Pólos (Piracicaba, Ribeirão Preto e São Carlos); e 51 alunos responderam a avaliação diagnostica 03, dos quais 35 eram do Pólo São Paulo e 16 alunos dos demais Pólos (Piracicaba, Ribeirão Preto e São Carlos).

Para analisar esses dados buscou-se amparo no referencial teórico adotado e foram criadas 04 categorias de pontuação para avaliar as respostas dadas pelos alunos nas avaliações diagnosticas realizadas pós-aula. As categorias criadas analisavam e classificavam o quanto as respostas dadas pelos alunos se aproximavam dos conceitos presentes no Modelo de Drude. Após, comparamos esses dados com 
aqueles obtidos na avaliação diagnóstica realizada em aula, a fim de se verificar se o uso do objeto virtual simulado auxiliou na compreensão do conceito de corrente elétrica, baseado no Modelo de Drude. 


\section{COLETA DE DADOS E ANÁLISES}

Neste capítulo são apresentados os dados coletados e suas devidas análises, relativas às investigações: da infraestrutura tecnológica existente e utilizada pelos alunos de licenciatura do CLC; do processo de criação de um objeto virtual simulado para RA; e da aplicação da RA em uma intervenção com alunos do CLC da USP/UNIVESP.

\subsection{Análise da infraestrutura tecnológica dos alunos do CLC da USP/UNIVESP}

Apresentou-se no capítulo 4.2 - "PANORAMA ATUAL DA APLICAÇÃO DAS TICs NO ENSINO" uma série de pesquisas que mostram um panorama atualizado da presença das TICs nas escolas brasileiras, agora será abordado um dos objetivos dessa dissertação que é a avaliação da infraestrutura tecnológica que alunos de graduação de um curso de Licenciatura possuem para desenvolvimento e aplicação da RA no ensino. Entende-se ser adequada a análise desse grupo, pois esses alunos se tornarão os novos professores que irão catalisar a aplicação dessas novas tecnologias nos processos de ensino e aprendizagem. Assim, o que pretende-se saber nesse capítulo é se esses alunos possuem acesso a infraestrutura tecnológica mínima para desenvolverem e utilizarem aplicações de Realidade Aumentada.

Considera-se que os recursos tecnológicos mínimos para utilização dessa ferramenta no ensino de Física são um computador de custo popular, uma webcam, um monitor de vídeo, um software de Realidade Aumentada e uma simulação que represente um modelo científico que se pretenda estudar.

Os softwares de RA, como por exemplo o ArtoolKit e o FlartoolKit, podem ser obtido gratuitamente na Internet, por isso, entende-se que o software não é fator limitante para utilização de RA.

Com relação aos demais itens, a fim de obter informações sobre acesso a Internet, posse de dispositivos (desktop, tablet, smartphone, notebook), uso de aplicativos educacionais em smartphones, conhecimento de Realidade Aumentada, uso de aplicativos de Realidade Aumentada, entre outras, elaborou-se 15 questões, vide 
anexo 01 (questões 02 a 16), para responder a pergunta dessa pesquisa. Elas foram inseridas no questionário veiculado aos alunos do curso de Licenciatura em Ciências da USP/UNIVESP, na semana "zero" do curso ou de ambientação ao Ambiente Virtual de Aprendizagem do curso.

Conforme discriminado no capítulo 7.3.2 - "Averiguação sobre infraestrutura tecnológica existente" o questionário esteve disponível a uma população de 352 alunos ingressantes, dentre 198 mulheres e 154 homens, da qual 233 responderam o questionário, ou seja, aproximadamente $66 \%$ da população investigada, percentual esse que pode ser efetivamente maior, considerando que 28 alunos ingressantes nunca acessaram o AVA. Uma comparação de taxas de resposta (NULTY, 2008) aponta que para pesquisas em educação as taxas de resposta a enquetes online entre 20 e 40\% são típicas. Não é necessariamente verdade que taxas de respostas altas significam resultados melhores, mas a taxa obtida, relativamente alta, quer dizer que os resultados da enquete dessa pesquisa são representativos pelo menos para a população de ingressantes ao CLC e pelas razões mencionadas no capitulo 4.2, também são para a população de docentes no sudeste do Brasil.

Os dados da pesquisa permitem observar que o público-alvo é uma população diversificada, e a princípio, presumia-se que alguns indivíduos já atuavam na área de ensino:

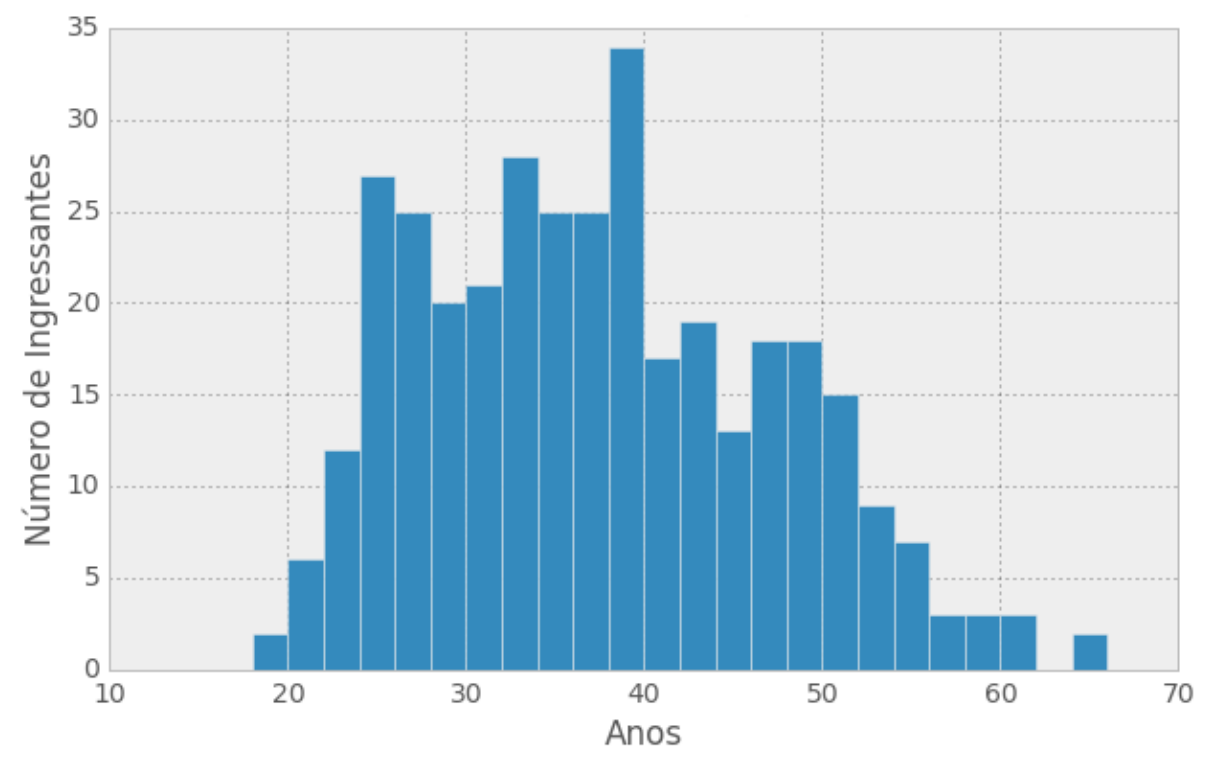

Gráfico 18 - Número de ingressantes por idade do CLC 
Pelo gráfico 18 observa-se que o número de ingressantes por idade é bastante variado, sendo reduzido para os casos de 18 a 22 anos e bem distribuído para as demais idades, fator que permite especular que para grande maioria desses alunos ingressantes poderia se tratar de uma segunda graduação.

A maioria dos entrevistados é do sexo feminino (56\%) e, embora sejam alunos do CLC, considerando-se que esses entrevistados serão futuros professores, ao comparar os percentuais de gênero obtidos com outras pesquisas que avaliam o perfil do professor brasileiro como a Pesquisa TIC Educação 2013 (CGI, 2014, p. 125), utilizada no Capitulo 4.2 dessa dissertação, percebe-se que também há concordância quanto à predominância do sexo feminino entre os professores, mas em maior percentual na pesquisa referenciada (71\%). Outros dados relativos ao perfil do professor brasileiro, provenientes da Pesquisa Internacional sobre Ensino e Aprendizagem, mais conhecida como Teaching and Learning International Survey TALIS (INEP, 2015), coordenada pela Organização para Cooperação e Desenvolvimento Econômico - OCDE e que tem por intuito que coletar dados comparativos em âmbito internacional a respeito dos ambientes de aprendizagem e condições de trabalho dos professores junto as escolas de diversos países do mundo, aponta que no Brasil, no que se refere a professores do Ensino Fundamental, a proporção de professores do sexo feminino é de $71 \%$ feminino (INEP, 2013, p. 11). Com isso, observa-se que os dados relativos ao gênero dos entrevistados, obtidos nessa enquete; refletem como nas demais pesquisas, a predominância do sexo feminino. Além disso, acredita-se que o fato de não se ter obtidos os mesmos percentuais de gênero apresentados nas outras pesquisas seja devido ao público entrevistado ser de um curso de licenciatura em ciências, enquanto que as demais pesquisas entrevistaram professores de outras áreas de conhecimento que não somente de ciências.

Quando consultados a respeito de sua formação acadêmica, 40\% dos ingressantes informaram possuir graduação, o que condiz a observação preliminar, $23 \%$ possui pós-graduação e $29 \%$ ensino médio, enquanto os demais casos referem-se a pósdoutorado e graduações não concluídas.

No que concerne a atuação profissional, $57 \%$ dos ingressantes informaram já ter atuado como professor, o que também confere com a especulação inicial, que dada a variação de idade deveria haver ingressantes que já atuavam na área de ensino. 
Com relação à infraestrutura tecnológica existente e utilizada pelo público-alvo verifica-se que a grande maioria possui notebook e/ou smartphone, conforme gráfico 19, demonstrando haver atualmente uma tendência para uso de dispositivos móveis e, nesse sentido, os dados dessa pesquisa encontram respaldo na Pesquisa TIC Educação 2013, onde é apresentado que aproximadamente $81 \%$ dos professores (CGI, 2014, p. 144) e 51\% dos alunos (CGI, 2014, p. 158) possuem computadores portáteis em seus domicílios.

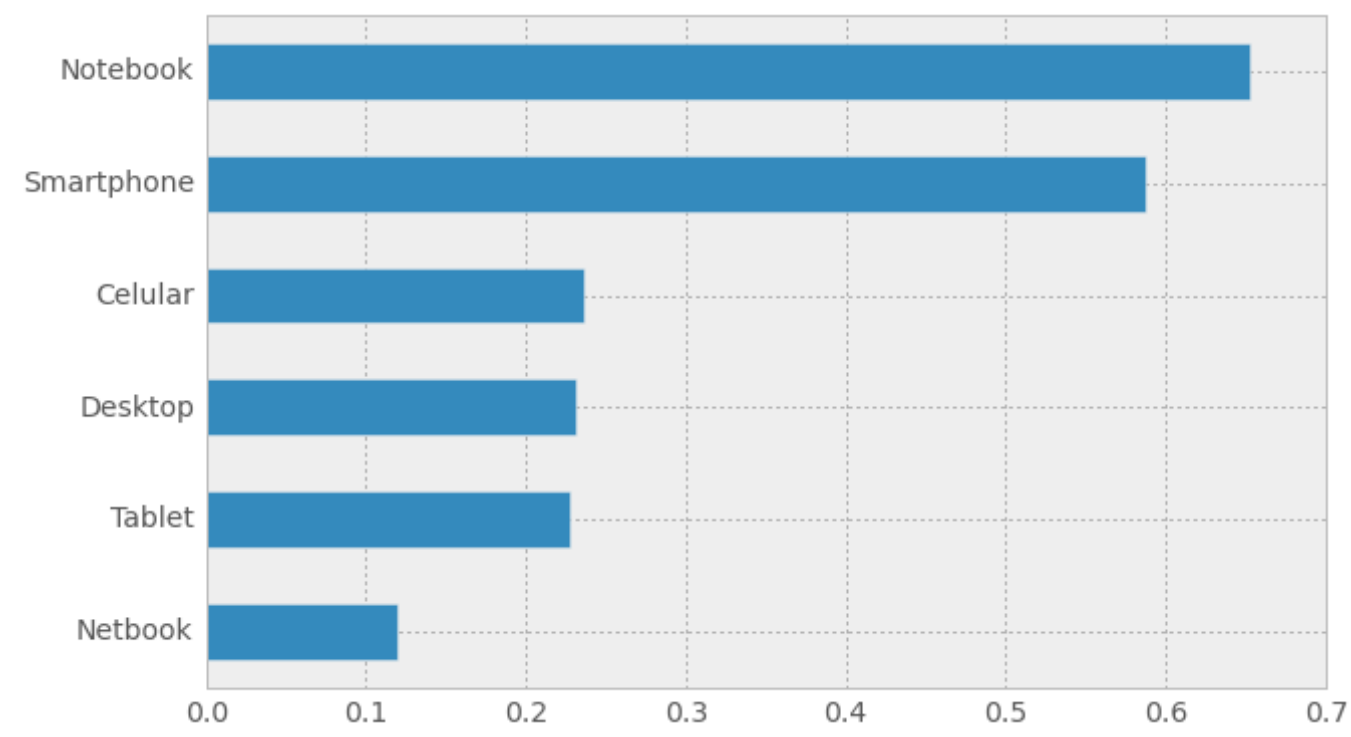

Gráfico 19 - Dispositivos que os ingressantes do CLC possuem, em fração.

A exceção dos aparelhos celulares simples, todos os demais dispositivos do gráfico acima, permitem o uso de aplicações e softwares de RA, sendo mais simples sua utilização em plataformas móveis como, notebooks, smartphones, tablets e netbooks que por esses possuírem câmeras nativas, torna desnecessário a aquisição de uma webcam, sem a qual não é possível viabilizar aplicações de RA.

Analisando ainda a infraestrutura tecnológica, foram questionados os ingressantes do CLC quanto a frequência (Frequentemente, raramente ou nunca) que faziam uso de dispositivos tecnológicos (notebook, smartphone, tablet e desktop) para fins acadêmicos, vide tabela 03, e observou-se que o notebook é o dispositivo apontado como de uso mais frequente, em $77 \%$ dos casos, em contrapartida o tablet foi elencado como dispositivo com maior percentual de "nunca" utilizado, em $60 \%$ dos casos. Um dado interessante obtido nessa questão é que os percentuais de frequência de uso dos smartphones e dos desktops são muito próximos, o que 
talvez decorra da constante presença desse dispositivo móvel no cotidiano do ingressante, permitindo que ela seja utilizada inclusive nas atividades acadêmicas.

Tabela 3 - Frequência de uso de dispositivos tecnológicos em atividades acadêmicas

\begin{tabular}{|l|c|c|c|}
\hline Respostas & Frequentemente & Raramente & Nunca \\
\hline Notebook & $77 \%$ & $12 \%$ & $11 \%$ \\
\hline Smartphone & $33 \%$ & $27 \%$ & $40 \%$ \\
\hline Tablet & $17 \%$ & $23 \%$ & $60 \%$ \\
\hline Desktop & $36 \%$ & $28 \%$ & $36 \%$ \\
\hline
\end{tabular}

Tendo em vista que a RA necessita de recursos de câmera para pleno funcionamento, foram questionados os ingressantes se eles faziam uso regular da "webcam" de seu smartphone, tablet ou computador, e de acordo com as respostas $68 \%$ dos alunos não faz uso, enquanto $32 \%$ sim. Considerando o percentual elevado de não utilização desse recurso, pode-se chegar à conclusão que a forma como a pergunta foi elaborada pode ter prejudicado a resposta dessa questão, pois os dispositivos móveis fazem referência a seus dispositivos de captura de imagem e vídeo tão somente como "câmera" e não "webcam", assim seria necessário reformular a questão para observar se os percentuais seriam alterados.

No que se refere à Internet, não foi elaborada na enquete uma pergunta direta sobre acesso a web pois entendeu-se que por se tratar de alunos ingressantes no CLC, um curso a distância, semi-presencial, fica esse acesso fica subentendido. Assim, optou-se por questionar os alunos ingressantes sobre qual a velocidade de banda que possuíam para acesso a Internet e em $32 \%$ dos casos a velocidade é superior a $5 \mathrm{Mbps}$ e em $35 \%$ entre $1 \mathrm{Mbps}$ e $5 \mathrm{Mbps}$, conforme gráfico 20 : 


\begin{tabular}{|l|l|}
\hline Resposta & Média \\
\hline menos de $500 \mathrm{kbps}$ & $\mathbf{2 6 \%}$ \\
\hline entre $500 \mathrm{kbps}$ e $1 \mathrm{Mpbs}$ & $35 \%$ \\
\hline entre $1 \mathrm{Mbps}$ e $5 \mathrm{Mbps}$ & $32 \%$ \\
\hline mais de $5 \mathrm{Mbps}$ & \\
\hline Não possuo Internet com banda larga & \\
\hline Total & \\
\hline
\end{tabular}

Gráfico 20 - Velocidade de conexão à Internet que os alunos do CLC possuem

Para os objetivos desse trabalho, considerou-se que o acesso a Internet é importante no uso da RA em pelo menos dois casos: na obtenção de objetos virtuais simulados junto a repositórios virtuais; e na veiculação junto a Internet de aplicações de RA que possam ser executadas em um navegador da Internet que possua os plugins adequados. Assim, pelos dados obtidos foi observado que a maioria dos ingressantes do CLC (67\% dos casos) possui velocidade de conexão que permite realizar essas ações, que dependem da Internet, e que são consideradas necessárias para implantação e desenvolvimento de aplicações de RA.

Em relação à frequência de acesso à Internet (gráfico 21), 94\% dos entrevistados afirmam navegar diariamente, enquanto os outros casos, uso semanal e eventual, somados perfazem $5 \%$ dos casos, o que demonstra a presença efetiva da Internet no cotidiano desses alunos.

\begin{tabular}{|l|l|}
\hline Resposta & Média \\
\hline Diariamente & \\
\hline Semanalmente & $3 \%$ \\
\hline Apenas nos finais de semana & $-1 \%$ \\
\hline Eventualmente & $1 \%$ \\
\hline Total & \\
\hline
\end{tabular}

Gráfico 21 - Frequência de uso da Internet pelos ingressantes do CLC 
Conforme observado no Gráfico 19, verificou-se ser grande a fração de entrevistados que possuem smartphones. A presença desses dispositivos junto à sociedade vem crescendo e transformando a forma como os jovens se relacionam com o mundo, podendo gerar impactos nas escolas e na formação de alunos para uso dessas tecnologias (CGI, 2014, p. 27).

Os smartphones, assim como os tablets, possuem inúmeros aplicativos, chamados app, alguns deles são criados especificamente para fins acadêmicos e podem auxiliar alunos e professores no estudo de diversas disciplinas. Além disso, por possuírem recursos como câmera e acesso a Internet permitem a execução de aplicativos de Realidade Aumentada, facilitando e viabilizando o uso dessa ferramenta tecnológica, o que torna esse dispositivo importante para essa pesquisa, por isso, entre as questões apresentadas aos ingressantes do CLC, foram elaboradas algumas que visavam avaliar o uso desses dispositivos em atividades acadêmicas.

Preliminarmente os ingressantes foram questionados quanto ao Sistema Operacional executado nos smartphones que possuem. A importância dessa pergunta esta relacionado ao fato que os aplicativos de smartphones são criados especificamente para cada Sistema Operacional, podendo existir em alguns sistemas e não em outros. Os dados obtidos na enquete apontam ser predominante a presença do Sistema Android do Google nos smartphones, superior a $50 \%$ dos casos, seguido do Sistema IOS da Apple e do Windows Phone da Microsoft, conforme gráfico 22 , a seguir:

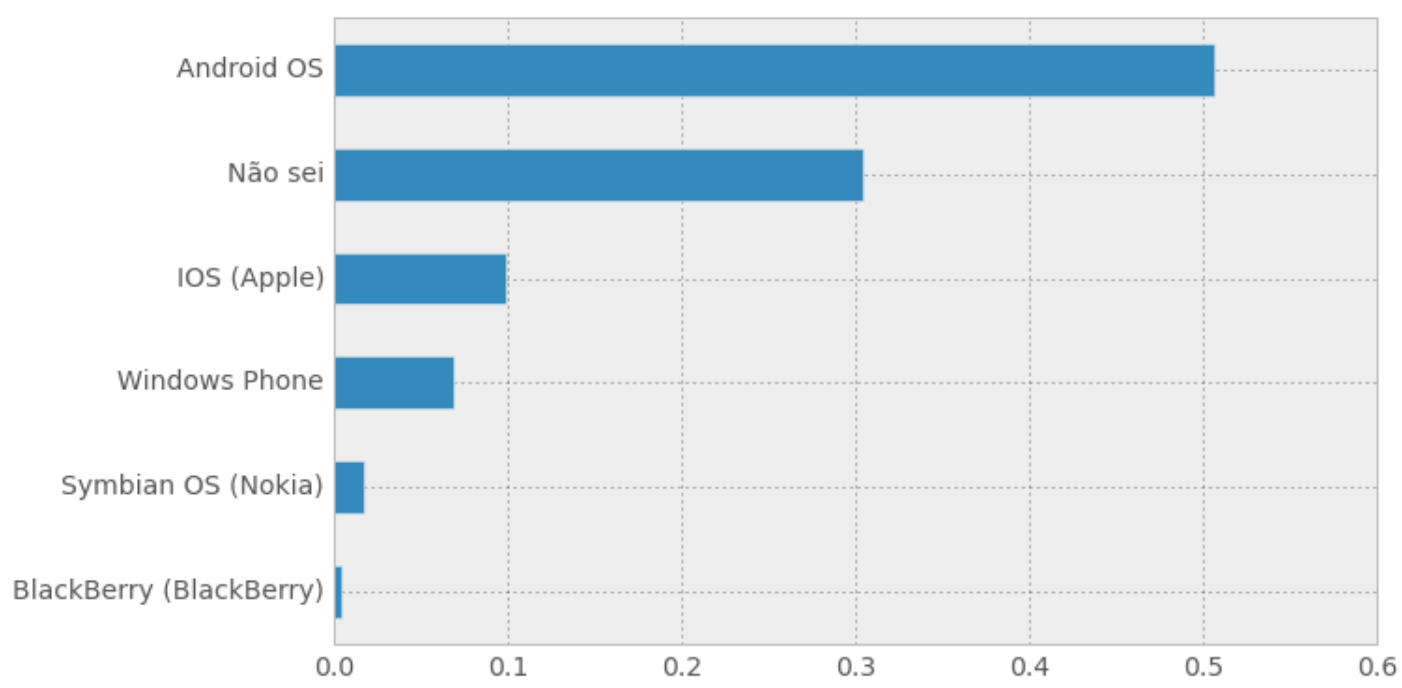

Gráfico 22 - Sistema operacional executado nos smartphones dos ingressantes do CLC. 
Os entrevistados também foram consultados se utilizavam o dispositivo para estudo de alguma disciplina e a reposta foi negativa em $82 \%$ dos casos. Para os casos afirmativos (18\%), foi solicitado informar qual aplicativo utilizado e para estudo de qual disciplina. As respostas mais frequentes foram o uso do aplicativo Duolingo para estudo de inglês ou de outro idioma, outras respostas apontavam o uso dos aplicativos Khan Academy para estudo de Matemática e Adobe Reader para leitura de textos em formato pdf, contudo a grande maioria das respostas não fazia menção a um aplicativo de smartphone, mas sim a algum software de computador ou ainda a alguma ferramenta da Internet como Youtube, Google ou repositórios virtuais.

Ainda em relação ao uso de smartphones, os entrevistados foram questionados se algum professor sugeriu o uso de aplicativo(s) para estudo de alguma disciplina, e obteve-se como resposta "Não" para 96\% dos casos. O baixo percentual de casos afirmativos (4\%) implica em quase não ter havido sugestão de uso de aplicativos por parte de professores. Para os casos em que houve indicação de aplicativo por parte do professor para uso em alguma disciplina, foram obtidas as seguintes repostas: o Duolingo no estudo de idiomas; o OneNote para anotação de lembretes, mas sem informar para qual disciplina era utilizado; aplicativos com funções de calculadoras cientificas para estudo de Matemática; sendo que as demais repostas não deixam claro o aplicativo nem a disciplina para qual era utilizado, ou então não faziam referência a nenhum aplicativo, mas sim a sites da Internet ou softwares de conversação telefônica via Internet.

Para avaliar a possibilidade de uso da RA por meio dos smartphones, foi perguntado aos ingressantes do CLC se eles conheciam a tecnologia RA e a resposta foi negativa para $84 \%$ dos casos. Para os entrevistados que informaram conhecer a RA $(16 \%)$ foi questionado se já utilizaram algum aplicativo de Realidade Aumentada e os percentuais de resposta foram de $71 \%$ para "Não" e $29 \%$ para "Sim". Nos casos afirmativos foi perguntado aos entrevistados quais foram os aplicativos de Realidade Aumentada utilizados e as respostas foram: aplicativos de jornais e revistas voltados a propaganda de produtos, e aplicativos de busca de estabelecimentos próximos que aceitam cartões de benefícios (alimentação, refeição e cultura), as demais repostas não fazem menção a aplicativos de Realidade Aumentada.

Além das questões que foram elaboradas para verificar a infraestrutura tecnológica dos alunos, fez-se uso também de uma pergunta da enquete (questão 17) que foi criada pela equipe pedagógica do CLC. A pergunta versa sobre fluência tecnológica 
e questiona os ingressantes do CLC quanto ao nível de conhecimento tecnológico que possuem sobre diversos softwares, games, recursos da Internet, linguagem de programação, entre outros. Os entrevistados para avaliar seu nível de conhecimento a respeito desses itens deveriam pontuar cada um deles com uma nota e seu respectivo critério: 1 = nada; 2 = pouco; 3 = razoável; e 4 = muito.

Os dados obtidos nessa questão mostram ser alto o percentual de alunos que informam ter "muito" conhecimento quanto ao uso de email (67\%), programas de busca $(60 \%)$, editores de texto (50\%), em contrapartida é alto o percentual de alunos que informam ter "nada" de conhecimento acerca de Linux (46\%), simulações de computador (31\%), linguagem de programação (56\%). A tabela 04 apresenta os percentuais de alunos por nível de conhecimento tecnológico:

Tabela 4 - Percentuais de alunos ingressantes do CLC por nível de conhecimento tecnológico

\begin{tabular}{|l|c|c|c|c|}
\hline Respostas & Nada & Pouco & Razoável & Muito \\
\hline E-mail & $0 \%$ & $3 \%$ & $30 \%$ & $67 \%$ \\
\hline Windows/Mac OS & $8 \%$ & $14 \%$ & $50 \%$ & $28 \%$ \\
\hline Linux & $46 \%$ & $31 \%$ & $18 \%$ & $5 \%$ \\
\hline Editor de texto (Word, por exemplo) & $1 \%$ & $5 \%$ & $44 \%$ & $50 \%$ \\
\hline $\begin{array}{l}\text { Editor de apresentação (PowerPoint, por } \\
\text { exemplo) }\end{array}$ & $6 \%$ & $14 \%$ & $42 \%$ & $38 \%$ \\
\hline $\begin{array}{l}\text { Baixar (download) e enviar (upload) para a } \\
\text { Internet }\end{array}$ & $2 \%$ & $13 \%$ & $44 \%$ & $41 \%$ \\
\hline Baixar arquivos em áudio (mp3, mp4, podcast) & $9 \%$ & $18 \%$ & $38 \%$ & $35 \%$ \\
\hline Programas de buscas (Google, Yahoo, Bing) & $1 \%$ & $5 \%$ & $34 \%$ & $60 \%$ \\
\hline Simulaç̃es no computador & $31 \%$ & $30 \%$ & $28 \%$ & $11 \%$ \\
\hline Redes sociais (Facebook, Twitter, Google+) & $3 \%$ & $17 \%$ & $39 \%$ & $41 \%$ \\
\hline Lista de discussão & $23 \%$ & $34 \%$ & $33 \%$ & $10 \%$ \\
\hline $\begin{array}{l}\text { ChatVídeoconferência (Skype, Gtalk, Hangout, } \\
\text { etc) }\end{array}$ & $15 \%$ & $33 \%$ & $32 \%$ & $20 \%$ \\
\hline Blog & $21 \%$ & $35 \%$ & $31 \%$ & $13 \%$ \\
\hline Video Game (Wii, Xbox, PlayStation, PC) & $39 \%$ & $31 \%$ & $19 \%$ & $11 \%$ \\
\hline Linguagem de programação & $56 \%$ & $34 \%$ & $7 \%$ & $3 \%$ \\
\hline $\begin{array}{l}\text { Mundo Virtual (SecondLife e MMOs, por } \\
\text { exemplo) }\end{array}$ & $69 \%$ & $22 \%$ & $6 \%$ & $3 \%$ \\
\hline
\end{tabular}

Considerando os dados obtidos de fluência tecnológica observou-se que alguns deles podem impactar no uso de RA, principalmente no que se refere a simulações 
de computador e linguagem de programação. Essas duas ferramentas tecnológicas se relacionam com a RA, pois essa faz uso de simulações que são desenvolvidas por meio de linguagens de programação. Assim os altos percentuais de alunos que apresentam "nada" ou "pouco" conhecimento sobre essas ferramentas tecnológicas pode, a principio, refletir em dificuldades para construção de aplicações em RA, principalmente no que tange a linguagem de programação, necessária para elaboração de simulações de modelos científicos mais complexos.

Esses dados de fluência tecnológica também encontram consonância com a pesquisa realizada pela Fundação Victor Civita (FUNDAÇÃO VICTOR CIVITA, 2010, p. 313), apresentada no Capítulo 4.2, que mostra ser baixo o percentual de professores que fazem uso de softwares de programação e simulações.

\subsubsection{Discussão dos dados obtidos sobre a infraestrutura tecnológica dos alunos do CLC da USP/UNIVESP.}

De modo geral, os dados obtidos nessa enquete, apontam que os alunos do CLC possuem minimamente infraestrutura tecnológica para utilização de aplicações de RA, contudo, a falta de conhecimento de linguagem de programação, necessária para confeccionar ou customizar objetos virtuais simulados para uso em em RA, pode fazer com que o aluno, futuro professor, necessite de um programador que participe do processo de elaboração das simulações que serão utilizadas em RA, do contrário dependerá da disponibilidade desse material em repositórios virtuais.

Os dados também permitem verificar que é grande a presença de smartphones junto ao público entrevistado. Alguns recursos desse dispositivo, como por exemplo câmera, acesso a Internet e aplicativos desenvolvidos especificamente para Realidade Aumentada, o tornam um forte concorrente da tríade desktop, webcam e monitor, principalmente por permitir maior liberdade de movimento quando do uso dessa ferramenta tecnológica.

A enquete permitiu observar que ainda é minoritário o uso de smartphones e aplicativos no estudo de alguma disciplina. O mesmo se pode dizer da RA e seus aplicativos. Isso pode estar associado ao fato de se tratar de uma tecnologia relativamente nova e que ainda será melhor explorada no futuro. Todavia, embora 
pouco conhecida pelos alunos entrevistados, a RA possui uma diversidade de aplicativos para uso nos smartphones e seus respectivos sistemas operacionais, por isso, considera-se que esse é mais um fator a corroborar que esse dispositivo que dominará a veiculação dessa tecnologia no futuro.

Como se pode observar no gráfico 22 o sistema Android é predominante nos smartphones do público-alvo, além disso, apresenta o maior número de aplicativos de RA em sua loja virtual, a Google Play (GOOGLE, 2015), sejam eles gratuitos ou pagos. Uma pesquisa junto ao site do Google Play, por meio da expressão "Realidade Aumentada", apresentou como resultado de buca mais de 200 aplicativos desenvolvidos, entre eles o app SENAI RA (GOOGLE, 2015), da Confederação Nacional da Industria, que apresenta aplicações de RA para smartphones, destinada a auxiliar alunos do Curso Técnico de Automação Industrial na visualização de objetos de aprendizagem que podem ser acessados a partir de marcadores impressos em livros-texto. A Apple Store também possui um grande número de aplicativos de RA em sua loja virtual, como o SunSeeker que permite ao apontar a câmera do smartphone para o céu, observar na tela do dispositivo o caminho percorrido pelo Sol, além de outras informações sobre esse astro (APPLE STORE, 2015). Por fim na loja virtual do Windows Phone também se encontram inúmeros aplicativos de RA, entre eles o Wikitude (WINDOWS PHONE, 2015), que possibilita ao usuário do dispositivo encontrar locais, como restaurantes, e ter informações sobre eles bastando apontar a câmera do smartphone e esperar que o aplicativo sobreponha essas informações sobre a imagem capturada pela câmera.

Considera-se que a enquete forneceu dados suficientes para responder sobre a infraestrutura tecnológica mínima para uso da RA, que os alunos do CLC possuem. Retornaremos a essa questão no capitulo 09, quando teceremos nossas considerações finais.

\subsection{O Desenvolvimento De Uma Aplicação De Realidade Aumentada: Uma Experiência Prática}

Para aplicar a RA ao ensino de Física, além da infraestrutura tecnológica (computador, webcam, monitor) também é necessária a utilização de objetos virtuais que simulem os modelos científicos que se pretendam estudar em sala de aula. 
Tais objetos virtuais simulados podem ser obtidos em repositórios virtuais ou então ser criados ou customizados por um professor. Ocorre que é muito difícil encontrar em repositórios, objetos virtuais que simulem modelos científicos complexos e que ainda possam ser utilizados em aplicações de RA, assim, até que tal situação se modifique é provável que o professor se depare com a tarefa de criar esses objetos. Softwares livres de Realidade Aumentada, como o ARToolkit ou Flartoolkit, além de não apresentarem custos, permitem que os objetos virtuais sejam criados em linguagem VRML, podendo ser elaborados em editores de texto, como o Bloco de Notas, ou então em editores de modelagem 3D gratuitos.

A criação de objetos virtuais por meio de editores de texto pressupõe conhecimento prévio em linguagem VRML, pois nesse caso não há visualização direta do que se está criando, somente a programação por linhas de comando. Nesse caso, um professor de Física que não tenha tido acesso a alguma disciplina de programação em sua graduação enfrentaria grande dificuldade nesse caso.

A linguagem VRML foi desenvolvida para uso na Internet sendo possível utilizar plugins que permitam visualizar os objetos virtuais criados em um navegador Web. Nesse trabalho optou-se por utilizar o plugin Cortona 3D Viewer desenvolvido e distribuído gratuitamente pela empresa Parallelgraphics, que permite inspecionar o objeto virtual em 3 dimensões.

A experiência prática dessa pesquisa permite considerar que para um professor sem conhecimentos de programação em VRML pode ser mais vantajosa a utilização de softwares de modelagem tridimensional ao invés de editores de texto, pois esses primeiros, em sua maioria, permitem criar os objetos virtuais em um ambiente tridimensional e possuem também, em sua maioria, formas primitivas (cubo, cilindro, cone, esfera) predefinidas que podem ser combinadas entre si, facilitando a ação do usuário no processo de construção. Esses softwares permitem alterar as características do objeto virtual (material, textura, entre outras) e do cenário (iluminação, ponto de vista, nível de detalhes, cor de fundo, entre outras), bem como realizar transformações (translação, rotação e escala) de maneira mais simples, por vezes por meio de ferramentas pré-definidas e não obrigatoriamente por meio de scripts de programação. A seguir são apresentados alguns softwares de modelagem tridimensional que foram utilizados nessa dissertação, e em seguida será discutido as facilidades e dificuldades que um professor leigo em programação se depararia na confecção de objetos virtuais para uso em RA: 
- Flux Studio da empresa Media Machines e o Vivaty Studio, da empresa Vivaty: ambos são softwares livres com a mesma interface possuindo quatro pontos de vista diferentes, objetos predefinidos com formas primitivas (cubo, cilindro, cone, esfera), ferramentas de modelação de objetos, animação, sensores, entre outros. Com esses softwares é possível criar objetos virtuais estáticos e com formas básicas mais facilmente, contudo para elaboração de objetos virtuais simulados que representem modelos científicos mais complexos será necessário conhecimentos mais sofisticados de VRML que permitam animá-los e aproximá-lo mais efetivamente do modelo que se propõe a representar.

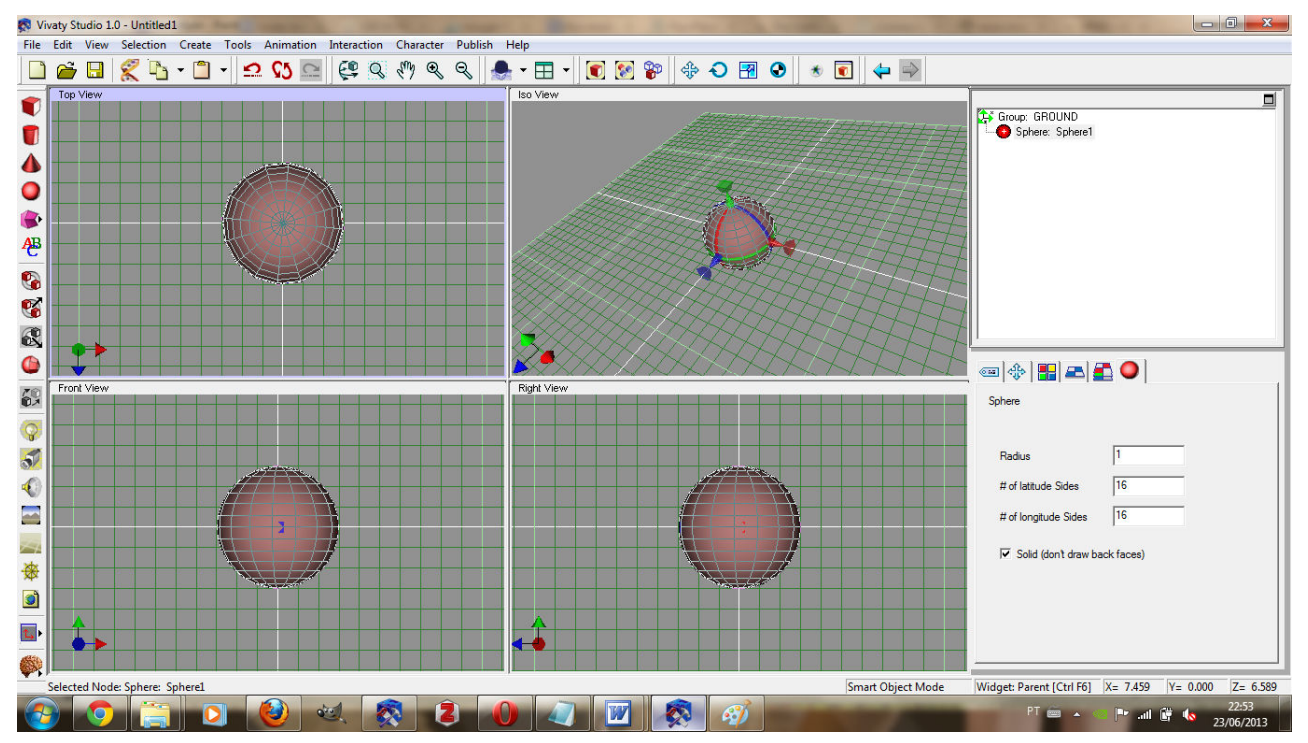

Figura 16 - Vivaty Studio 1.0

- Blender desenvolvido pela Blender Foundation: software de código aberto utilizado para computação gráfica de alto nível e que em sua versão 2.49 permitia exportação em VRML. Apresenta interface customizável que facilita o uso do usuário, além de ferramentas de simulação de fenômenos avançadas que permitem criar efeitos de física como dinâmica de corpos (rígidos e macios) e fluídos, partículas, entre outros. Contudo para acessar tais recursos demanda-se conhecimento específico do software e linguagem de programação. 


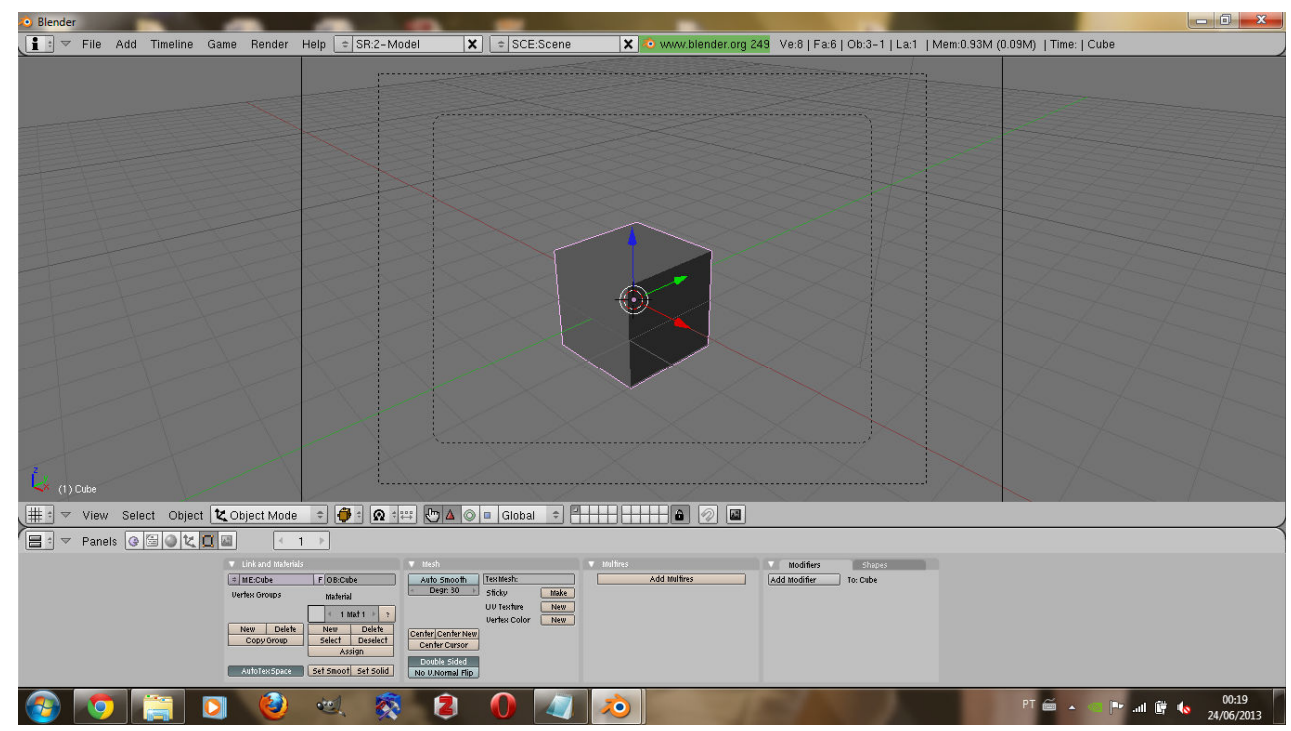

Figura 17 - Software Blender

- 3ds Max desenvolvido pela Autodesk: software proprietário de modelagem tridimensional de alto custo que permite exportar objetos virtuais em VRML. Possui interface customizavel, elevado número de formas básicas predefinidas (cubo, esfera, cilindro, cone, tubo, pirâmide, entre outras) além de opções avançadas de simulação e renderização. Por conta de seus recursos sofisticados necessita de um computador de alto desempenho e assim como o Blender necessita de conhecimentos específicos do software para seu uso.

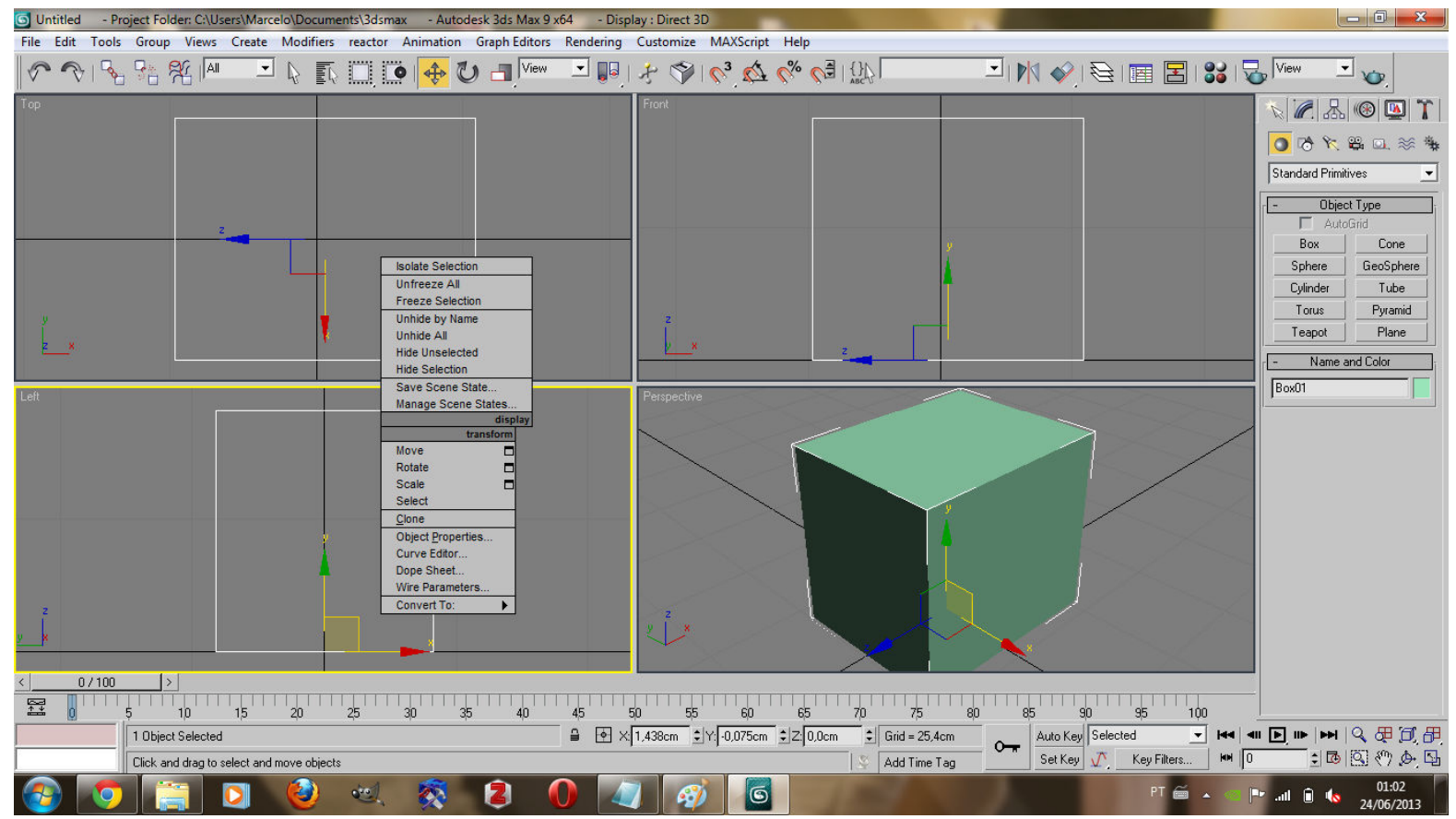

Figura 18 - Software 3DS Max 
- VrmIPad desenvolvido pela Parallelgraphics: software proprietário de edição profissional em VRML com visualização e modo de criação em linhas de comando, que impede a visualização direta do objeto virtual criado. Por não possuir formas básicas predefinidas nem opções de simulação pré-elaboradas, necessita de amplo conhecimento em linguagem VRML de seu usuário.

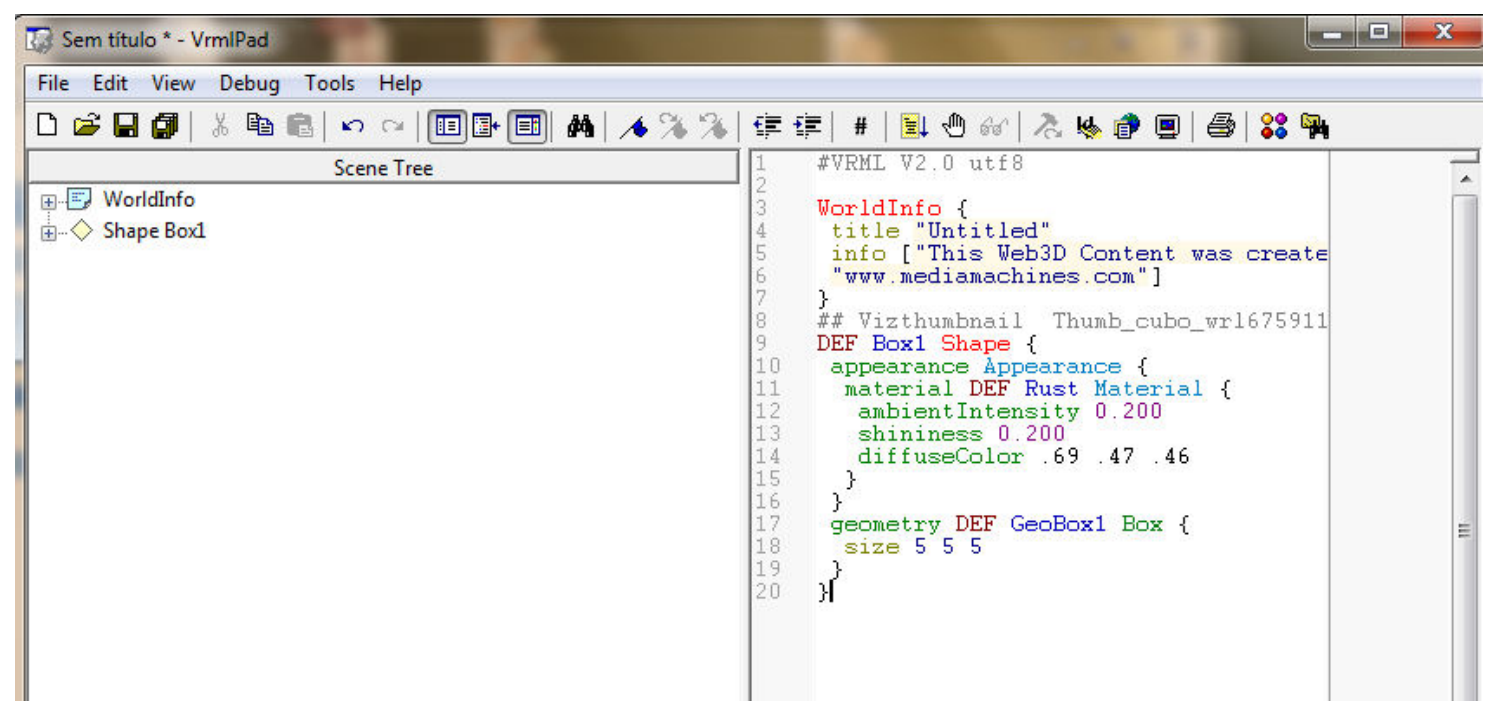

Figura 19 - Software VRMLPad

\subsubsection{Discussão sobre a experiência prática.}

Uma característica comum a maioria desses softwares é o oferecimento de formas básicas pré-definidas (cubos, esferas, cilindros, pirâmides, etc) que permitem a um professor leigo em programação construir objetos virtuais a partir da modelagem dos parâmetros dessas formas básicas (medida das arestas de um cubo, raio de uma esfera, altura do cilindro, entre outros) ou da união dessas formas. Dessa forma, seria possível para esse professor construir objetos virtuais simples e estáticos, mas com grande potencial didático, como por exemplo, a estrutura cristalina de um sólido, algo que nem todos os alunos conseguem conceber em 3 dimensões a partir de desenhos presentes em livros textos. É certo que seria possível apresentar tais modelos de sólidos por meio de maquetes, contudo uma das vantagens da utilização 
da RA nesses casos é permitir que os alunos possam manusear os objetos virtuais livremente sem risco de danificá-los nos casos de queda, além de permitir que o professor não precise carregar maquetes para sala de aula. Embora a elaboração de objetos virtuais por meio das formas predefinidas seja perfeitamente possível para um professor, devemos levar em consideração que sua simples construção mantém tais objetos estritamente estáticos. Modelos científicos mais complexos necessitariam de um objeto virtual simulado que permita reproduzir suas características mais vitais e que se pretenda abordar em uma situação de ensino e aprendizagem, contudo, isso exigiria do professor um conhecimento mais profundo em VRML.

Os softwares utilizados nesse trabalho, a exceção do VrmIPad, possuem ferramentas próprias que permitem introduzir animações predefinidas aos objetos virtuais criados.

Essas animações possibilitam que o objeto descreva trajetórias específicas, tenha sua escala alterada, rotacione em relação a seu próprio eixo ou em relação a um centro definido, entre outras. Mas pelo fato de serem predefinidas não permitem muitas alterações em seu funcionamento, assim é preciso ter cuidado quando de sua aplicação em objetos virtuais, pois se ela não permitir a representação exata do fenômeno que se pretende representar, acabará por levar o aluno a uma concepção equivocada do modelo científico.

A inserção de animação nos objetos virtuais possibilita que os alunos possam observar mais claramente as características de determinado fenômeno físico. Ressalte-se que mesmo se a animação aplicada ao objeto virtual puder representálo com exatidão, se não for possível para o aluno alterar os parâmetros da variáveis que o descrevem, restará ao aluno uma postura passiva, basicamente de espectador da aplicação de RA.

A criação de um menu de ferramentas que permita alterar valores de variáveis presentes num objeto virtual permitirá que os alunos possam observar como um fenômeno físico evolui quando da modificação dessas variáveis, o que torna sua postura mais investigativa em detrimento da passiva. Mas para criar tal menu de ferramentas, seria necessário que não somente o professor tivesse conhecimento em VRML, mas também de outros programas que permitissem modificar parâmetros internos da programação em VRML. 
Em suma, conclui-se que para criar um objeto virtual que represente um modelo científico de alta complexidade será necessário para o professor ter conhecimento avançado em linguagem VRML. O uso de softwares de modelagem tridimensional pode realmente ajudar o professor nesse processo de criação de objetos, mas eles são pouco intuitivos para aqueles que não possuem nenhum conhecimento em VRML.

Nenhum dos softwares utilizados nesse trabalho possui alguma limitação para produzir objetos virtuais em VRML, à limitação estará antes em seu usuário que necessitará aprender como utilizar as ferramentas oferecidas nesses programas da maneira que atenda as suas necessidades.

Dos softwares utilizados, o Flux Studio e o Vivaty foram softwares que permitiram a criação de objetos virtuais básicos e estáticos de forma mais simples, sem necessitar recorrer a tutoriais ou apostilas, estando ao alcance de um professor leigo em programação, que deseje desenvolver aplicações de RA.

Por fim, tendo em vista as dificuldades apresentadas na elaboração de um objeto virtual que represente fielmente um modelo científico, chega-se a conclusão que um professor leigo em programação possa recorrer ao auxílio de especialistas em programação no processo de criação. Caberá então ao professor orientar esses especialistas quanto aos conceitos que regem o modelo científico a fim de que o objeto virtual a ser criado seja ao máximo fidedigno.

Nesse trabalho foi adotada como meta a elaboração de um objeto virtual que representasse o modelo de Drude para condução elétrica, por acreditarmos que existam dificuldades para os alunos compreenderem os conceitos que regem esse modelo. Contudo, por conta das deficiências em linguagem VRML desse mestrando isso não foi possível, assim foi necessário o apoio da equipe do Centro de Ensino e Pesquisa Aplicada (CEPA) do Instituto de Física da Universidade de São Paulo que criou o objeto virtual necessário para o uso da Realidade Aumentada.

\subsection{O desenvolvimento de uma aplicação de RA: construindo com professores e programadores}

Definiu-se neste trabalho que o objeto virtual a ser criado para uso na Realidade Aumentada deveria representar o modelo de Drude para condução elétrica, pela 
suposição que os alunos compreendam a corrente elétrica exclusivamente como um fluído que percorre um fio condutor, sem considerar os entes (elétrons livres, íon fixos, estrutura cristalina) relacionados com esse fenômeno e suas interações (elétron-elétron, elétron-íon). As características do Modelo de Drude para corrente elétrica foram apresentadas no capítulo 7.2.1.

A partir das variáveis que fundamentam o modelo de Drude deu-se início a elaboração da aplicação de RA a ser utilizada nessa dissertação.

A equipe do CEPA no processo de desenvolvimento optou pelo uso do software FLARToolkit por permitir seu uso em desktops e sua veiculação na Internet. O modo de exibição de RA escolhido para uso foi o sistema de visão por vídeo baseada em monitor, ou seja, os marcadores utilizados no uso da RA serão manipulados pelo usuário, capturados numa webcam e projetados em um monitor de vídeo ou ainda projetados em um telão.

A equipe do CEPA construiu o objeto virtual que simula o Modelo de Drude utilizando o software 3ds Max desenvolvido pela Autodesk. O objeto virtual elaborado compreende o segmento de um fio condutor onde se podem observar os íons fixos que compõe a estrutura cristalina, bem como os elétrons livres, que podem ser observados em movimento de origem térmica e ainda, em deslocamento oriundo da aplicação de um campo elétrico.
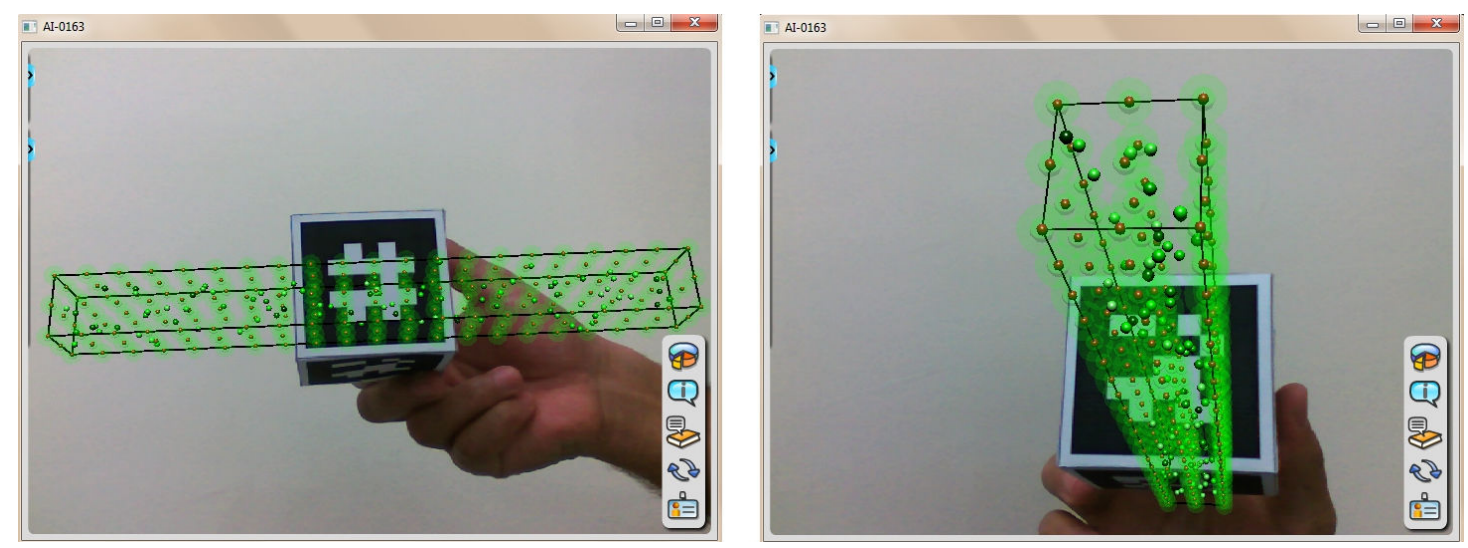

Figura 20 - Objeto virtual representando o Modelo de Drude

A equipe do CEPA para conferir um caráter mais exploratório a aplicação de Realidade Aumentada introduziu parâmetros que permitem alterar:

- escala da animação, para ampliar o objeto virtual e obter uma melhor visualização; 
- velocidade da animação, para observar a magnitude da velocidade térmica em comparação a velocidade de migração;

- intensidade do campo elétrico, que consequentemente altera a intensidade da velocidade de deriva.

Além disso, também foram inseridos botões extras que permitem ao aluno remover as bordas de contorno da representação do fio; remover de cena o objeto virtual; visualizar o objeto virtual em tela cheia e, por fim, inserir som ao objeto virtual.

O menu de opções do objeto virtual contem também um contador de elétrons por unidade de tempo e quando a opção de som é acionada no objeto virtual um ruído é emitido para cada elétron que atravessa uma determinada seção transversal do fio, permitindo que o aluno possa estimar qual o valor da corrente elétrica que percorre $o$ fio.

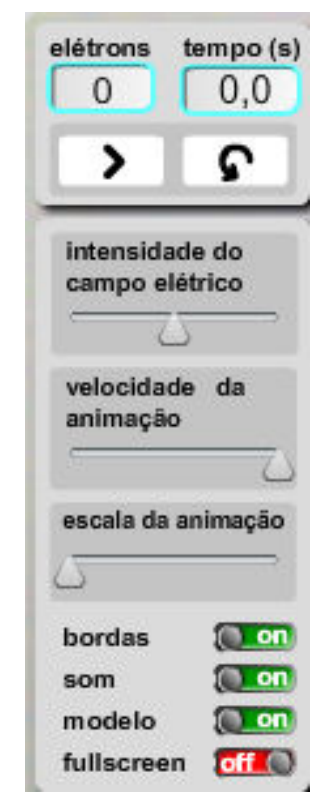

Figura 21 - Aplicativo de RA desenvolvido pelo CEPA

Para que as características do objeto virtual simulado estivessem adequadas ao modelo de Drude foi necessária a participação dos professores especialistas IFUSP para elucidar quais os conceitos relevantes do modelo científico deveriam estar representados no objeto virtual, a fim de evitar superficialidade na simulação ou erros conceituais, prejudicando o processo de ensino aprendizagem.

Entre as orientações dos professores para a equipe de criação do CEPA estavam:

- os elétrons livres deveriam apresentar movimento de origem térmica com velocidade superior a velocidade de migração; 
- as colisões entre elétrons livres deveriam ser desconsideradas e as colisões com os íons fixos da estrutura cristalina deveriam ser observadas;

- elaboração de um contador de elétrons que atravessam uma seção reta do fio por intervalo de tempo, com o intuito que os alunos possam estimar a corrente elétrica, bem como observar como varia a corrente elétrica quando se altera a intensidade do campo elétrico.

Embora os professores tenham sugerido que os elétrons livres deveriam ser muito menores que os íons fixos da estrutura cristalina para manter características mais próximas do modelo de Drude isso implicaria em dificuldades para visualizá-los no objeto virtual, inclusive prejudicando a observação de suas colisões com os íons fixos.

Uma vez elaborado o objeto virtual, a equipe do CEPA desenvolveu um conjunto de marcadores em formato de cubo onde cada face-marcador estaria vinculada a um ponto de vista do segmento virtual do fio, a ser observada na aplicação de RA.

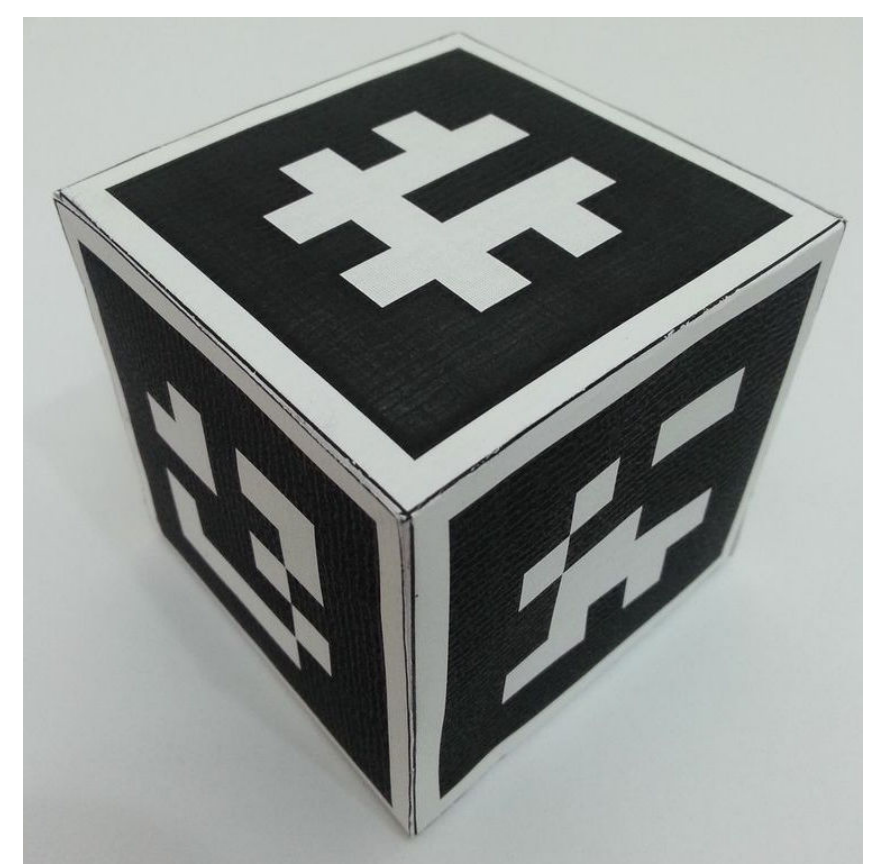

Figura 22 - Marcador em formato de cubo elaborado pelo CEPA

Como o modo de exibição da RA se daria por meio de um sistema de visão por vídeo baseada em monitor, foi criada também uma versão do cubo-marcador confeccionado em madeira com os marcadores de cada uma das faces pintados com tinta fosca. O objetivo era evitar que o cubo sofresse avarias durante seu uso e 
também minimizar a ocorrência de reflexos em suas faces devido a fontes de luz da sala de aula, pois caso isso ocorra, a webcam não capturaria fielmente a imagem de cada marcador, implicando em seu não reconhecimento pelo software de RA e assim não haveria a projeção do objeto virtual associado.

Ainda em relação aos marcadores e para fazer jus ao nome de "Realidade Aumentada", foi proposto pela equipe de professores que fosse utilizado um marcador fixado a um circuito real, de maneira que o objeto virtual fosse projetado sobre o circuito, na imagem do monitor, como se fosse uma ampliação nanoscópica de um trecho do circuito.

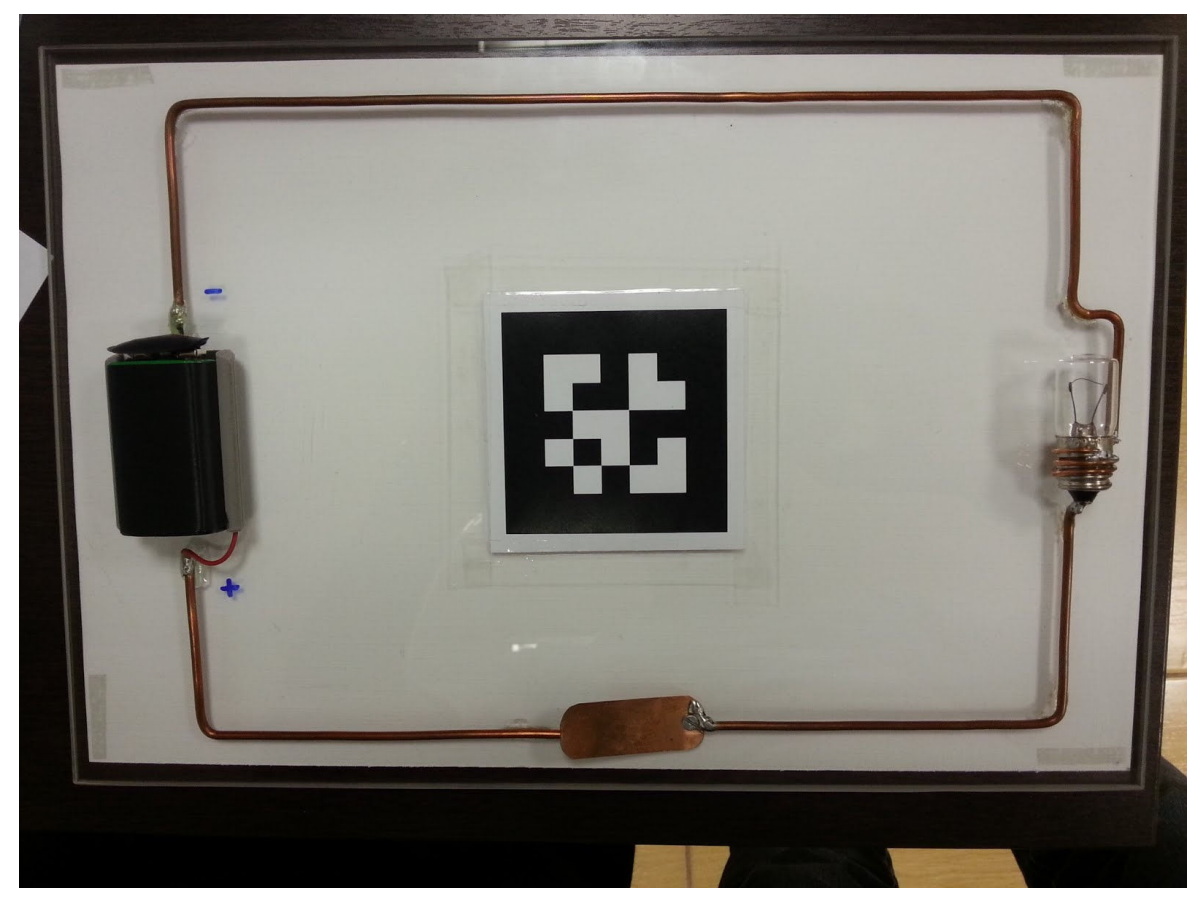

Figura 23 - Circuito real com marcador

O circuito real foi elaborado por um dos professores especialistas e dispunha de uma chave móvel que permitia abrir e fechar o circuito, respectivamente apagando e acendendo uma lâmpada presente no circuito. Concomitante a essa ação, por meio do programa de RA era possível alterar os parâmetros do objeto virtual, permitindo que os elétrons livres do fio permanecessem em movimento de origem térmica, no caso do circuito real estar aberto, ou se deslocar na direção oposta ao campo elétrico aplicado ao fio (ainda mantendo o movimento de origem térmica), quando o circuito estivesse fechado. 


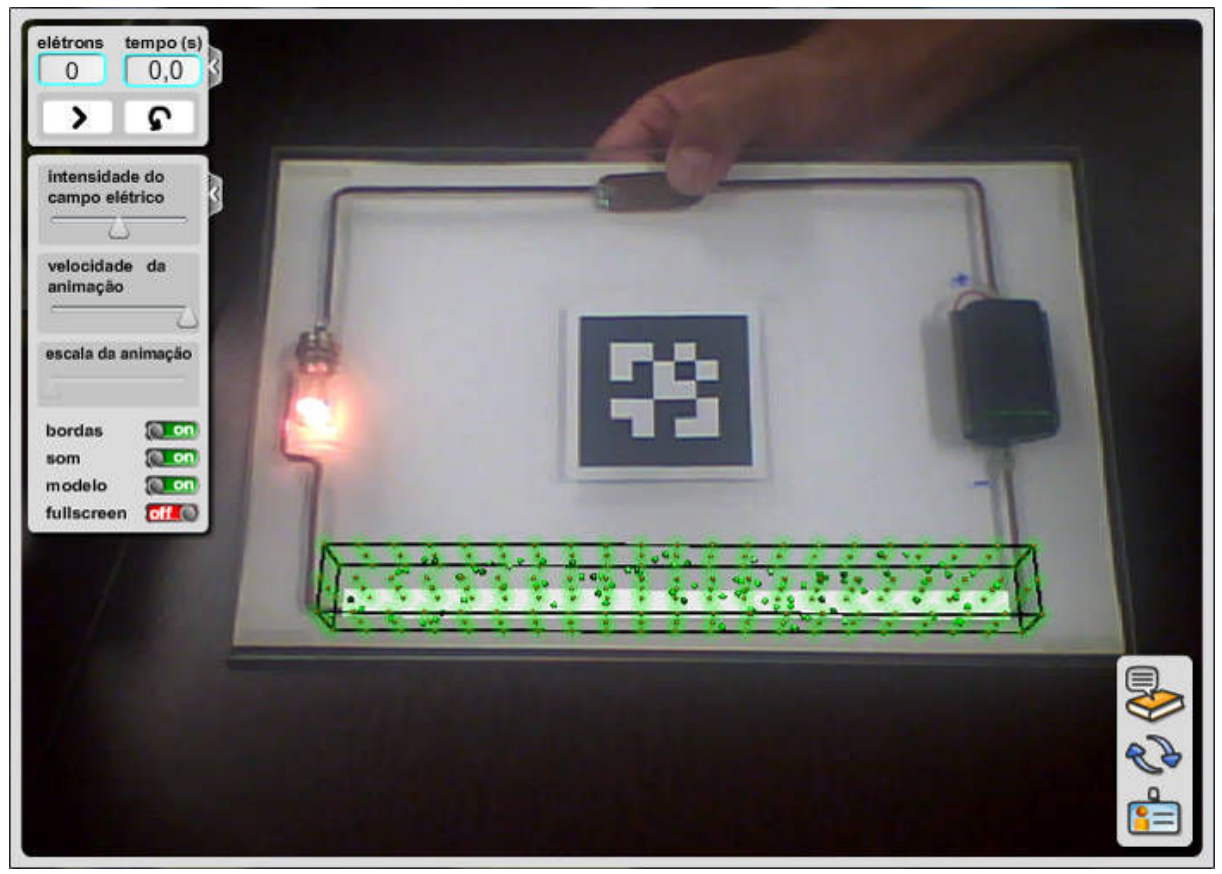

Figura 24 - Intervenção de RA apresentando o circuito fechado

\subsubsection{Discussão sobre a criação de objetos virtuais por uma equipe de professores especialistas e programadores.}

O processo de criação de uma intervenção em RA pela equipe do CEPA demandou tempo na análise do software FLARToolkit para conhecer suas possibilidades e limitações, bem como na elaboração do objeto virtual por meio de um software de uso profissional, o 3ds Max da Autodesk.

Embora o desenvolvimento do objeto virtual tenha ocorrido no período de setembro a outubro de 2012, estima-se que o tempo real de sua criação pela equipe de programadores seja de uma semana. O tempo transcorrido neste caso deve-se ao fato dos programadores estarem desenvolvendo outros projetos que não somente esse de RA, bem como a necessidade de adequação de agenda para reuniões periódicas com a equipe de professores.

Concluiu-se nesse trabalho que a presença dos professores é fundamental no processo de customização do objeto virtual para evidenciar quais são os conceitos mais relevantes do modelo científico que se pretende representar, bem como quais as formas pedagógicas mais salutares de aplicação, a fim de otimizar a experiência do aluno com a RA e ampliar o conhecimento do fenômeno físico estudado. 


\subsection{Análise e discussão da intervenção de RA aplicada aos alunos do CLC da USP/UNIVESP}

Após a criação do objeto virtual de RA pela equipe do CEPA, foi elaborada e aplicada uma intervenção, no segundo semestre de 2012 com o intuito de diagnosticar se os objetivos pretendidos no projeto são possíveis de serem atingidos.

O público alvo para intervenção foram os alunos do CLC da USP/UNIVESP. A intervenção se deu em uma aula presencial matutina da disciplina de Eletricidade, ocorrida em 03/11/2012 (sábado) no campus Butantã da USP. A aula foi ministrada por uma professora do IFUSP. Quarenta (40) alunos participaram da intervenção, numa proporção equilibrada de homens e mulheres. A sala de aula já dispunha de projetor e computador, mas para realização da intervenção utilizou-se como material de campo um notebook, uma webcam e um cubo marcador. No início da aula os alunos se acomodaram a frente da sala enquanto a professora resolvia exercícios sobre dipolos elétricos que pertenciam a uma lista para resolução em casa. Como o curso é semipresencial os alunos aproveitaram ao máximo para tirar todas as dúvidas que tinham, estando a professora a disposição para esclarecer todas as dúvidas que surgiram.

Em seguida os alunos foram divididos em grupos de 04 alunos para realizar uma atividade que consistia em desenhar um circuito baseado em fios, uma bateria e uma lâmpada com o objetivo de acender essa lâmpada. Feito isso, os grupos, com base nos desenhos que fizeram, retiraram os materiais necessários para montar o respectivo circuito. Como não havia plugues para contato dos fios com a bateria, nem com a lâmpada foi preciso que os alunos se ajudassem mutuamente para segurar as partes que compunham o circuito. Dos nove grupos formados, 05 acertaram no desenho esquemático para acendimento da lâmpada, enquanto 04 desenharam circuitos em curto.

Os alunos que conseguiram acender a lâmpada ficaram entusiasmados por atingirem o objetivo. Um fato interessante observado pela professora é que alguns grupos em sua representação do circuito não desenharam o filamento da lâmpada. 
A professora montou um circuito de maneira adequada para que a lâmpada acendesse, discutiu com os alunos a necessidade da corrente elétrica atravessar o filamento para que esse se tornasse incandescente e também desenhou na lousa algumas representações de circuitos em curto para que os alunos observassem de que maneiras a lâmpada não faria parte do circuito. Em seguida pediu que os grupos redesenhassem os circuitos e que também desenhassem e explicassem o que, para eles, acontecia no interior do fio condutor. Todos os 09 grupos resenharam o circuito da maneira correta, ou seja, nesses circuitos a lâmpada acenderia. Em relação aos desenhos feitos pelos grupos representando o interior do fio, apresenta-se a tabela 05, com as suas principais características:

Tabela 5 - Características dos desenhos dos 09 grupos sobre o que acontece no interior do fio condutor

\begin{tabular}{|c|c|c|c|c|c|c|}
\hline \multirow{2}{*}{ GRUPOS } & \multicolumn{2}{|c|}{$\begin{array}{c}\text { Movimento dos elétrons } \\
\text { livres }\end{array}$} & \multicolumn{2}{|c|}{$\begin{array}{l}\text { Presença } \\
\text { de } \\
\text { estrutura } \\
\text { cristalina }\end{array}$} & \multicolumn{2}{|c|}{$\begin{array}{l}\text { Sentido de movimento } \\
\text { dos elétrons em relação } \\
\text { ao campo elétrico }\end{array}$} \\
\hline & Ordenado & Desordenado & Sim & Não & $\begin{array}{l}\text { Oposto ao } \\
\text { campo }\end{array}$ & $\begin{array}{l}\text { Mesmo } \\
\text { sentido do } \\
\text { campo }\end{array}$ \\
\hline 01 & & $x$ & & $x$ & $x$ & \\
\hline 02 & & $x$ & & $x$ & & $x$ \\
\hline 03 & \multicolumn{2}{|c|}{ Não consta no desenho } & & $\mathrm{x}$ & $\begin{array}{c}\text { Vetor } \\
\text { indicando } \\
\text { sentido dos } \\
\text { elétrons } \\
\end{array}$ & \\
\hline 04 & $x$ & & $x$ & & $x$ & \\
\hline 05 & \multicolumn{2}{|c|}{$\begin{array}{c}\text { Consta no desenho, mas } \\
\text { sem caracterização de } \\
\text { movimento }\end{array}$} & $\mathrm{x}$ & & \multicolumn{2}{|c|}{$\begin{array}{c}\text { Não está representado no } \\
\text { desenho }\end{array}$} \\
\hline 06 & $x$ & & $x$ & & $x$ & \\
\hline 07 & \multicolumn{2}{|c|}{ Não consta no desenho } & & $\mathrm{x}$ & $\begin{array}{l}\text { Vetor } \\
\text { indicando } \\
\text { sentido dos } \\
\text { elétrons }\end{array}$ & \\
\hline 08 & \multicolumn{2}{|c|}{ Não consta no desenho } & & $x$ & $\begin{array}{l}\text { Vetor } \\
\text { indicando } \\
\text { sentido dos } \\
\text { elétrons }\end{array}$ & \\
\hline 09 & & $x$ & & $x$ & \multicolumn{2}{|c|}{$\begin{array}{c}\text { Não está representado no } \\
\text { desenho }\end{array}$} \\
\hline
\end{tabular}

Observa-se pela tabela 05 que embora três grupos tenham caracterizado o movimento dos elétrons livres no interior do fio condutor como desordenado e 
apenas 02 grupos como ordenado, restaram 04 grupos que não representaram os elétrons livres em seu desenho. Além disso, somente 03 grupos representaram a estrutura cristalina no interior do fio condutor. Quanto ao sentido do movimento dos elétrons em relação ao campo elétrico aplicado, 06 grupos representaram os elétrons livres em sentido contrário ao campo, 02 grupos não representaram o sentido desse movimento e apenas 01 grupo considerou esse movimento no mesmo sentido.

Desses 09 grupos, apenas dois apresentaram explicações textuais sobre o que acontecia no interior do fio condutor:

Grupo 07: "Os elétrons livres se movem dentro do filamento e colidem com os átomos da estrutura cristalina de cobre, promovendo agitação das moléculas e gerando calor e acendendo a lâmpada"

Grupo 08: "A lâmpada acendeu pois os elétrons saíram de um dos pólos da pilha, passaram pelo fio 1, que estava em contato com a pilha, passou pela lâmpada, acendendo-a e voltaram pelo fio 2, para a pilha."

A explicação apresentada por esse grupo 07 representa em quase sua totalidade as características do modelo de Drude, contudo esse grupo não desenhou esquematicamente como isso ocorre dentro do fio condutor. A explicação do grupo 08 atentou para o sentido percorrido pelos elétrons sem atentar para a estrutura cristalina do fio tanto na sua explicação quanto em seu desenho.

Uma análise parcial das representações nos mostra que para boa parte dos grupos nem a estrutura cristalina do fio condutor nem as características do movimento dos elétrons (movimento desordenado ou movimento ordenado) são levadas em consideração para explicar o fenômeno da corrente elétrica. Exemplo disso está em uma dúvida manifestada pelo aluno durante a elaboração desses desenhos, que questionou se o filamento da lâmpada esquentava porque os elétrons ficavam travados/parados dentro dele.

A atividade dos desenhos ocupou boa parte da aula e os alunos se mantiveram focados em seus grupos. Os desenhos feitos pelos grupos foram analisados após a aula pela professora. 
O uso da RA teve início nos últimos 20 minutos de aula. Inicialmente havia sido programada a aplicação da Avaliação Diagnóstica 01 antes do uso da RA para averiguar as concepções prévias que os alunos possuem sobre corrente elétrica, contudo, dada a brevidade do tempo, a avaliação foi entregue para os alunos concomitantemente ao uso da RA.

$\mathrm{Na}$ intervenção, para propiciar o uso da RA já estavam preparados os seguintes materiais e equipamentos: um notebook com o software FLARToolkit e com uma webcam móvel; um projetor conectado ao notebook; um telão e um conjunto de marcadores-cubo, sendo que a versão em madeira seria utilizada pelo professor e a versão em papel pelos alunos.

Os alunos foram preliminarmente apresentados, de forma suscinta, ao conceito de RA, seu funcionamento e sua infraestrutura. De maneira geral, quase todos os alunos desconheciam a RA, muito embora, tenham observado marcadores em revistas ou na Internet.

A intervenção manteve a discussão sobre o que acontece no interior de um fio condutor. Nessa etapa esse mestrando e seu orientador (observador participante da aula) auxiliaram a professora em sua ação com os alunos, mais especificamente na apresentação do circuito real (figura 22) com o marcador fixado a ele. Primeiramente o circuito foi fechado para que os alunos observassem a lâmpada acendendo, após foi pedido que eles olhassem para o telão pois o circuito real seria capturado pela webcam e então seria possível ver no telão o objeto virtual que representa o que ocorre no interior do fio.

Os alunos demonstraram grande entusiasmo ao observar o objeto virtual ser posicionado sobre o circuito e pareceram impressionados com a RA, mantendo os olhares fixos para o telão.

Foi possível por meio do menu de ferramentas da RA, reduzir ao máximo a opção intensidade do campo elétrico e mostrar para os alunos o que ocorre no interior do fio quando na ausência de campo elétrico aplicado: os elétrons livres se mantêm em movimento aleatório proveniente da agitação térmica, chocando -se com os íons fixos da estrutura cristalina do fio. No circuito real essa situação ocorria quando a chave que fecha o circuito estava aberta, ou seja, a lâmpada não acendia.

Variando a opção intensidade do campo elétrico, os alunos observaram que os elétrons livres, além de manterem o movimento de origem térmica, também se deslocavam do pólo negativo para o pólo positivo, ou seja, no sentido oposto ao 
campo elétrico aplicado ao fio condutor e variavam a velocidade desse deslocamento a medida que a intensidade do campo elétrico variasse, chocando-se com a estrutura cristalina do fio condutor durante a combinação desses movimentos. No circuito real essa situação ocorria quando a chave do circuito estava fechada, ou seja, a lâmpada acendia.

O intuito ao apresentar tais características sobre o que ocorre no interior do fio era mostrar aos alunos que o movimento ordenado dos elétrons em uma corrente elétrica não significa dizer que eles se deslocam especificamente em "linha reta" ao longo do fio, mas que durante esse movimento eles se chocam com a estrutura cristalina do condutor ocasionando dissipação de energia em forma de calor, conforme prevê o modelo de Drude. Trata-se de uma visualização difícil de representar em uma imagem estática de lousa ou livro.

Em meio ao uso da RA foi necessário deixar claro que o objeto virtual era apenas uma representação do fio condutor, baseado no modelo de Drude, e não o fio realmente, pois alguns alunos perguntaram se realmente se tratava do interior do fio. Como os alunos estavam interessados no uso da RA, o notebook foi deixado a disposição para que eles pudessem manipular não somente o circuito real com o marcador fixado, mas também o cubo-marcador, e pudessem observar no telão o objeto virtual em distintos pontos de vista. Muitos se puseram a manipular o marcador, um por vez, bem como modificar os parâmetros da representação para observar como eles modificavam a evolução da representação e como só havia uma webcam para intervenção os demais alunos ficaram sentados observando ou esperando uma oportunidade de experimentar a RA.

Em meio à intervenção, tanto os alunos que faziam uso da RA quanto os alunos que estavam em grupo recorreram à professora ou a equipe (mestrando e orientador) para tirar dúvidas sobre o objeto virtual, suas características, seus movimentos. Muitos alunos enalteceram o fato de ser possível visualizar o "fio condutor" em três dimensões, pois isso permitia observar melhor a estrutura cristalina, os íons fixos, o movimento dos elétrons, entre outras características. Outros alunos ao manipular o objeto virtual e posicioná-lo em uma visão frontal conseguiram observar o que era a seção reta do condutor, utilizada para calculo da corrente elétrica.

Durante o uso da Realidade Aumentada foi aplicada a Avaliação Diagnóstica 01 e os alunos que não estavam manipulando o objeto virtual permaneceram em grupo, 
dialogando entre si e buscando auxílio na professora para respondê-lo. Ao fim da aula as Avaliações Diagnósticas 01 foram recolhidas para análise posterior.

Terminada a intervenção os alunos foram orientados a realizar as AvaliaçõesDiagnósticas 02 e 03, que estariam disponíveis no Ambiente Virtual de Aprendizagem - AVA do curso de Licenciatura em Ciências da USP/UNIVESP.

Ressalte-se que pelo fato da RA ter sido desenvolvida com o FLARToolkit, foi possível disponibilizá-la na plataforma online do curso para uso dos alunos, mas para isso era necessário que o aluno tivesse o plugin Flash Player desenvolvido pela Adobe System Software, bem como uma webcam. O cubo-marcador também estava disponível na plataforma online.

\subsubsection{Análise e discussão da Avaliação Diagnóstica 01}

A Avaliação Diagnóstica 01 era composta por 04 imagens das quais o aluno deveria escolher duas que considerava melhor representar uma analogia para corrente elétrica e justificar sua escolha.
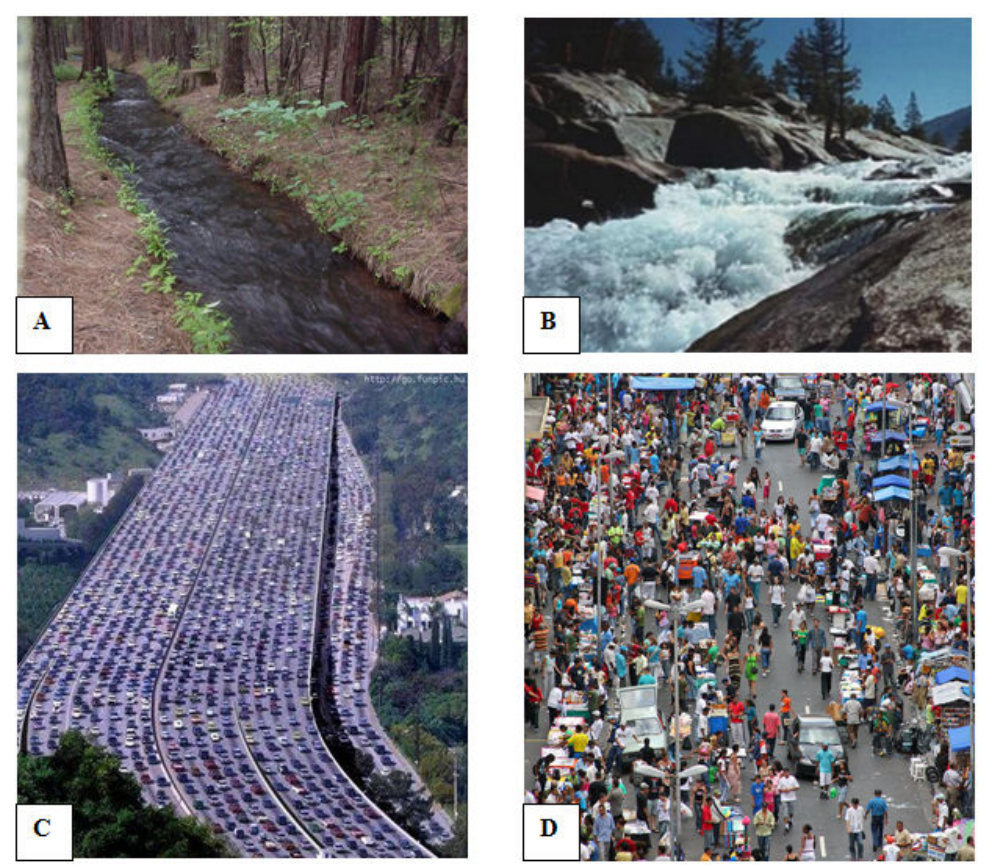

Figura 25 - Imagens da avaliação diagnóstica 01

As imagens dessa avaliação foram escolhidas para analisar qual a concepção prévia o aluno apresentava do conceito de corrente elétrica, se para eles a corrente elétrica 
era como um fluído, ordenado ou turbulento, imagens A e B respectivamente, ou ainda um movimento de elétrons, ordenado ou desordenado, figuras C e D respectivamente.

As escolhas dos alunos são apresentadas na tabela 06:

Tabela 6 - Duplas de imagens escolhidas pelos alunos na Avaliação Diagnóstica 01

\begin{tabular}{|c|c|c|c|c|c|}
\hline \multicolumn{5}{|c|}{$\mathbf{N}^{\circ}$ de ocorrências das duplas de imagens escolhidas pelos alunos } \\
\hline $\mathrm{A}$ e B & $\mathrm{A} \mathrm{e} \mathrm{C}$ & $\mathrm{A} \mathrm{e} \mathrm{D}$ & $\mathrm{B} \mathrm{e} \mathrm{C}$ & $\mathrm{B} \mathrm{e} \mathrm{D}$ & $\mathrm{C}$ e D \\
\hline 24 & 05 & 01 & 05 & 03 & 02 \\
\hline
\end{tabular}

Observa-se pelas ocorrências das duplas de imagens que para maioria dos alunos, 24 deles, a analogia dos rios é a que melhor representa o conceito de corrente elétrica, ou seja, associam a corrente elétrica a uma espécie de fluído. Somente 02 alunos escolheram conjuntamente as duas imagens que representam a corrente elétrica como o movimento de elétrons. Analisando-se isoladamente as escolhas das imagens verificou-se que: a figura $A$ foi escolhida 30 vezes; a figura $B$ foi escolhida 32 vezes; a figura $C$ foi escolhida 12 vezes e a figura $D$ foi escolhida 07 vezes. Assim, predominou como escolha de analogia para corrente elétrica o movimento turbulento de um fluído. Entre as justificativas para a escolha das imagens estão:

Figura A: " (A figura) A equivale a uma corrente elétrica porque demonstram um movimento ordenado dos elétrons como ocorre numa corrente"

Figura B: "A imagem oferece uma boa analogia, pelo fato dessa "fluidez" que é a corrente elétrica e as pedras como os átomos presentes na estrutura oferecendo uma certa resistência. Porém, um dos nossos maiores "erros" ou falhas da analogia é o fato de a água não representar de forma ideal a corrente elétrica e o movimento um tanto aleatório dos elétrons."

Figura C: " $A$ letra $C$ dá uma idéia da movimentação em relação ao sentido da corrente, porém engessa a movimentação do elétron que fica reduzido num sentido apenas" 
Figura D: "...mostra o movimento dos elétrons se movimentando em todas as direções. Além disso, mesmo que vagarosamente [...] caminham num determinado sentido"

Embora as imagens $\mathrm{A}$ e $\mathrm{B}$ tenham tido maior número de ocorrência, a maioria das justificativas dos alunos fez menção ao movimento dos elétrons como um fluido, caracterizado como ordenado, que se desloca em linha reta, ou desordenado, que se desloca aleatoriamente. Isso pode demonstrar que as figuras $C$ e $D$, mesmo caracterizando partículas se deslocando em uma via (rodovia ou rua) que poderiam ser associadas aos elétrons dentro do fio condutor, não causaram a mesma sensação de movimento quanto aos outras duas imagens, diminuindo assim a ocorrência de suas escolhas.

Ainda em relação às justificativas dos alunos, somente uma pequena parte delas menciona a presença de uma estrutura cristalina com a qual os elétrons livres possam colidir.

Um fator a ser ressaltado na Avaliação Diagnóstica 01 é que ela foi elaborada para ser aplicado antes do uso da RA, todavia, essa aplicação acabou ocorrendo concomitantemente a essa Avaliação, assim, não foi possível medir de que maneira essa mudança pode ter afetado as justificativas dos alunos para escolha das imagens dessa avaliação.

\subsubsection{Análise e discussão das Avaliações Diagnósticas 02 e 03.}

As Avaliações Diagnósticas 02 e 03 foram veiculadas no AVA para resolução dos alunos no período de 03/11/13 a 13/11/13.

Ressalte-se que a Avaliação Diagnostica 02 era composta por duas questões e revertia em nota para o aluno, enquanto a avaliação diagnóstica 03 não valia nota alguma, tinha caráter apenas participativo.

A Avaliação Diagnóstica 02 apresentava ao aluno cinco representações de corrente elétrica em condutores (figura 26), encontrados em materiais didáticos e livros-texto. $\mathrm{O}$ objetivo era que $\mathrm{o}$ aluno avaliasse $o$ quanto as representações se aproximavam 
do modelo científico clássico para corrente elétrica (modelo de Drude) e são funcionais para interpretar o que ocorre, no nível microscópico da matéria, para explicar os fenômenos macroscópicos que observamos como acendimento de lâmpada, funcionamento de dispositivos, etc.

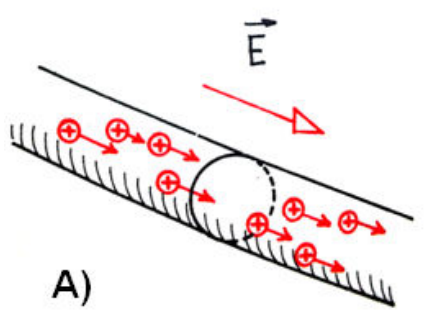

B)
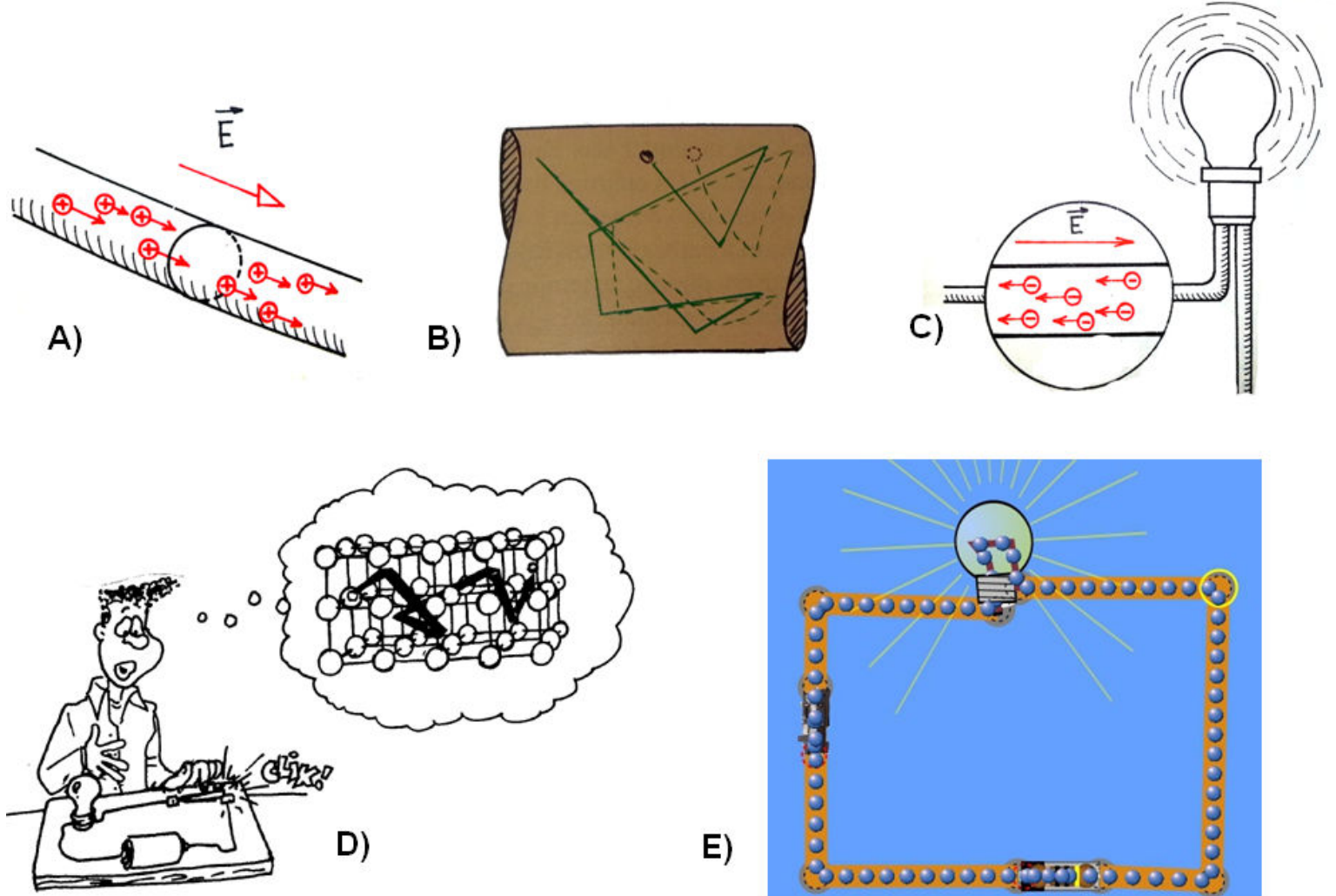

E)

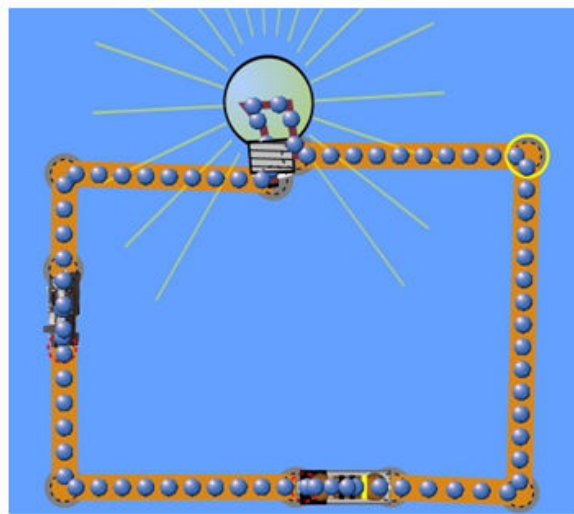

Figura $26^{3}$ - Representações do modelo clássico de corrente elétrica

Na primeira questão da Avaliação Diagnóstica 02, os alunos deveriam atribuir um conceito entre Ruim, Regular, Bom, Muito Bom e Excelente para cada uma das

${ }^{3}$ Fonte: Figura A: ALVARENGA, Beatriz G.; LUZ, Antônio Máximo R., Física, Volume 3,Editora Bernardo Alvares S.A.

Figura B: HEWITT, Paul G., Física Conceitual, 9ª Edição; tradução Triente Freire Ricci e Maria Helena Gravina, Artmed Editora S.A., 2002, Reimpressão 2007.

Figura C: ALVARENGA, Beatriz G.; LUZ, Antônio Máximo R., Física, Volume 3,Editora Bernardo Alvares S.A.

Figura D: Grupo de Reelaboração do Ensino de Físíca. Leituras de Física: GREF-Eletromagnetismo / Para ler, fazer e pensar 1 a 6 - Versão Preliminar, Disponível em http://www.if.usp.br/gref/eletro/eletro1.pdf , acesso em 29/10/12

Figura E: Animação PHET disponível em:_http://phet.colorado.edu/pt BR/simulation/circuitconstruction-kit-ac , acesso em 28/10/12. 
figuras que representam o modelo clássico de corrente elétrica, enquanto que na segunda questão eles deveriam escolher ao menos duas dessas figuras e comentar os motivos pelos quais atribui tal conceito, indicando: quais as limitações da representação para interpretação dos fenômenos, quais as vantagens e que concepções erradas a figura poderia induzir ao aluno. A Avaliação Diagnóstica 02 ainda apresentava um campo de "observação" indicando para os alunos que essa questão não apresentava "certos" ou "errados", que tinha natureza opinativa e que somente a justificativa/comentário sobre os conceitos para cada figura seria objeto de avaliação.

Participaram da Avaliação Diagnóstica 02, 91 alunos dos diferentes Pólos (Piracicaba, Ribeirão Preto, São Carlos e São Paulo) do curso de Licenciatura em Ciências, desses somente 79 responderam a primeira questão, sendo que 49 alunos eram do Pólo São Paulo e os outros 30 dos demais Pólos (Piracicaba, Ribeirão Preto e São Carlos). Os conceitos que foram atribuídos as 05 figuras pelos alunos dos diferentes Pólos, na resolução da primeira questão são apresentados nas tabelas 07 e 08 a seguir:

Tabela 7 - Questão 01 da avaliação diagnóstica 02 - Atribuição de conceito as figuras - Pólo São Paulo

\begin{tabular}{|c|c|c|c|c|c|}
\hline \multirow{2}{*}{ Conceito } & \multicolumn{5}{|c|}{ Figura (n. ${ }^{\circ}$ de votos por conceito) } \\
\cline { 2 - 6 } & A & B & \multicolumn{1}{|c|}{ C } & D & Eaulo \\
\hline Excelente & 03 & 01 & 04 & 01 & 15 \\
\hline Muito Bom & 02 & 01 & 09 & 11 & 11 \\
\hline Bom & 10 & 11 & 08 & 09 & 12 \\
\hline Regular & 10 & 06 & 11 & 12 & 08 \\
\hline Ruim & 24 & 30 & 17 & 16 & 03 \\
\hline
\end{tabular}


Tabela 8 - Questão 01 da avaliação diagnóstica 02 - Atribuição de conceitos - demais Pólos

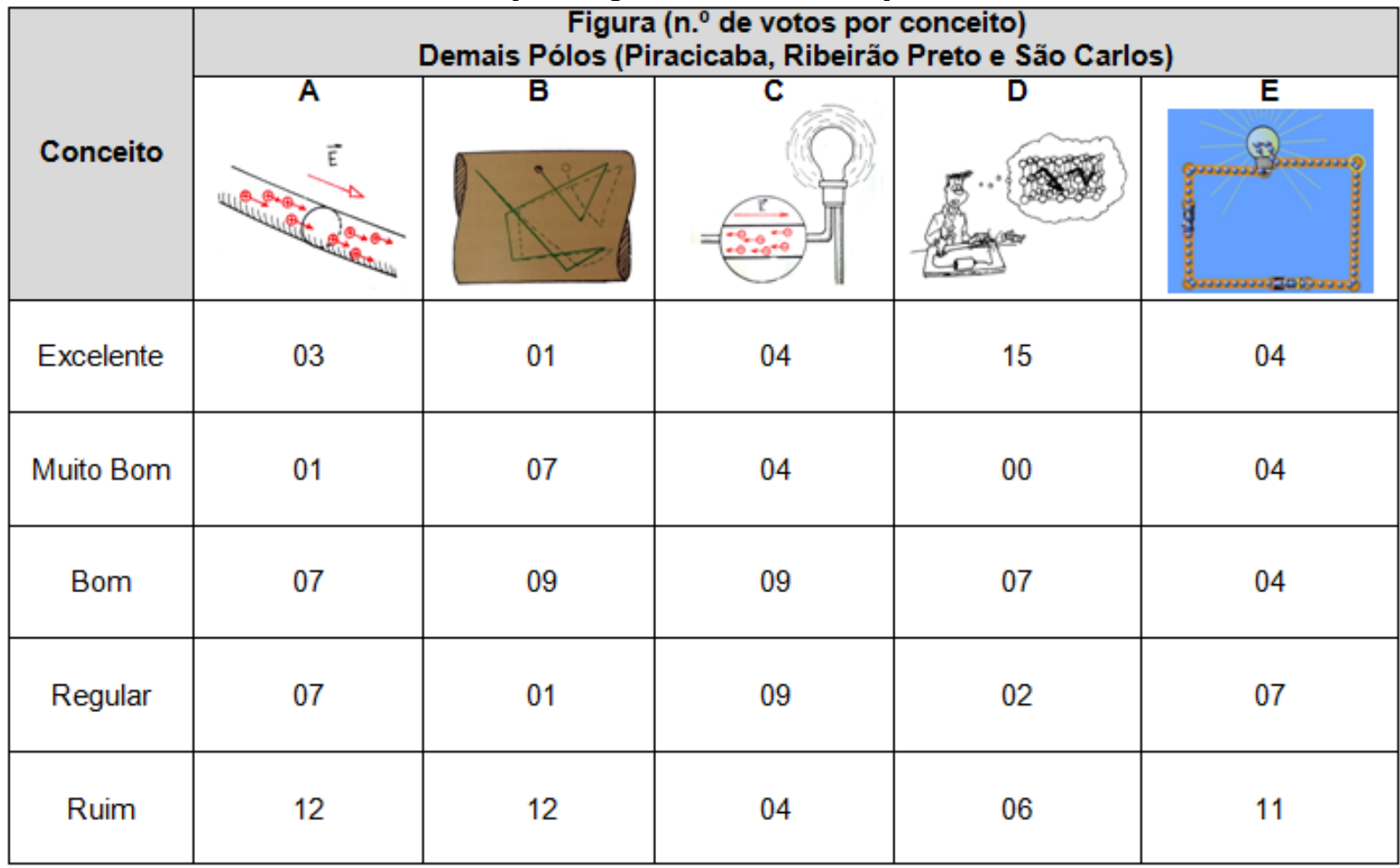

Pela tabela 07 podemos observar que a figura $E$ apresenta 15 votos para o conceito Excelente muito acima da figura $\mathrm{C}$, segunda mais pontuada, que para o mesmo conceito apresenta apenas 04 votos. Essas duas figuras, bem como a figura D apresentam votos bem distribuídos ao longo de todos os conceitos, diferente das figuras A e B que apresentam maior incidência de votos no conceito Ruim. Interessante analisar que as figuras $\mathrm{C}$ e $\mathrm{E}$ apresentam em seu circuito uma lâmpada acesa o que pode ter influenciado os votos dos alunos nos conceitos Bom, Muito Bom e Excelente pelo fato de ter sido realizada uma atividade no Pólo São Paulo em que os alunos precisavam desenhar um circuito contendo uma lâmpada.

A tabela 08 apresenta a figura D com 15 votos para o conceito Excelente, muito diferente do que ocorreu no Pólo São Paulo, onde essa figura recebeu apenas 01 voto para esse conceito. Em contrapartida, as figuras A, B e E apresentam em média 12 votos para o conceito Ruim. Interessante também comparar o resultado da figura E com o Pólo São Paulo, pois enquanto nos demais Pólos (Piracicaba, Ribeirão Preto e São Carlos) essa figura teve baixa conceituação, conceito Ruim, em São Paulo foi a figura com conceituação mais elevada, conceito Excelente. Essa diferença pode estar relacionada com os exemplos utilizados pelos professores que 
aplicaram as aulas presenciais, contudo, não se pode afirmar nada a esse respeito pois não foram acompanhadas as aulas nos demais pólos.

Para entender melhor a conceituação dada para cada figura é preciso analisar as justificativas apresentadas pelos alunos na segunda questão da Avaliação Diagnóstica 02. Conforme dito anteriormente, na segunda questão, os alunos deveriam escolher duas ou mais figuras as quais havia aplicado os critérios de conceituação (Ruim, Regular, Bom, Muito Bom e Excelente) e justificar os motivos por ter atribuído tal conceito a elas, apresentando quais as vantagens, as limitações e as concepções erradas ou confusões que essas imagens poderiam induzir ao aluno. Assim para analisar essas justificativas foram criados 4 critérios de pontuação, baseados em como o aluno relacionou as figuras com o conceito de corrente elétrica e com o modelo de Drude. São eles:

0 pontos - Quando não há relação nenhuma das figuras com os conceito-modelo.

Exemplo de justificativa: "(Figura A)...na figura fica muito fácil de identificar a corrente elétrica é de fácil explicação e os aprendizes conseguiram entender"

1 pontos - Quando a relação das figuras com o conceito-modelo é superficial ou apresenta deficiências conceituais.

Exemplo de justificativa: "A letra (figura) $C$ representa bem que o fluxo dos elétrons de dá no sentido contrário do campo elétrico. Com esta ilustração, fica claro este conceito, acreditando eu que o aluno compreenda perfeitamente que o sentido do fluxo da corrente elétrica é oposto ao campo elétrico."

2 pontos - Quando a relação das figuras explora características do conceito (corrente elétrica) sem explorar aspectos do modelo (modelo de Drude) e vice-versa. Exemplo de justificativa: "(Figura D) $O$ exemplo desta imagem é interessante no sentido do aluno imaginar uma rede cristalina de átomos e os elétrons, mesmo sem ter uma corrente elétrica, estarem em movimento. Porém, a desvantagem é o aluno pensar que os elétrons empurram uns os outros, sendo que eles se movimentam todos ao mesmo tempo. Além de imaginarem que os elétrons podem ser do mesmo tamanho que os átomos." 
3 pontos - Quando relaciona as figuras com características presentes no conceito e no modelo.

Exemplo: "A opção (figura) $C$ demonstra a corrente como movimento de cargas negativas em oposição ao campo elétrico, faltando enfatizar que este movimento é dos elétrons livres dentro da estrutura cristalina do metal condutor e não ocorre de maneira linear como representado, mas com os elétrons colidindo entre si, com os núcleos fixos e as paredes do condutor de forma que a corrente só se estabeleça na presença de uma diferença de potencial suficiente para superar estas resistências, que também causa um aquecimento do condutor e não só o aquecimento da lâmpada."

Dos 91 alunos dos distintos pólos, apenas 71 responderam a segunda questão da Avaliação-Diagnóstica 02, sendo 44 alunos do Pólo São Paulo e 27 alunos dos demais Pólos (Piracicaba, Ribeirão Preto e São Carlos). As tabelas 09 e 10 apresentam respectivamente a pontuação obtida pelos alunos do Pólo São Paulo e dos demais Pólos, de acordo com as justificativas apresentadas na resolução da segunda questão:

Tabela 9 - $2^{\mathrm{a}}$ Questão da avaliação diagnóstica 02 - Pólo São Paulo

\begin{tabular}{|c|c|c|c|c|}
\hline & \multicolumn{5}{|c|}{ N. de pontos na $\mathbf{2}^{\circ}$ questão da Avaliação Diagnóstica 02} \\
& $\mathbf{0}$ & $\mathbf{1}$ & $\mathbf{2}$ & $\mathbf{3}$ \\
\hline $\begin{array}{c}\text { N. de alunos } \\
\text { por pontuação }\end{array}$ & 09 & 08 & 17 & 10 \\
\hline
\end{tabular}

Tabela 10 - 2 ${ }^{\text {a }}$ Questão da avaliação diagnóstica 02 - Demais Pólos

\begin{tabular}{|c|c|c|c|c|}
\hline & \multicolumn{5}{|c|}{$\begin{array}{c}\text { N. de pontos na 2 } \\
\text { Alunos demais Pólos (Piracicaba, Ribeirão Preto e São Carlos) }\end{array}$} \\
\cline { 2 - 5 } & $\mathbf{0}$ & $\mathbf{1}$ & $\mathbf{2}$ & $\mathbf{3}$ \\
\hline $\begin{array}{c}\text { N. de alunos } \\
\text { por pontuação }\end{array}$ & 07 & 06 & 08 & 06 \\
\hline
\end{tabular}

Pelas Tabelas 09 e 10 pode-se observar que o percentual para alunos que obtiveram 03 pontos com suas justificativas é muito próximo, sendo 22,73\% para São Paulo e $22,22 \%$ para os demais Pólos. Se levarmos em consideração os 
percentuais associados à soma de alunos que obtiveram 02 e 03 pontos, o Pólo São Paulo leva ligeira vantagem com 61,36 \% enquanto os demais Pólos apresentam $51,85 \%$. Tendo em vista que as pontuações obtidas na questão 02 referem-se a justificativas apresentadas pelos alunos para conceituação das figuras da questão 01 e que essas justificativas deveriam estar pautadas nas características do conceito de corrente elétrica e do modelo de Drude, pode-se supor que a diferença entre os percentuais apresentados pelo Pólo São Paulo em relação aos demais Pólos, para acertos de 02 e 03 pontos, além de estar associado à ação de cada professor que aplicou a aula presencial, possa estar relacionada ao uso da RA, utilizada a princípio apenas no Pólo São Paulo.

Como essa tecnologia evidenciou características tanto do conceito de corrente elétrica, quanto do modelo de Drude, ela pode ter auxiliado os alunos do Pólo São Paulo na compreensão do fenômeno o que os permitiria maior respaldo para justificar os conceitos dados as figuras na questão 01 da Avaliação-Diagnóstica 02. Ressalte-se que para avaliar esses dados considerou-se somente a intervenção de RA promovida no Pólo São Paulo, todavia o fato dessa ferramenta ter sido disponibilizada no AVA tornou possível que tanto alunos quanto outros professores tenham feito uso dela, mas nada se pode afirmar a esse respeito.

Ainda em relação aos alunos do Pólo São Paulo, se comparadas à carga conceitual das justificativas apresentadas na Avaliação Diagnóstica 01 e 02 (questão 02) veremos que o uso das características do modelo de Drude, principalmente os choques dos elétrons contra os íons fixos da estrutura cristalina é mais predominante na Avaliação-Diagnóstica 02 do que na Avaliação Diagnóstica 01 onde maior ênfase foi dada pelos alunos no deslocamento dos elétrons como um fluxo, ordenado ou desordenado, quase sem citar a estrutura cristalina em suas justificativas. Isso pode sugerir que o uso da RA permitiu aos alunos uma ampliação de sua bagagem conceitual a respeito do conceito de corrente elétrica e do modelo de Drude permitindo justificativas mais precisas e que contemplam maior número de características desses modelos científicos, mas nada se pode afirmar a esse respeito.

Na Avaliação-Diagnóstica 03 os alunos eram convidados a visitar o site Wikipédia (WIKIPEDIA, 2013) para observar a definição de corrente elétrica: 
"A corrente elétrica (AO 1945: corrente eléctrica) é o fluxo ordenado de partículas portadoras de carga elétrica, ou também, é o deslocamento de cargas dentro de um condutor, quando existe uma diferença de potencial elétrico entre as extremidades. Tal deslocamento procura restabelecer o equilíbrio desfeito pela ação de um campo elétrico ou outros meios (reação química, atrito, luz, etc.)2 .

Sabe-se que, microscopicamente, as cargas livres estão em movimento aleatório devido à agitação térmica. Apesar desse movimento desordenado, ao estabelecermos um campo elétrico na região das cargas, verifica-se um movimento ordenado que se apresenta superposto ao primeiro. Esse movimento recebe o nome de movimento de deriva das cargas livres." (WIKIPEDIA, 2013, grifo nosso)

O objetivo dessa avaliação era saber de que forma os alunos poderiam contribuir para melhorar a definição de corrente elétrica da Wikipédia. Que termo(s) estaria(am) impreciso(s) ou errado(s) na definição? Por que estaria(am) errado(s)? Como você o(s) substituiria?

Os alunos eram instruídos nessa Avaliação-Diagnóstica 03 a não dar uma nova definição para corrente elétrica, mas apenas dialogar a partir da definição apresentada na Wikipédia, indicando o que devia ser melhorado e por quê.

Essa avaliação foi aplicada a 83 alunos dos distintos Pólos (Piracicaba, Ribeirão Preto, São Carlos e São Paulo) do curso de Licenciatura em Ciências, contudo por ser essa uma avaliação de natureza complementar, ou seja, não valia nota, seu índice de resolução foi baixo. Participaram dessa Avaliação-Diagnóstica 03, 35 alunos do Pólo São Paulo e 16 alunos dos demais Pólos (Piracicaba, Ribeirão Preto e São Carlos).

Esperava-se nessa avaliação que os alunos observassem que o termo "fluxo ordenado" na definição de corrente elétrica pode soar impreciso, pois, causa a falsa impressão que os elétrons se deslocam em "linha reta" pelo condutor, sem que haja choques com os íons fixos da estrutura cristalina, como prevê o modelo de Drude.

Tendo isso em consideração, apresentamos algumas frases dos alunos que foram consideradas adequadas para essa avaliação: 
Frase 01: "Eu diria que não é bem um fluxo "ordenado" de partículas, já que os elétrons vão colidindo um aos outros, embora realmente estejam, como um todo, caminhando em direção ao outro pólo vagarosamente."

Frase 2: "O termo ordenado não condiz com o movimento real das cargas no interior do condutor elétrico. Esta semana estudamos sobre o assunto, e podemos observar que as cargas estão em agitação aleatória, mas que todas elas sofrem atração simultânea do campo magnético, que pode induzir o uso incorreto do termo "ordenado"

Frase 3: "Que o caminho do elétrons pelo condutor é tortuoso, sofrendo varias colisões.entre eles e também pela sua malha cristalina, que esse movimento produz energia térmica, e que esse aquecimento dependerá do material e de como ele esta sendo usado dentro de um circuito."

A seguir apresentamos exemplo de frases formuladas pelos alunos que foram consideradas inadequadas:

Frase 1: "Acho que esta bem definida, não encontrei erro ou imprecisão no texto do wiki."

Frase 2: "colocaria que é movimento ordenado de cargas elétricas através de um condutor elétrico"

Frase 3: "Para mim, fluxo ordenado de partículas não é corrente elétrica, as partículas não se movimentam, o que se movimenta é a carga elétrica. Os elétrons deveriam estar melhor explicado, como ocorre o DDP, parece-me na explicação do Wikipédia, que deslocamento é uma energia em vez de resultado da força."

Dos 35 alunos do Pólo São Paulo, apenas 09 se manifestaram em relação ao termo "fluxo ordenado" como se esperava, tendo como principal crítica a esse termo a existência do movimento de origem térmica que não torna o fluxo de elétrons tão ordenado. A mesma manifestação foi apresenta por 04 alunos dentre os 16 que 
representavam os demais Pólos (Piracicaba, Ribeirão Preto e São Carlos). Em ambos os casos esses alunos representam $25 \%$ do total de alunos por Pólos (Pólo São Paulo e demais Pólos) que realizaram a avaliação.

As outras frases dos alunos a respeito do texto da Wikipédia não propunham alterações em relação ao termo "fluxo ordenado", mas sim a outras características da corrente elétrica como diferença de potencial, orientação da corrente, entre outras que não eram objeto dessa avaliação.

O fato do percentual de frases consideradas corretas para Avaliação - Diagnostica 03 ser igual para o Pólo São Paulo e demais Pólos (Piracicaba, Ribeirão Preto e São Carlos) não permite aferir se o uso da Realidade Aumentada foi determinante para que os alunos do Pólo São Paulo propusessem alterações no texto do Wikipédia. O que se pode observar é que as frases desses alunos, na maioria, indicavam que os elétrons se chocavam com a estrutura cristalina do condutor quando se deslocavam devido a um campo elétrico aplicado, algo que foi possível observar no objeto virtual que representava o modelo de Drude.

Apenas uma aluna fez menção ao uso da Realidade Aumentada quando de sua resposta à Avaliação-Diagnóstica 03 , mesmo não propondo alteração ao texto da Wikipédia:

"Confesso que antes da última aula de eletromagnetismo aonde vimos àquela simulação dos elétrons passando pelo condutor, eu iria ler essa definição de corrente elétrica e provavelmente nem entenderia. Porém após aquela aula, a qual me empolgou achando que realmente estava vendo os elétrons, fica difícil dar outra definição e ou até mesmo corrigir algum ponto, pois quando leio a definição é como se realmente estivesse vendo os elétrons em movimento, com aquela ultra velocidade, ultra quantidade de partículas, enfim. Estendendo-se não só naquele circuito como também na queda do raio, ao ligar uma tomada, etc. Nesse momento não consigo visualizar alterações necessárias ao texto do wiki"

A aplicação de RA (REALIDADE AUMENTADA CEPA, 2013) utilizada na aula presencial dos alunos do Pólo São Paulo foi disponibilizada no Ambiente Virtual de Aprendizagem - AVA para uso dos alunos e foi acessada por 32 de 129 dos 
diferentes Pólos. Infelizmente, não temos como saber quantos destes alunos conseguiram de fato usar essa tecnologia. 


\section{CONSIDERAÇÕES FINAIS}

O uso das TICs no ensino é uma alternativa de enriquecimento do diálogo entre o professor e o aluno, que vai além da oralidade, da escrita e dos habituais livrostextos.

Para além das políticas públicas no Brasil que desde a década de 80 vem incentivando a produção e o uso pedagógico das TICs, cabe especialmente aos professores preocupados em buscar formas de otimizar o acesso dos alunos ao conhecimento, encontrar quais dessas TICs são mais adequadas e adaptadas para uso em sala de aula.

No ensino de Física as TICs podem dinamizar a compreensão dos fenômenos físicos, indo além das gravuras estáticas presentes nos livros didáticos. Um exemplo disso são as simulações, que permitem ao aluno visualizar a representação de fenômenos de difícil compreensão, podendo inclusive por meio dessas, encontrar relações entre as variáveis que regem e determinam sua evolução. A Realidade Aumentada, como ferramenta de simulação em três dimensões, pode ser utilizada no Ensino de Física com esse intuito, com o diferencial que pode apresentar a simulação de um fenômeno físico, vinculada a um ambiente real onde esse fenômeno ocorre.

Nessa dissertação investigaram-se as possibilidades de implantação da RA no ensino de Física, averiguando: se escolas públicas e alunos licenciandos em Ciências possuem infraestrutura tecnológica mínima para sua utilização; se é possível para um professor "típico", sem conhecimento em programação construir as simulações que serão utilizadas em Realidade Aumentada; o processo de desenvolvimento e customização de simulações para Realidade Aumentada, por meio de uma equipe formada por professores de Física e programadores; a aplicação dessa simulação, desenvolvida para RA, em uma intervenção em sala de aula, para alunos de Licenciatura em Ciências da USP/UNIVESP, visando analisar se essa ferramenta tecnológica contribui para melhor interpretação dos conceitos que regem modelos científicos complexos de difícil compreensão. Como considerações finais deste trabalho são apresentados os seguintes aspectos:

Para analisar a infraestrutura tecnológica necessária para uso da RA no ensino de Física, estabeleceu-se como critério que os requisitos mínimos são um computador 
de custo popular (desktop ou notebook), uma webcam, um monitor de vídeo (no caso de um desktop), um software de RA e uma simulação que represente um modelo científico que se pretenda estudar. Considerou-se também que o acesso a Internet é vital para as aplicações da RA afim de que se possa obter e disponibilizar objetos virtuais em repositórios virtuais e na veiculação de aplicações de RA que possam ser executadas em um navegador que possua os plugins adequados.

As pesquisas investigadas nessa dissertação (FUNDAÇÃO VICTOR CIVITA, 2010; CGI.br, 2014), apontam que as escolas públicas, avaliadas no período de 2007 a 2013, possuem os requisitos mínimos para uso da RA, contando com a presença de computadores e Internet, restando providenciar a aquisição de webcam, que é um dispositivo periférico de baixo a médio custo. Isso não significa que as condições de infraestrutura tecnológica nas escolas sejam satisfatórias para atender a demanda de alunos, mas somente que a limitação de não haver equipamentos em quantidade suficiente para uso individualizado, graças à alta a proporção de alunos por computador, não será considerada um empecilho para uso da RA, uma vez que essa tecnologia possui um sistema de visão baseado em monitor, que permite a observação concomitante por diversos alunos. Tal sistema de visão pode ainda ser otimizado se a saída de vídeo do computador for conectada a um projetor com telão, o que maximizará a visão da simulação.

Com relação aos softwares de RA, considera-se que esses não são fatores limitantes para uso dessa tecnologia, uma vez que existem diversos deles com disponibilidade gratuita, como é o caso do ArtoolKit e suas variações, sendo que alguns ainda permitem o uso da RA diretamente no próprio computador, sem necessitar da Internet. Isso diminui o impacto da Internet como fator limitante para uso da RA, uma vez que apenas $55 \%$ das escolas possui velocidade de conexão de até $2 \mathrm{Mbps}$, o que dificulta a veiculação dessa tecnologia.

Um fator que avaliado como limitante para o uso da RA nas escolas é a falta de preparo por parte dos professores para utilização das TICs que os leva a buscar diversas formas de aprender a usar o computador e a Internet, seja por meio de cursos específicos ou por si mesmos. Um possível efeito decorrente dessa falta de preparo para uso da TICs no ensino é a predominância de uso de programas de computador de baixa complexidade, como editores de texto ou de apresentação, que contrasta com a baixa incidência do uso de softwares de programação, 
modelagem 3D e simulações seja no uso exclusivo dos professores, seja no uso entre professores e alunos.

Para modificar esse quadro será necessário repensar a formação inicial e continuada de professores, fornecendo acesso e capacitação constante para uso das TICs, uma vez que essas tecnologias estão em incessante aperfeiçoamento, inclusive a RA. Embora insistamos na capacitação dos professores para uso das TICs entendemos que o professor é um profissional do ensino e não um desenvolvedor/programador profissional, todavia, ao não encontrar material didático apropriado para alguma atividade de ensino que pretenda abordar em sala de aula, pode o professor, desde que devidamente qualificado, desenvolver seu próprio material e disponibilizá-lo para outros professores.

Um fator positivo apresentado nas pesquisas e que tem especial relevância neste estudo para aplicação de RA é tendência de professores estarem levando seus notebooks para escola para, na maioria das vezes, utilizá-lo em atividades na sala de aula. Essa tendência é conhecida como Bring Your Own Device - BYOD (NMC, 2015) e favorece o uso da RA, uma vez que os notebooks possuem webcam nativa, restando ao professor apenas obter um software de RA e uma simulação adequada para finalidade pretendida.

As investigações acerca da infraestrutura tecnológica possibilitaram constatar que os alunos do Curso de Licenciatura em Ciências da USP/UNIVESP também possuem aparato tecnológico mínima para uso da RA, confirmando as conclusões baseadas nas pesquisas em larga escala mencionada acima.

Esses alunos, futuros professores que utilizarão essas novas tecnologias, possuem computadores (desktops e/ou notebooks), acesso à Internet, bem como smartphones. Nessa dissertação utilizou-se a RA por meio de um notebook com webcam, mas espera-se que no futuro essa tecnologia seja implementada por meio de plataformas móveis, como smartphones. Esse dispositivo possui diversas vantagens para uso da RA pelo fato de possuir webcam nativa, que associada a sua facilidade de manuseio, permite utilizar aplicativos de RA em qualquer lugar, até mesmo em sala de aula, bastando na maioria das vezes ter acesso a Internet.

Os smartphones dispõem de uma diversidade de programas, comumente chamados de aplicativos ou app, que são desenvolvidos para inúmeras finalidades, entre elas as acadêmicas; todavia, pelos dados obtidos na investigação com alunos do CLC, ainda é minoritário o uso desse dispositivo para esses fins, seja por falta de 
conhecimento do aluno, seja por falta de indicação dos professores. O mesmo vale para aplicativos de RA desenvolvidos para smartphones. Esse estudo aponta que menos de $20 \%$ dos alunos entrevistados do CLC conhecem a RA, e desses, apenas $16 \%$ disseram ter utilizado algum aplicativo de RA para smartphone. Considera-se, portanto, que o desconhecimento da RA decorra do fato de ser uma tecnologia relativamente nova que vem aos poucos se disseminando nos diversos segmentos sociais, tendo a princípio maior aplicação na propaganda. Além disso, o fato da RA estar presente nos smartphones poderá contribuir para sua popularização, dada a disseminação desses dispositivos na sociedade.

Vale ressaltar que existem inúmeros aplicativos de RA para smartphones, específicos para cada sistema operacional (Android, IOS, Windows Phone, entre outros). Alguns desses aplicativos, como o Layar, não necessitam de marcador a ser rastreado pela câmera, o que gera maior liberdade para o usuário, aumentando sua sensação de imersão quando do uso dessa tecnologia. Em suma, considera-se neste trabalho que os smartphones serão grandes aliados no uso da RA no ensino, permitindo que alunos tenham acesso a essa tecnologia dentro e fora da sala de aula, entretanto, para que isso ocorra será necessário que as aplicações de RA sejam devidamente disponibilizadas na Internet e, acima de tudo, que seja repensado o uso desse dispositivo em atividades de ensino e aprendizagem, uma vez que existem leis ou decretos estaduais que regulamentam o uso desse equipamento nos ambientes escolares.

A investigação da infraestrutura tecnológica dos alunos do CLC permitiu também avaliar a fluência tecnológica desse público, ou melhor, o nível de conhecimento que esses alunos possuem sobre softwares, recursos da Internet, sistemas operacionais, entre outros. Foi constatado que os entrevistados informaram possuir "muito" conhecimento sobre editores de texto, email e programas de busca, enquanto consideraram como "nada" ou "pouco" o que sabem sobre linguagem de programação e simulações.

A falta de conhecimento de linguagens de programação tem implicações no uso da RA, principalmente quando se pretende criar ou customizar uma simulação que representará um modelo científico. Essa conclusão foi alcançada na investigação quanto às dificuldades que um professor "típico", sem conhecimento em programação, se depara nesse processo de criação. Os softwares gratuitos e proprietários de modelagem em 3D que foram utilizados neste estudo permitiram 
concluir que a elaboração de simulações necessita de conhecimento avançados em programação, principalmente quando se pretende representar o mais fielmente possível os modelos científicos, o que requer o desenvolvimento de simulações animadas. Tais simulações conseguem mostrar mais adequadamente os conceitos que regem um modelo científico, seja por apresentar seus movimentos, suas interações, seus vetores, em suma sua evolução, algo que não se pode obter através de simulações estáticas. Não se pode negar, entretanto, que os softwares de modelagem 3D, por possuírem objetos virtuais predefinidos (esferas, cubos, pirâmides, tubos, entre outros), permitem que professores sem conhecimento em programação possam criar modelos científicos mais simples, como por exemplo a representação das forças que agem sobre um corpo; nesse caso é possível utilizar umas dessas formas predefinidas e introduzir vetores nas direções e sentidos apropriados, sem necessidade de imprimir movimento, ou seja animação, contudo o mesmo não se pode dizer para modelos científicos mais complexos, como é o caso do Modelo de Drude. Nesse sentido as simulações animadas minimizam um possível reducionismo na representação do fenômeno físico, o que pode gerar implicações na sua efetiva compreensão.

As dificuldades para criar ou customizar simulações de RA podem levar o professor sem conhecimento em programação a duas alternativas: buscá-las em repositórios virtuais na Internet, como objetos de aprendizagem; ou recorrer a programadores profissionais.

Pelo fato da RA ser uma tecnologia relativamente nova ainda é difícil encontrar simulações em formato compatível nos repositórios virtuais, assim a alternativa mais viável será recorrer a programadores, e nesse caso será necessária a presença do professor durante o processo de criação ou customização para orientar sobre os aspectos conceituais do modelo científico que deverão ser considerados.

Nesse processo conjunto, envolvendo professores e programadores, há que se considerar o tempo destinado a criação da simulação, que pode variar dependendo da complexidade do modelo científico, e eventuais custos decorrentes da contratação desses profissionais, caso não seja possível obter esse serviço especializado de forma gratuita. Nesse sentido, espera-se que no futuro haja maior compartilhamento dessas simulações de RA, o que possibilitará que mais professores façam uso dessa tecnologia. 
No tocante a utilização da RA no ensino de Física, constatou-se na intervenção aplicada em uma aula presencial aos alunos do CLC da USP/UNIVESP, que essa tecnologia não era conhecida pela grande maioria, situação essa concordante com a enquete veiculada junto ao AVA. Observou-se ainda que a RA atraiu a atenção dos alunos e aparentemente os motivou a explorar o objeto virtual.

Ressalta-se que nesse processo de aplicação da RA é importante a presença dos professores, pois na utilização dessas novas tecnologias não é raro os alunos associarem a representação como o fenômeno em si, algo que ocorreu em nossa intervenção, quando alguns alunos questionaram se o que estavam observando era realmente o interior do fio condutor.

As atividades desenvolvidas em sala de aula, antes e até mesmo durante a intervenção com RA, permitiu constatar que a maioria dos alunos associa a corrente elétrica a um fluído, ordenado ou desordenado, sem fazer menção à estrutura cristalina na qual colidem os elétrons livres. Em contrapartida, observou-se que na avaliação diagnóstica 02, que as repostas da maioria dos alunos do Pólo São Paulo, para escolha das figuras que melhor representavam o modelo clássico de corrente elétrica continham elementos característicos do modelo de Drude, como por exemplo, elétrons em movimento se chocando contra os íons fixos da estrutura cristalina. A princípio, isso poderia sugerir que o uso da RA possibilitou uma melhor compreensão do modelo científico estudado, nesse caso o Modelo de Drude. Considerando isso a hipótese apresentada de que a RA pode atuar como um signo (VIGOSTKY, 2007) que media o acesso do aluno ao modelo científico se confirmaria; todavia, uma vez que esses dados são provenientes de única intervenção e podem existir ruídos que não foram devidamente considerados na análise dos resultados, considera-se prematura qualquer afirmação a esse respeito, logo, recomenda-se realizar novas investigações para avaliar se o uso da RA pode realmente auxiliar na compreensão de modelos científicos complexos.

Em um panorama geral, considera-se ser viável e possível o uso da RA no ensino de Física, tendo em vista que as escolas e professores dispõem de infraestrutura tecnológica mínima para sua aplicação; todavia, ficou claro que uma barreira no uso dessa tecnologia foi a dificuldade de desenvolvimento de objetos virtuais que simulam modelos científicos, por parte dos professores conforme investigações realizadas neste trabalho. 
Verificou-se também neste trabalho que a RA está evoluindo de maneira oposta a outros softwares ou recursos da Internet que possuem uso quase universalizado, como é o caso de editores de texto e emails que quando surgiram só eram utilizados em sua plenitude por usuários experientes e hoje se tornaram tão acessíveis e fáceis de usar que a grande maioria da população é capaz de fazer uso da totalidade de seus recursos. A investigação realizada aponta que a RA tende para um desenvolvimento profissionalizado, estando presente em projetos de grandes empresas, como é o caso da Nintendo (NINTENDO, 2015) que desenvolve jogos com essa tecnologia, e a Google que equipa seu dispositivo Google Glass (GLOBO, 2015) com RA, entre outras.

Se por um lado, o desenvolvimento profissional usando uma equipe de especialistas vai resultar em objetos de aprendizagem de alta qualidade e o custo alto deste tipo de desenvolvimento justifica a sua disponibilização em repositórios de objetos de aprendizagem, por outro lado, a experiência relatada nesta dissertação coloca dúvidas acerca da possibilidade real de um professor "típico" desenvolver aplicações para RA, seja agora ou num futuro próximo.

Assim, a conclusão obtida a respeito do desenvolvimento de objetos virtuais é que a dificuldade na sua criação e customização coloca o professor numa condição de usuário dessa tecnologia e não como agente ativo na sua produção ou contextualização para sala de aula.

Por fim, acreditamos que seja necessário pensar em outras formas de aplicar a RA no ensino de Física, como por exemplo, fomentando seu uso em livros-texto de forma a permitir a visualização de gravuras, gráficos, modelos científicos, entre outros, sempre buscando formas de mediar, da melhor maneira possível, o acesso do aluno ao conhecimento científico. 


\section{BIBLIOGRAFIA ${ }^{4}$}

ALVES-MAZZOTTI, A. J. O planejamento de pesquisas qualitativas em Educação. Cadernos de Pesquisa (Fundação Carlos Chagas. Impresso), São Paulo, v. 77.Maio, p. 53-61, 1991

APPLE STORE, SunSeeker: 3D Augmented Reality Viewer, by ozPDA, 2015. Disponível em <https://itunes.apple.com/br/app/sun-seeker-3d-augmented reality/id330247123?mt=8>. Acesso em 14 de março de 2015.

ARIADNE Foundation. Disponível em <http://www.ariadne-eu.org > Acesso em 26042013.

ARTOOLKIT (2013) Software disponível em: http://www.hitl.washington.edu/artoolkit/ Acesso em 15 de junho de 2013

AURASMA, 2015. Software disponível em < http://www.aurasma.com/> Acesso em janeiro 2015

AZUMA, R. A Survey of Augmented Reality, In Presence: Teleoperators and Virtual Environments vol. 6, no. 4, Aug. 1997, pp. 355-385.

AZUMA, R.; BAILLOT, Y.; BEHRINGER, R.; FEINER, S.; JULIER, S.; MACINTYRE, B. Recent Advances in Augmented Reality. IEEE Computer Graphics and Applications 21, 6 (Nov/Dec 2001), 34-47

BELLONI, M. L. Educação à distância. São Paulo: Editores Associados, 1999.

BIBLIOTECA DIGITAL DE CIÊNCIAS, Biblioteca Digital de Ciências Website - Unicamp. Disponível em <http://www. Ite.ib.unicamp.br/bdc/index.php >. Acesso em 26042013.

BILLINGHURST, M.; KATO, H.; POUPYREV, I. I. The MagicBook - Moving Seamlessly between Reality and Virtuality. IEEE Computer Graphics \& Applications, v. 21 , n. 3 , p. $6-8,2001$

\footnotetext{
${ }^{4}$ De acordo com a Associação Brasileira de Normas Técnicas. NBR 6023.
} 
BOGDAN, R.C.; BIKLEN, S.K. Dados Qualitativos. In BOGDAN, R.C.; BIKLEN, S.K. Investigação qualitativa em educação - uma introdução à teorias e aos métodos. Porto: Porto Editora, 1994. P.147- 202.

BRASIL, MEC. Secretaria de Educação Média e Tecnológica. PCN+ Ensino Médio: orientações educacionais complementares aos Parâmetros Curriculares Nacionais. Ciências da Natureza, Matemática e suas Tecnologias. Brasília: MEC, SEMTEC, 2002. 144p.

BRASIL. Cartilhas Projeto UCA: Projeto UCA. Brasília: MEC, 2010

BRASIL. DECRETO № 6.300, DE 12 DE DEZEMBRO DE 2007. Diário Oficial [da] República Federativa do Brasil, Poder Executivo. Disponível em <http://www.planalto.gov.br/ccivil_03/_Ato2007-010/2007/Decreto/D6300.htm>. Acesso em 19 de maio de 2013.

BRASIL. Informática Educativa: plano de ação integrada. Secretaria Nacional de Educação Tecnológica. Brasília: MEC, 1991.

BRASIL. LEI No 12.249, DE 11 DE JUNHO DE 2010. Presidência da República. Brasília. Disponível em <http://www.planalto.gov.br/ccivil_03/_Ato2007 2010/2010/Lei/L12249.htm> Acesso em 19 de maio de 2013.

BRASIL. MEC/INEP. Relatório Nacional Pisa 2012: Resultados Brasileiros. Disponível em: <http://download.inep.gov.br/acoes_internacionais/pisa/resultados/2014/relatorio_nacion al_pisa_2012_resultados_brasileiros.pdf>. Acesso em: 20 nov 2014.

BRASIL. Ministério da Educação e do Desporto. Secretaria de Educação a Distância. Programa Nacional de Informática na Educação: Prolnfo: diretrizes. Brasília, DF, 1997a.

Disponível

em:

<http://www.dominiopublico.gov.br/download/texto/me001166.pdf>. Acesso em: maio. 2013

BRASIL. Ministério da Educação. Programa Banda Larga nas Escolas. Disponível em $<$

http://portal.mec.gov.br/index.php?option=com content\&view=article\&id=15808:program a-banda-larga-nas-escolas\&catid=193:seed-educacao-a-distancia>. Acesso em 20 de novembro de 2014.

BRASIL. Secretaria de Educação Fundamental. Parâmetros curriculares nacionais: introdução aos parâmetros curriculares nacionais / Secretaria de Educação Fundamental. - Brasília: MEC/SEF, 1997. 126p. 
BRASIL. Secretaria de Educação Média e Tecnológica. Programa Nacional de informática educativa/MEC/ SEMTEC.-Brasília: PRONINFE, 1994 39p.

CAMARGO, C. A. X.; RAIMANN, E.; CAMARGO, V. A. X.; CUNHA, I. T.; RIBEIRO, M; W. S. Aplicações de Realidade Aumentada para Ensino de Física no Instituto Federal de Educação, Ciência e Tecnologia de Goiás - Campus Jataí. UFMG, 2010. Disponível em <http://www.lbd.dcc.ufmg.br/colecoes/wrva/2010/0029.pdf>. Acesso em 22/06/13.

CARDOSO, A.; LAMOUNIER, J.; EDGARD, A. Realidade Virtual na Educação e Treinamento. In:TORI, Romero; KIRNER, Cláudio. (Org.). Realidade Virtual - Conceitos e Tendências. $1^{\text {a }}$. ed. São Paulo - SP, 2004, v. 01, p. 259-265.

CASTELLS, M. A Era da Informação: Economia, Sociedade e Cultura. Vol. 1 A Sociedade em Rede. São Paulo: Paz e Terra, 2000.

CGI, 2014. Pesquisa sobre o uso das tecnologias de informação e comunicação nas escolas brasileiras: TIC Educação 2013 [livro eletrônico] = Survey on the use of information and communication technologies in brazilians schools : ICT Education 2013 / [coordenação executiva e editorial/ executive and editorial coordination, Alexandre F. Barbosa / tradução / translation DB Comunicação ]. - - 1. ed. - - São Paulo : Comitê Gestor da Internet no Brasil, 2014.

CONAE (CONFERÊNCIA NACIONAL DE EDUCAÇÃO). Brasília, DF. Construindo o Sistema Nacional articulado de Educação: o Plano Nacional de Educação, diretrizes e estratégias; Documento Final. Brasília, DF: MEC, 2010b. 164p. Disponível

em:

<http://conae.mec.gov.br/images/stories/pdf/pdf/documetos/documento final.pdf>

Acesso em maio 2013.

DONZELLI, T. M.; TOMAZELLO, M. G. C. A utilização da Realidade Virtual no Ensino de Conceitos de Física. $4^{a}$ Mostra Acadêmica UNIMEP, 2006.Disponível em $<$ http://www.unimep.br/phpg/mostraacademica/anais/4mostra/pdfs/434.pdf >. Acesso em 22/06/13.

DUARTE, M.; CARDOSO, A.; JUNIOR, E. L. O uso de Realidade Aumentada no Ensino de Física. II Worshop de Realidade Aumentada, 2005. Disponível em <http://www.ckirner.com/download/anais/WRA2005-Anais/WRA2005-1-24.pdf>. Acesso em 22/06/13. 
FUNDAÇÃO VICTOR CIVITA. Estudos e Pesquisas Educacionais. São Paulo: Fundação Victor Civita, n.1, maio 2010, p. 275-335.

GEIGER, C., REIMANN, C., STOCKLEIN, J., PAELKE, V. Jartoolkit - a java binding for artoolkit. In: The First IEEE International Workshop on Augmented Reality Toolkit, Darmstadt. Germany, 2002

GIORDAN, M. O computador na escola: questões de pesquisa na educação em ciências. In: IV Encontro de Pesquisa em Ensino de Ciências, 2003, Bauru. Anais do IV ENPEC, 2003.

GIORDAN, M. O computador na educação em ciências: breve revisão crítica acerca de algumas formas de utilização. Ciência e Educação, v.11, n.2, p.279-304, 2005

GLOBO, 2015. TechTudo - Eletrônicos - Google Glass. Disponível em $<$ http://www.techtudo.com.br/tudo-sobre/google-glass.html>. Acesso em 30 de março de 2015.

GOOGLE, Google Play, 2015. Disponível em <https://play.google.com/store/search?q=realidade\%20aumentada\&c=apps\&hl=pt BR>. Acesso em 14 de março de 2015.

GOOGLE, Google Play. Senai RA, Confederação Nacional da Industria, 2015. Disponível em <https://play.google.com/store/apps/details?id=com.senai.ra\&hl=pt BR>. Acesso em 14 de março de 2015.

HENDERSON, S. J.; FEINER S. K. Augmented Reality Maintenance and Repair (ARMAR). Columbia University, 2007.

HOBSBAWM, E. J. A Era das Revoluções: Europa 1789-1848, tradução de Maria Tereza Lopes Teixeira e Marcos Penchel. Rio de Janeiro, Paz e Terra, 1977

IEEE - LTSC. IEEE1484.12.1 - Standard for Learning Object Metadata. New York, $2002 . \quad$ Disponível em $<$ http://Itsc.ieee.org/wg12/files/LOM $1484121 \mathrm{v} 1$ Final Draft.pdf>. Acesso em 25/04/13.

IMS - Instructional Management Systems (2006). Disponível em $<$ http://www.imsglobal.org/metadata/mdv1p3/imsmd bestv1p3.html > Acesso em 26042013. 
INEP (Instituto Nacional de Estudos e Pesquisas Educacionais Anísio Teixeira). TALIS Pesquisa Internacional sobre Ensino e Aprendizagem: Relatório Nacional. Disponível em $<$ http://download.inep.gov.br/acoes internacionais/pesquisa talis/2013/talis2013 rela orio brasil.pdf>. Acesso em: 21 de março de 2015.

INEP (Instituto Nacional de Estudos e Pesquisas Educacionais Anísio Teixeira). Pesquisa Talis. Disponível em <http://talis.inep.gov.br/pesquisa-talis>. Acesso em: 21 de março de 2015.

KIRNER, C. Usando Realidade Aumentada em Publicidade. 2010 Disponível em $<$ http://www.ckirner.com/download/artigos/RA-Publicidade.html>. Acesso em 15 de junho de 2013

KIRNER, C.; TORI, R. Introdução à Realidade Virtual, Realidade Misturada e Hiperrealidade. In: Kirner, C.; Tori, R. (Org.). Realidade Virtual: Conceitos, Tecnologia e Tendências. 1 ed. São Paulo: Editora SENAC, 2004, v. 1, p. 3-20. Disponível em <http://www.realidadevirtual.com.br/cmsimple-rv/?download=Cap1-prelim-kirner-tori.zip>. Acesso em 15 de junho de 2013.

KIRNER, C.; ZORZAL, E. R. Aplicações Educacionais em Ambientes Colaborativos com Realidade Aumentada. Anais do Simpósio Brasileiro de Informática na Educação, 2005, p. 103-113. Disponível em <http://ceie sbc.tempsite.ws/pub/index.php/sbie/article/view/398/384>. Acesso em 16 de junho de 2013.

LABVIRT, Laboratório Didático Virtual da Escola do Futuro da Universidade de São Paulo. Website. Disponível em < http://www.cienciamao.usp.br/tudo/index.php?midia=lab >. Acesso em 26042013.

LAYAR 2009. Software disponível em < https://www.layar.com/> Acesso em janeiro 2015

LEONTIEV, A. N. O desenvolvimento do psiquismo. Tradução Manuel Dias Duarte. 3 ed.Lisboa: Horizonte Universitário, 1978.

LÉVY, P. Cibercultura; Tradução de Carlos Irineu da Costa. - São Paulo: Ed. 34, 1999.

LÉVY, P. As tecnologias da Inteligência; Tradução de Carlos Irineu da Costa. - Rio de Janeiro: Ed. 34, 1993. 
LICENCIATURA EM CIÊNCIAS, Universidade de São Paulo - Universidade Virtual do Estado de São Paulo, 2013. Disponível em $<$ http://licenciaturaciencias.usp.br/apresentacao-do-curso/>. Acesso em 14 de março de 2015.

LUDKE, M.; ANDRÉ, M.E.D.A. Pesquisa em Educação: Abordagens Qualitativas. São Paulo: E.P.U., 1996

MACEDO, L. N. de; CASTRO FILHO, J. A. de; MACEDO, A. M. M.; SIQUEIRA, D. M. B.; OLIVEIRA, E. M. de; SALES, G. L.; FREIRE, R. S. Desenvolvendo o pensamento proporcional com o uso de um objeto de aprendizagem. In: PRATA, Carmem Lucia, NASCIMENTO, Anna Christina Aun de Azevedi. Brasília; MEC, SEED. Objetos de Aprendizagem: Uma proposta de recurso pedagógico. 154. 2007.

MEDEIROS, A. \& MEDEIROS, C. F. D. Possibilidades e limitações das simulações computacionais no ensino da Física. Revista Brasileira de Ensino de Física, São Paulo, v.24, n.2, p.77-86, 2002

MEIGUINS, B. S; SANTOS, A. M. C.; MEIGUINS, A. S. G.; GODINHO, P. I. A.; GARCIA, M. B. Construção de Projetos Arquitetônicos com Realidade Aumentada. II Worshop de Realidade Aumentada, 2005.

MENDES, R. M.; SOUZA, V .I.; CAREGNATO, S. E. A propriedade intelectual na elaboração de objetos de aprendizagem. 2005. Disponível em: $<$ http://wiki.sj.cefetsc.edu.br/wiki/images/7/7d/Propriedintelec.pdf> Acesso em $23 / 04 / 2013$.

MERLOT - Multimedia Educational Resource for Learning and Online Teaching. Disponível em:<http://www.merlot.org/Home.po>. Acesso em: 26042013

MILGRAM, P.; KISHINO, F. A Taxonomy of Mixed Reality Visual Displays. IEICE Trans. Information Systems. vol. E77-D, no. 12, 1994, pp. 1321-1329.

NASCIMENTO, J. K. F. Informática aplicada à educação. / João Kerginaldo Firmino do Nascimento. - Brasília : Universidade de Brasília, 2007.

NATIONAL DIGITAL LEARNING RESOURCES NETWORKING, National Digital Learning Resources Networking. Website. Disponível em <http://www.ndlrn.edu.au/default.asp?id=1691 >. Acesso em 26 de abril de 2013.

NINTENDO, 2015. Jogos RA: Realidade Aumentada. Disponível em $<$ https://www.nintendo.pt/-Familia-Nintendo-3DS/Software-instantaneo/Jogos-RA Realidade-Aumentada/Jogos-RA-Realidade-Aumentada-115169.html>. Acesso em 30 de março de 2015 
NMC (The New Media Consortium). NMC Horizon Report: 2015 Higher Education Edition. Disponível em <http://cdn.nmc.org/media/2015-nmc-horizon-report-HE EN.pdf>. Acesso em março 2015.

NULTY, D.D., 2008. The adequacy of response rates to online and paper surveys: what can be done?. Assessment \& Evaluation in Higher Education 33, 301-314. doi:10.1080/02602930701293231

OER, Open Educational Resources Website. Disponível em <http://oer.avu.org/ >. Acesso em 26042013.

OKAWA, E. S.; KIRNER, C.; KIRNER, T. G. Livro sobre o Sistema Solar potencializado com Realidade Aumentada. Disponível em <http://www.ckirner.com/sacra/aplica/sol-ra/>. Acesso em 15 de junho de 2013

OLIVEIRA, F.; RECCHIA, R. Projeto LIRA - Livro Interativo com Realidade Aumentada. In: Anais do WARV'05 - I Workshop de Aplicações de Realidade Virtual, 2005, Uberlândia, MG, v. 01.

OLIVEIRA, M. K. Vygotsky: Aprendizado e Desenvolvimento: um processo sócio histórico. São Paulo: Scipione, 1997.

PIEKARSKI, W.; THOMAS, B. ARQuake: The Outdoor Augmented Reality Gaming System, $2002 . \quad$ Disponível em $<$ http://citeseerx.ist.psu.edu/viewdoc/summary?doi=10.1.1.19.1858>. Acesso em 22/06/13.

PIMENTA, B.; BATISTA, A. A. Das plataformas de E-learning aos objetos de aprendizagem. In. DIAS, A. A.; DIAS, P.; GOMES, M. J. (Org.). E-learning para formadores. 2004 Disponível em: $<$ http://repositorium.sdum.uminho.pt/bitstream/1822/666/1/eLES-DDG.pdf>. acesso em junho de 2009.

PNAD. Pesquisa Nacional por Amostra de Domicílio - Acesso à Internet e Posse de Telefone Móvel Celular para Uso Pessoal. IBGE, 2013. Disponível em <ftp://ftp.ibge.gov.br/Acesso a internet e posse celular/2011/PNAD Inter 2011.pdf> Acesso em 07 de junho de 2013.

PORTAL DO PROFESSOR, Portal do Professor Website. Disponível em <Portal do Professor>. Acesso em 26042013. 
REALIDADE AUMENTADA CEPA. A simulação do modelo de Drude implementada com Realidade Aumentada. Disponível em <http://midia.atp.usp.br/atividades interativas/Al-0163/>. Acesso em 02 de julho de 2013.

RIPOLL, G. P. Desenvolvimento de um modelo de simulação para dimensionamento de equipe polivalente de manutenção da produção: uma abordagem estratégica. Programa de Pós-Graduação em Administração/ Universidade Federal do Rio Grande do Sul, 1998

RIVED, Rede Interativa Virtual de Educação Website. Disponível em $<$ http://rived.mec.gov.br/site objeto lis.php >. Acesso em 26 de abril de 2013.

SAQOOSHA. Disponível em <http://www.libspark.org/wiki/saqoosha/FLARToolKit/en>. Acesso em 22 de junho de 2013.

SCORM. ADL - ADVANCE DISTRIBUTED LEARNING. Overview, 2004. Disponível em: <http://www.adlnet.org>. Acesso em: 26 abril 2013.

SIELHORST, T.; TRAUB, J. Augmented Reality in Medicine. 2004. Disponível em $<$ http://campar.in.tum.de/twiki/pub/Chair/TeachingSs04SeminarAR/01Motivation.pdf>.

Acesso em 15/06/2013.

SILVA, B. D. In: SALGADO, M. U. C. \& AMARAL, A. L. Tecnologias da Educação: Ensinando e Aprendendo com as TIC: Guia do Cursista. Brasília: Ministério da Educação a Distância, 2008.

SILVA, J. E.; ROGADO, J. Aplicação da Realidade Virtual na Educação Química - O Caso do Ensino de Estrutura Atômica. 6a Mostra Acadêmica UNIMEP, 2008. Disponível em <http://www.unimep.br/phpg/mostraacademica/anais/6mostra/1/187.pdf>. Acesso em 22/06/13.

SILVEIRA, A. L. M; BIAZUS, M. C. V. A realidade aumentada aplicada a museologia. Disponível em <http://www.academia.edu/2670294/A_realidade_aumentada_aplicada_a_museologia>. Acesso em 15/06/2013.

SIMÕES, F.P.M.; LIMA, J.P.S.M.; TEICHRIEB, V.; KELNER, J. Realidade aumentada sem marcadores baseada na amostragem de pontos em arestas. Workshop de Realidade Virtual e Aumentada; 5. : 2008 : Bauru, SP. 
TAROUCO, L. M. R.; DUTRA, R.L.S.D. Padrões e interoperabilidade. In: Carmem Lucia Prata, Anna Christina Aun de Azevedo Nascimento. (Org.). Objetos de Aprendizagem - Uma proposta de recurso pedagógico. Brasília - DF: MEC/SEED, 2007, v. , p. 81-92.

TAROUCO, L. M. R.; SCHMITT, M. A. R. Adaptação de metadados para repositórios de objetos de aprendizagem. RENOTE: Revista de Novas Tecnologias na Educação, Porto Alegre, v. 8, n. 2, jul. 2010.OLCOS. Open Educational Practices and Resources.

TAVARES, N. R. B. História da informática educacional no Brasil observada a partir de três projetos públicos. Universidade Anhembi Morumbi, 2002. Disponível em <http://www.lapeq.fe.usp.br/textos/tics/ticspdf/neide.pdf > Acesso em 14 maio 2013.

TAVARES, R.; SANTOS, J. N. Organizador prévio e animação interativa. In: INTERNATIONAL MEETING ON MEANINGFUL LEARNING MARAGOGI, 4, 2003, Alagoas. Anais..., Alagoas: UFPB, 2003.

TEICHRIEB, V.; et al.. A Survey of Online Monocular Markerless Augmented Reality, International Journal of Modeling and Simulation for the Petroleum Industry, 2007, vol. 1, no. 1, pp. 1-7.

TIPLER, P. A. Física para cientistas e engenheiros. $4^{a}$ Edição, Volume 2. LTC Livros Técnicos e Científicos S.A. Rio de Janeiro, 2002

TORI, R. A presença das tecnologias interativas na educação. RECET v.2, n. ., 2010 Disponível em: <http://revistas.pucsp.br/index.php/ReCET/article/view/3850/2514>. Acesso em 23 de junho de 2013.

TORI, R.; KIRNER, C.; SICOUTO, R. Fundamentos e Tecnologia de Realidade Virtual e Aumentada. Porto Alegre: SBC, 2006, 422 p.

VIGOSTKY. The Genesis of Higher Mental Functions. In: WERTSCH, James V. (Ed.) The concept of Activity in Soviet Psychology. New York: M.E. Sharpe, 1981.

VIGOTSKY, L. S. A construção do pensamento e da linguagem, São Paulo: Martins Fontes, 2001.

VIGOTSKY, L. S. A formação social da mente. São Paulo: Martins Fontes, 1999. 
VLAHAKIS V., IOANNIDIS N., KARIGIANNIS J. (2002) ARCHEOGUIDE: Challenges and Solutions of a Personalised Augmented Reality Guide for Archaeological sites. Computer Graphics in Art, History and Archaeology,Special Issue of the IEEE Computer Graphics and Applications Magazine, 22,5, September-October

WAGNER D., SHMALSTIEG D. First Steps Towards Handheld Augmented Reality. In: International Conference on Wearable Computers. 2003.

WIKIPEDIA. Definição de Corrente Elétrica. Disponível em $<$ http://pt.wikipedia.org/wiki/Corrente el\%C3\%A9trica> Acesso em 15 de junho de 2013.

WILEY, D. A. Conecting learning objects to instructional theory: A definition, a methaphor and a taxonomy. 2000. Disponível em: <http://www.reusability.org/read/chapters/wiley.doc>. Acesso em maio de 2012

WINDOWS PHONE, Wikitude, 2015. Disponível em <http://www.windowsphone.com/ptbr/store/app/wikitude/ff54ce89-9a93-4d18-98f3 868268964c71>. Acesso em 14 de março de 2015.

WISCONSIN ON-LINE RESOURCE CENTER. Wisconsin On-line Resource Center website. Disponível em:< http://www.wisc-online.com/index.htm> Acesso em: 26042013.

ZORZAL, E. R. ; KIRNER, C. Jogos Educacionais em Ambiente de Realidade Aumentada. In: WRA2005, 2005, Piracicaba. II Workshop de Realidade Aumentada. Piracicaba : Editora UNIMEP, 2005. v. 1. p. 52-55. 
11. ANEXOS

ANEXO 01 - Enquete utilizada para avaliar a infraestrutura existente e utilizada por alunos do CLC da USP/UNIVESP (Questões utilizadas 02 a 17) 


\section{CiÊNCAAS}

Conhecendo um pouco mais sobre você

Página 1

Prezado aluno! Prezada aluna!

Esta atividade tem por objetivo de conhecer um pouco mais sobre você. Iremos trabalhar de maneira inovadora neste curso via Internet. É uma forma de colocarmos você em contato com tecnologias diferenciadas que lhe ajudarão na vida universitária e profissional.

Responda sinceramente às perguntas a seguir. Elas nos ajudarão a identificar algumas de suas necessidades de estudo. Identificarão também as formas como podemos melhor auxiliar para que você inicie sua carreira universitária de forma brilhante.

A equipe Univesp - USP agradece muito a sua colaboração!

De qual local você acessa a internet?
Própria Casa
Casa de amigos
Escola
Lan-house
Trabalho
Outro: Qual/Quais?

2 * Com qual frequência você acessa a internet?
Diariamente
Semanalmente
Apenas nos finais de semana
Eventualmente

3 * Você possui:

Celular 3G / Smartphone

Celular sem acesso a internet 


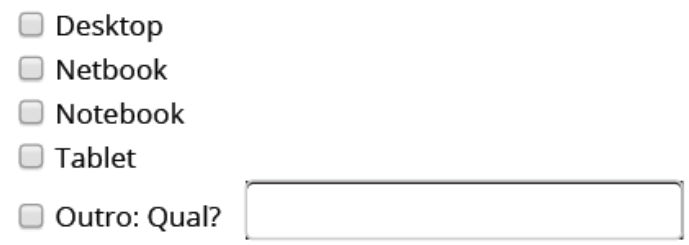

4 * Você possui Internet banda larga?

$\bigcirc \operatorname{Sim} \bigcirc$ Não

5 * Qual é a velocidade da banda larga que você utiliza?

menos de $500 \mathrm{kbps}$

entre $500 \mathrm{kbps}$ e $1 \mathrm{Mpbs}$

entre $1 \mathrm{Mbps}$ e $5 \mathrm{Mbps}$

mais de $5 \mathrm{Mbps}$

Não possuo Internet com banda larga

$6 * \quad$ CASO VOCÊ POSSUA SMARTPHONE/TABLET

Qual o sistema operacional do seu smartphone/tablet:
Android OS
Windows Phone
IOS (Apple)
Symbian OS (Nokia)
BlackBerry (BlackBerry)
Não sei

7 * CASO VOCÊ POSSUA SMARTPHONE/TABLET

Com que frequência você troca seu aparelho smartphone/tablet?
Sempre que surge um aparelho mais sofisticado
Quando meu aparelho quebra
Raramente

8 * Você faz uso de aplicativos do seu smartphone/tablet no estudo de alguma disciplina?

$\bigcirc \operatorname{Sim} \bigcirc$ Não

Página 2

9 Em caso afirmativo, qual(ais) aplicativo(s) você faz uso? E no estudo de qual(ais) disciplinas? 
10 * Algum dos seus professores já sugeriu alguma vez o uso de algum aplicativo de smartphone/tablet para estudo de sua disciplina?

Sim Não

Página 4

$11 *$ Em caso afirmativo, qual(ais) aplicativo(s)?

12 * Você conhece a tecnologia chamada Realidade Aumentada?

$\bigcirc \operatorname{Sim} \bigcirc$ Não

Página 6

13 Você já utilizou algum aplicativo de Realidade Aumentada?

$\bigcirc$ Sim $\bigcirc$ Não $\bigcirc$ Sem resposta

Página 7

14 Em caso afirmativo, qual aplicativo você fez uso?

Página 8

15 * Você faz uso regularmente da webcam do seu smartphone, tablet ou computador?

$\bigcirc \operatorname{Sim} \bigcirc$ Não

Página 9

16 * Com que frequência você utiliza os dispositivos tecnológicos abaixo para fins acadêmicos?

Notebook

Smartphone

Tablet

Desktop

\begin{tabular}{|c|c|c|c|}
\hline & Frequentemente & Raramente & Nunca \\
\hline - & 0 & 0 & 0 \\
\hline$\theta$ & 0 & 0 & 0 \\
\hline & 0 & 0 & 0 \\
\hline & 0 & 0 & 0 \\
\hline
\end{tabular}


Sobre o seu nível de conhecimento tecnológico, pontue de 1 a 4, sendo: 1 = nada 2 = pouco 3 =razoável $4=$ muito

E-mail

Windows/Mac OS

Linux

Editor de texto (Word, por exemplo)

Editor de apresentação (PowerPoint, por exemplo) Baixar (download) e enviar (upload) para a Internet Baixar arquivos em áudio (mp3, mp4, podcast) Programas de buscas (Google, Yahoo, Bing) Simulações no computador

Redes sociais (Facebook, Twitter, Google+)

Lista de discussão

Chat/Vídeoconferência (Skype, Gtalk, Hangout, etc) Blog

Video Game (Wii, Xbox, PlayStation, PC)

Linguagem de programação

Mundo Virtual (SecondLife e MMOs, por exemplo)

\begin{tabular}{|c|c|c|c|c|}
\hline & nada & pouco & razoável & muito \\
\hline • & 0 & 0 & 0 & 0 \\
\hline • & 0 & 0 & 0 & 0 \\
\hline ○ & 0 & 0 & 0 & 0 \\
\hline ○ & 0 & 0 & 0 & 0 \\
\hline ○ & 0 & 0 & 0 & 0 \\
\hline • & 0 & 0 & 0 & 0 \\
\hline ○ & 0 & 0 & 0 & 0 \\
\hline ○ & 0 & 0 & 0 & 0 \\
\hline ○ & 0 & 0 & 0 & 0 \\
\hline • & 0 & 0 & 0 & 0 \\
\hline ○ & 0 & 0 & 0 & 0 \\
\hline ○ & 0 & 0 & 0 & 0 \\
\hline ○ & 0 & 0 & 0 & 0 \\
\hline ○ & 0 & 0 & 0 & 0 \\
\hline ○ & 0 & 0 & 0 & 0 \\
\hline$\circ$ & 0 & 0 & 0 & 0 \\
\hline
\end{tabular}

18 * Sobre o seu nível de utilização, pontue de 1 a 4, sendo: 1 = nada 2 =pouco 3 = razoável 4 = muito

E-mail

Windows/Mac OS

Linux

Editor de texto (Word, por exemplo)

Editor de apresentação (PowerPoint, por exemplo) Baixar (download) e enviar (upload) para a Internet Baixar arquivos em áudio (mp3, mp4, podcast) Programas de buscas (Google, Yahoo, Bing) Simulações no computador Redes sociais (Facebook, Twitter, Google+) Lista de discussão

Chat/Vídeoconferência (Skype, Gtalk, Hangout, etc) Blog

Video Game (Wii, Xbox, PlayStation, PC)

Linguagem de programação

\begin{tabular}{|c|c|c|c|c|}
\hline & nada & pouco & razoável & muito \\
\hline ? & 0 & 0 & 0 & O \\
\hline ○ & 0 & 0 & 0 & 0 \\
\hline ○ & 0 & 0 & 0 & 0 \\
\hline ○ & 0 & 0 & 0 & 0 \\
\hline ○ & 0 & 0 & 0 & 0 \\
\hline ○ & 0 & 0 & 0 & 0 \\
\hline ○ & 0 & 0 & 0 & 0 \\
\hline • & 0 & 0 & 0 & 0 \\
\hline ○ & 0 & 0 & 0 & 0 \\
\hline ○ & 0 & 0 & 0 & 0 \\
\hline ○ & 0 & 0 & 0 & 0 \\
\hline ○ & 0 & 0 & 0 & 0 \\
\hline ○ & 0 & 0 & 0 & 0 \\
\hline ○ & 0 & 0 & 0 & 0 \\
\hline ( & 0 & 0 & 0 & 0 \\
\hline
\end{tabular}


Mundo Virtual (SecondLife e MMOs, por exemplo)

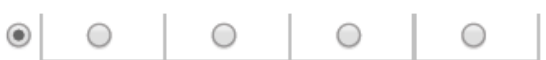

$19 *$

EDUCAÇÃo A DISTÂNCIA

Você já fez algum curso a distância?

Sim $\bigcirc$ Não

Página 10

20 O curso foi de:

$\square$ Graduação

Pós-graduação

Curta duração

Outro: Qual?

Outro: Onde realizou o curso?

Página 11

21 O curso a distância realizado era:

Semipresencial (com encontros presenciais)

$100 \%$ a distância

Não fiz curso a distância

- Sem resposta

22 * No seu entender, qual é o papel do tutor em um curso a distância?

Professor

Suporte Técnico

Administrador do curso

23 * Qual tipo de mídia você prefere para estudar?
Vídeos
Animações
Texto online
Texto impresso
Outro: Qual?

24 * Para você, quais são as principais vantagens de estudar a distância?

Flexibilidade de horário

Conteúdos disponíveis pela internet

$\square$ Uso de materiais interativos

Interatividade com os colegas 
$\square$ São cursos mais fáceis de aprender

$\square$ Menor exigência de desempenho

$25 *$

FORMAÇÃO ACADÊMICA

Qual a sua formação atual?

Ensino Médio

Graduação

Pós-graduação

Outro: Qual?

26 * Por que você pretende fazer o curso de Licenciatura em Ciências?

Obter um diploma USP

Obter uma graduação

Ser professor de ciências

Ascensão profissional

Vivenciar um curso de graduação semipresencial

Outro: Quais?

27 * Qual o seu nível de conhecimento de outro idioma?

Alemão

Espanhol

Francês

Inglês

Italiano

Português (alunos estrangeiros)

28

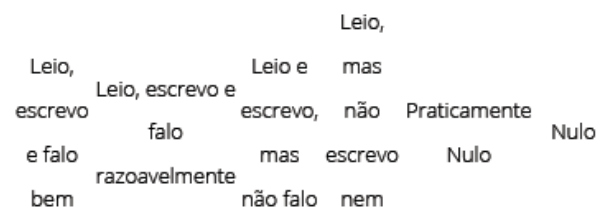

\begin{tabular}{|c|c|c|c|c|c|c|}
\hline & & \multicolumn{5}{|c|}{ falo } \\
\hline - & 0 & 0 & 0 & 0 & 0 & 0 \\
\hline ( & 0 & 0 & 0 & 0 & 0 & $\bigcirc$ \\
\hline ( & 0 & 0 & 0 & 0 & 0 & 0 \\
\hline - & 0 & 0 & 0 & 0 & 0 & 0 \\
\hline (-) & 0 & 0 & 0 & 0 & $\bigcirc$ & 0 \\
\hline 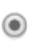 & 0 & 0 & 0 & 0 & 0 & 0 \\
\hline
\end{tabular}

ATUAÇÃO PROFISSIONAL

Você tem alguma ocupação regular profissional regular (trabalho)?
Não
Sim

Página 12

$29 *$ Qual? 
Página 13

30 * Você tem alguma experiência como professor?

Não

Sim

Página 14

$31 *$ Qual?

Página 15

32 * o que você espera deste curso de licenciatura? Marque as duas opções mais relevantes.

$\square$ Ampliar os conhecimentos prévios na área de ciências

$\square$ Reconhecimento profissional onde atua

$\square$ Aprender conteúdos atualizados de ciências

$\square$ Saber como ensinar através das tecnologias digitais

$\square$ Outro: Quais?

Fechar esta janela

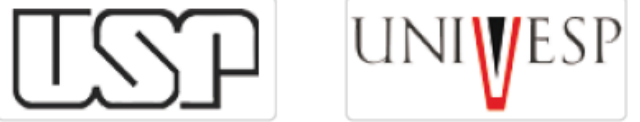

Universidade de São Paulo - Portal da Licenciatura em Ciências - USP

f $y$ in $8^{+}$ 